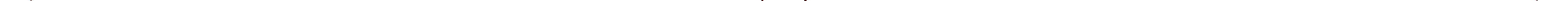




\section{Propositions}

1. Migration of geese in Western Palearctic is an expensive tradition. (this thesis)

2. Stopover sites play a far more important role in controlling the population of greater white-fronted goose than wintering or breeding sites. (this thesis)

3. EU subsidies to agriculture should be defined as unsustainable practices and abolished.

4. Western countries have neither legal nor moral rights to intervene in development of social values in Russia and the former USSR.

5. Current commitment of corporations to sustainability is merely a fad.

6. A remark of recruiters about job markets being overheated due a shortage of talent is a reflection of an ongoing class struggle in the world.

7. The capitalist system has no future due to unequal distribution of resources between classes and nations.

Propositions belonging to the thesis, entitled

'Land use changes in Russia and their impact on migrating geese'.

Mikhail Grishchenko

Wageningen, 12 June 2018. 


\section{Land use changes in Russia and their impact on migrating geese}

Mikhail Grishchenko 


\section{Thesis committee}

\section{Promotors}

Prof. Dr H.H.T. Prins

Professor of Resource Ecology

Wageningen University \& Research

Prof. Dr R.C. Ydenberg

Professor of Behavioural Ecology

Simon Fraser University, Burnaby, Canada

\section{Co-promotors}

Prof. Dr M.E. Schaepman

Professor of Remote Sensing

University of Zürich, Switzerland

Dr H.J. de Knegt

Researcher, Resource Ecology Group

Wageningen University \& Research

\section{Other members}

Prof. Dr M. Herold, Wageningen University \& Research Prof. Dr D. Kleijn, Wageningen University \& Research Dr E.S. Bakker, Netherlands Institute of Ecology, Wageningen Dr M.J.J.E. Loonen, University of Groningen

This research was conducted under the auspices of the C.T. de Wit Graduate School for Production Ecology and Resource Conservation. 


\title{
Land use changes in Russia and their impact on migrating geese
}

\author{
Mikhail Grishchenko
}

\section{Thesis}

submitted in fulfilment of the requirements for the degree of doctor at Wageningen University

by the authority of the Rector Magnificus

Prof. Dr A.P.J. Mol,

in the presence of the

Thesis Committee appointed by the Academic Board

to be defended in public

on Tuesday 12 June 2018

at 4 p.m. in the Aula. 
Mikhail Grishchenko

Land use changes in Russia and their impact on migrating geese, 164 pages.

PhD thesis, Wageningen University, Wageningen, the NetherlandsNL (2018) With references, with summaries in English and Dutch

ISBN: 978-94-6343-855-1

DOI: $10.18174 / 446108$ 
Contents

Chapter 1: General Introduction

Chapter 2: Large-scale landscape change in European Russia after the break-up of the USSR

Chapter 3: Automated identification of potential stopover sites of migratory geese in European Russia

Chapter 4: Changes in landcover at stopover sites confirm decline of agriculture in European Russia

Chapter 5: The effect of politics on the migration geography of greater

89 white-fronted geese in European Russia

Chapter 6: Synthesis: greater white-fronted geese in the Anthropocene

References

Summary

Samenvatting

Affiliation of Co-authors

Acknowledgments

Biography

List of publications

PE\&RC Training and Education Statement 


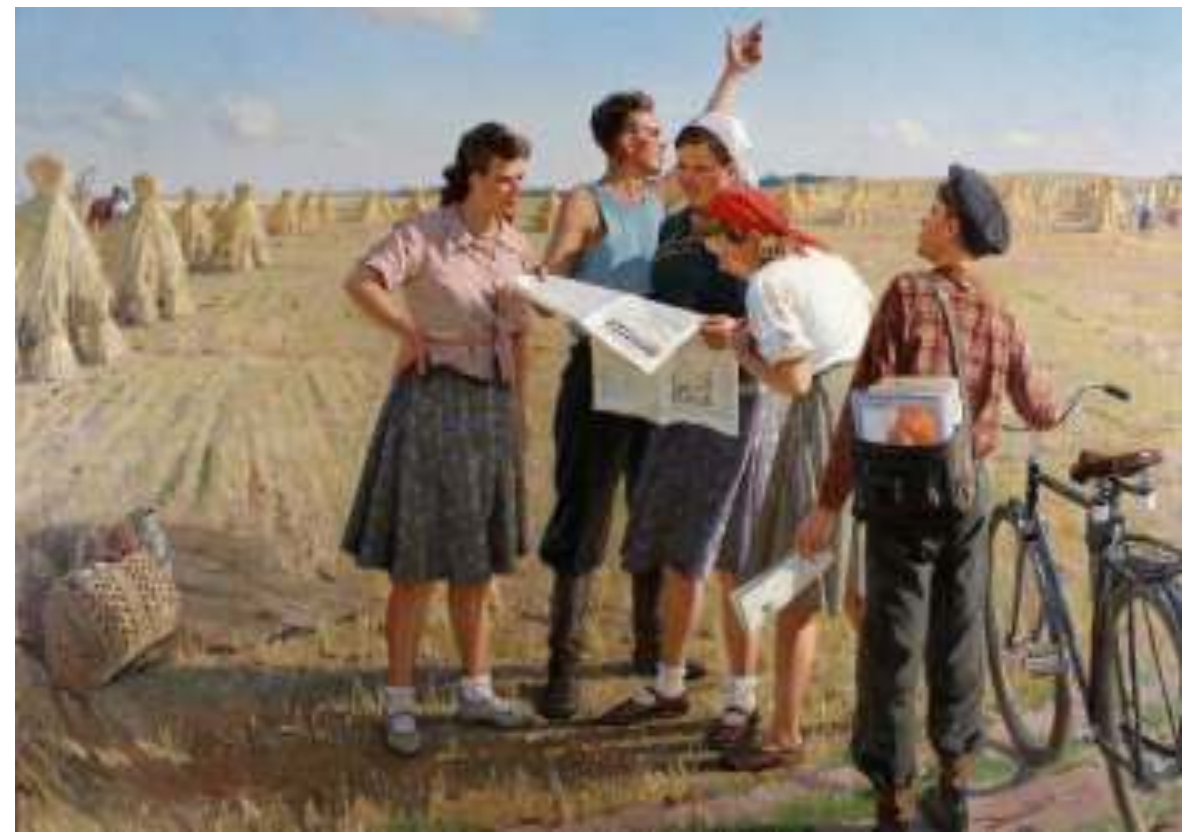

I. Grinyuk "Decree in awarding" (1949) / И. Гринюк "Указ о награждении". 


\section{Chapter 1 \\ General Introduction}

Mikhail Grishchenko

\section{Migration of geese on the East Atlantic Flyway}

Many Western Palearctic populations of bird species migrate annually between their breeding and wintering areas. Most use the East Atlantic Flyway which stretches over most of Europe, including the European part of Russia (Figure 1.1). Waterfowl are among the most frequent users of the flyway, with a significant proportion of goose species. A number of these geese show typical long-distance migrant behaviour as they travel long distances to their breeding grounds making use of multiple stopover sites in between (Kaiser 1999) where they rest and re-fatten (Drent et al. 1978; van der Graaf et al. 2006; Drent et al. 2007). However, goose species show different utilization patterns of stopover sites. While brent geese Branta bernicla (Ebbinge et al. 1999; Dokter and Ebbinge 2013) or lesser white-fronted geese Anser erythropus (Aarvak and Oien 2003; Romanov and Pospelov 2010) migrate quickly with very few stops, barnacle geese B. leucopsis (Eichhorn et al. 2006; de Boer et al. 2014) and greater white-fronted geese Anser albifrons (Kölzsch et al. 2016) use many stopover sites. With about 1.3 million individuals (Fox et al. 2010) the greater white-fronted goose is the most numerous of the Western Palearctic goose species. Greater white-fronted geese migrate from their wintering grounds along the North Sea to the arctic breeding grounds in Russia in spring and back in fall (Koffijberg and van Winden 2014). The migration ecology of the species across Europe has been well explored, with most research activities initially concentrated in Western Europe (Drent \& Prins 1987; Ebbinge 1991; Mooij 1997; Eichhorn et al. 2006). However, less is known about their migration towards the east of the EU borders, particularly in Russia where major research activities concentrated on the breeding grounds (Mooij 1997; Kölzsch et al. 2016).

While sufficient understanding of migration ecology of the species at wintering and breeding grounds has accumulated, only limited knowledge exists 
about stopover sites in European Russia. In the past few decades research on the seaboards of the North sea surged (Arzel 2006) and with the fall of the Berlin wall more Western scientists got access to the Russian Arctic and the body of knowledge about geese (Arzel 2006; Emelchenko 2009). The research activities at stopover sites remained stagnant mostly due to four reasons. The first, and the most important, reason is poor accessibility of most stopover sites during the migration season. The area of European Russia comprises about $4 \mathrm{M} \mathrm{km}^{2}$ which is as vast as the EU. However, the poor road conditions in spring greatly impede travel, even making it temporarily impossible. The second reason is the long-lasting political isolation that prevented scientific communication greatly limited studying the breeding ecology of geese in the Russian Arctic. Also, few Russian ecologists worked on bird migration.

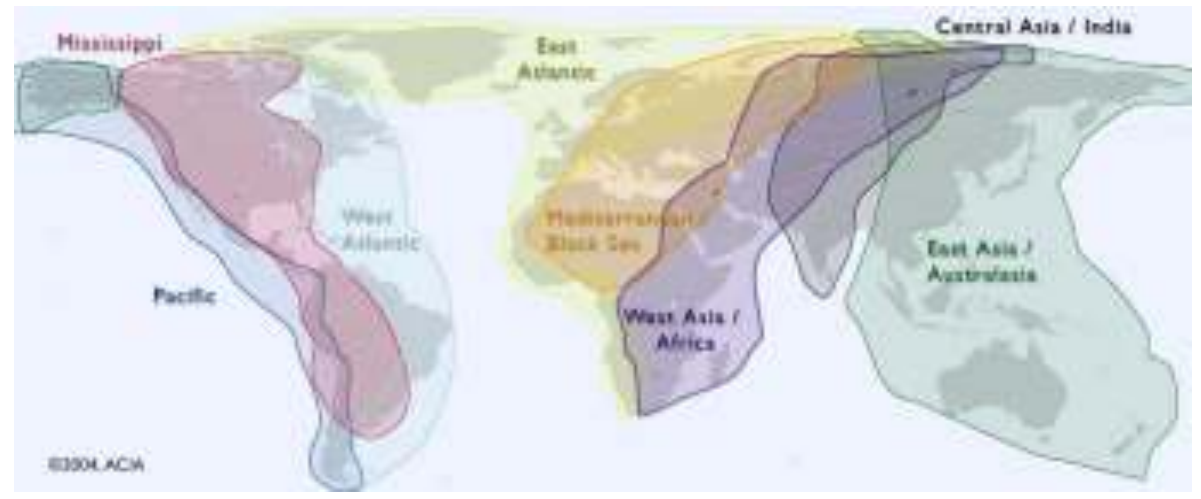

Figure 1.1. Global Migratory Bird Flyways (ACIA, 2004).

Apart from these reasons, the third reason of limited attention from ecologists to migration stopover sites reflects the development animal abundance theory since 1950s. A concept of bottom-up population control was developed in 1950s (Lack, 1956) where bird population numbers were said to be determined by abundance of their food supply. This idea was further developed in 1980s (Drent and van der Waal 1998) and tailored towards migrating geese whose numbers were said to be limited by their food sources in winter (Drent and Prins 1987), i.e. Western Europe for greater white-fronted geese. Later an alternative idea appeared that geese population numbers were 
in fact limited by the food supply on their breeding grounds (Cooke et al. 1983). This idea was tested (Cooke et al. 1983; Jefferies and Rockwell 2002) on tundra of Northern Canada where millions of Snow geese Anser caerulescens breed. Similar ideas could be tested in the Russian Arctic during multiple expeditions to Taymyr Peninsula (Kostin and Mooij 1995; Mooij et al. 1996; Ebbinge et al. 2013) once the relations between the West and Russia improved in last 1980s.

The fourth reason for lack of scientific attention to stopover sites concerns the technical limitations of bird tracking methods. Until the 1990s (Nowak and Berthold 1991), bird migration monitoring was possible only with metal ring recoveries reported back by hunters and diligent bird-watchers who reported their sightings to bird ringing centres, and later online databases. These techniques contained a significant delay between an observation and a date of reposting, and they did not allow tracking an individual goose or a group of geese throughout their entire migration. However, the introduction of GPS-GSM tracking and substantial cost reductions of tracking devices opened new opportunities to follow goose migration, providing large datasets of migration routes and stopovers at a fine scale. These developments also coincided with growing interest in birdwatching and (educated) hunting along the East Atlantic Flyway, which greatly increased a number of reported sightings from Poland, Ukraine, Belarus and Russia in recent decades. These new types of data allowed for better understanding of spatiotemporal aspects of migration ecology of greater white-fronted goose across Europe, their possible drivers and limiting factors (Kölzsch et al. 2016).

\section{Break-up of the USSR, changes in agriculture and land use}

While stopover sites now receive more attention from scientists, greater whitefronted geese might be facing new challenges that could impact their migration ecology and population numbers in the future. To complete their migrations successfully, geese use stopover sites where they benefit from abundant agricultural spillage as well as grasslands (Jefferies and Drent 2006). Therefore, geese became dependent on active farming all along their flyway from the North Sea to the Russian Arctic. However, European Russia has experienced a sweeping reorganisation of its agriculture following the break-up of the USSR in 
1991 (Wegren 1995; Grishchenko and Prins 2016). Dismantling of the USSR was followed by economic liberalisation reforms (Strayer 1998) that led to substantial reductions in subsidies to farming (Wegren 1995). Most collective farms were privatised with short notice, to improve their efficiency and financial performance. However, the economies of scale achieved in $1970-1980$ s, were not feasible under private management under market economy conditions (Lerman 1998). This swift transition forced many collective farms in Russia to halt operations (Ioffe 2005). In southern Russia agriculture was more profitable and these shocks were quickly followed with recovery, but most areas in the peripheral areas of European Russia could not sustain such profound changes (Ioffe 1991; Ioffe et al. 2004). Hence, farming activities in northern parts of European Russia faded as unprofitable farms went out of business and stopped field cultivation (Ioffe and Nefedova 2004). With the loss of this agriculture the economic basis of many small and medium cities was undermined while larger cities grew rapidly, especially after 2000, and became the new drivers of the national economy (Wegren 2012).

Most scholars of post-Soviet Russia have focussed on the economic, social and political upheavals (Ahrend 2005; Ickes and Ofer 2006) of the past three decades, and few studies have considered these changes in relation to land use (Ramankutty and Foley 1999; Prishchepov et al. 2013) and nature conservation (Pereira and Navarro 2015). Scientists using remote sensing and GIS methods have studied some landcover changes and their drivers in post-Soviet countries (Kümmerle et al. 2015), but these changes were related to the transition of the rural economy without much reference to changes in biodiversity (Poschlod et al. 2005), such as avian migrants. Current knowledge indicates that in east European countries, large areas of agricultural fields were abandoned and have been slowly turning into forests (Kümmerle et al. 2015). As the majority of collective farms in Russia were situated in the boreal zone, uncultivated fields should also undergo shrub and tree encroachment soon after their abandonment. These changes might lead to full reforestation within 2-3 decades (Prishchepov et al. 2013; Kümmerle et al. 2015) depending on seed dispersal and local soil conditions. If the succession develops in such a manner, the open fields used by migrating greater white-fronted geese will be overtaken by 
shrubland and forest. Further, the quality of forage on fields remaining under cultivation might be reduced due to lower fertilizer inputs and lower frequency of mowing. As these land use changes progressed over the past three decades, habitat at stopover sites of the East Atlantic Flyway within European Russia used by migrating greater white-fronted geese might become less suitable for the species. Thus, greater white-fronted geese might face new population limitations at their stopover sites in addition to its wintering (Mooij 1997; Koffijberg and van Winden 2014) and breeding grounds (Kölzsch et al. 2016).

Access to studies of biodiversity in Russia and field observations of land use changes seem to be very limited to date. The widely discussed 'rewilding' of Europe (Pereira and Navarro 2015) therefore shows a rather EU-centred approach, and has failed to appreciate the rapid rewilding of Russia that has gone on for at least for the past three decades. This thesis addresses these land use changes over the vast landmass of Russia. This knowledge should be useful to better understand some complex contemporary global issues: avian migration, and the influence of land use changes on biodiversity and the wellbeing of humans.

\section{Study area}

The study area in this thesis includes the European part of Russia. Its territory covers about 4 million $\mathrm{km}^{2}$ of land, which about the same size as the EU, hosts up to $80 \%$ of human population and agricultural activities. Migrating geese make extensive use of European Russia with its extreme north being their breeding grounds and the rest of the landmass being their stopover sites during migration in spring and fall. European Russia currently comprises 56 provinces which are further subdivided into 350 municipal districts (Figure 1.2). Since this study explores migration ecology of geese at stopover sites I excluded two province in the far North (Murmansk Oblast and Nenets Autonomous Okrug). I used the full spatial extent of the study area in my analysis of potential stopover sites using the automated classification model, as well as in the analysis of stopover site utilisation based on ring recoveries. Due to the incompleteness of the data, I selected municipal districts from the broader study area for the analysis of 
changes in human population and agricultural statistics, as well as changes in land cover at stopover sites.

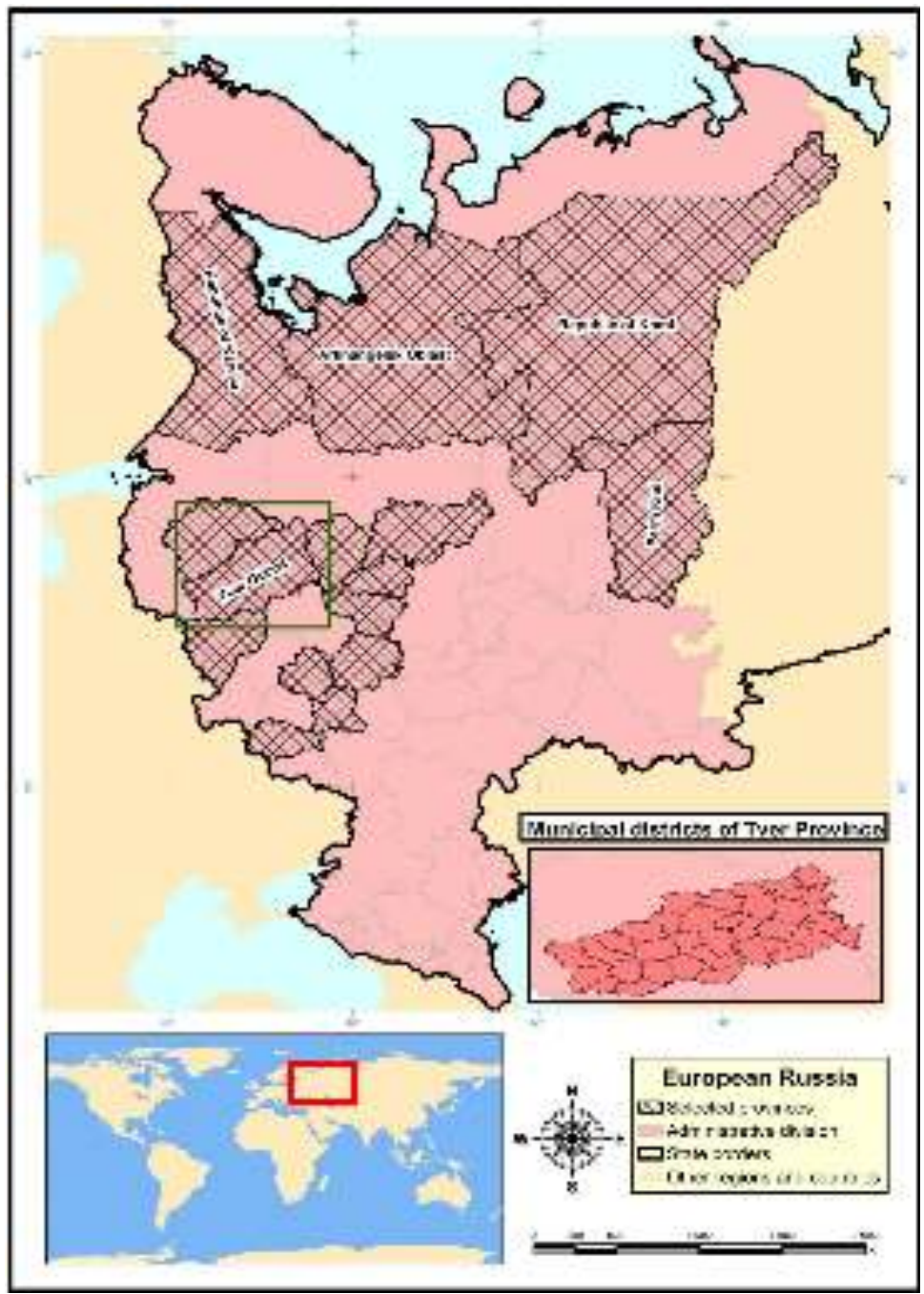

Figure 1.2. The 56 provinces of European Russia. The 15 selected for more detailed analysis are indicated by cross-hatching. Each province is further subdivided into municipal districts, of which there are a total of 350 in the 15 selected provinces. The municipal districts of Tver province are shown in the inset as an example. 


\section{Methods and design}

This study used a variety of heterogeneous datasets containing information about human population development, rural economy, land cover, goose sightings, and my own field observations of vegetation and land use. To analyse the developments in human population across the study area in 1959 through 2015, I used official census data provided by the Russian Federal Sate Statistics Services. The agricultural statistics of 1990 through 2015 also originated from this source, and were used to evaluate trends in the sweeping reorganisation of Russian agriculture since 1991 . To model the network of potential stopover sites in European Russia used by migrating greater white-fronted geese, I developed an automated classification model based on a set of spatial conditions, based on habitat suitability, especially the proximity and extent of roosting and foraging sites. This classification was ground-truthed with field visits to selected sites in central and northern parts of European Russia. To understand the scale of land abandonment and its impact on the habitat suitability of stopover sites, I measured land cover changes in 1990 through 2014 using spatiotemporal analysis of satellite images for several selected provinces. To attribute these land cover changes to changes in agricultural practices I compared observed trends with agricultural statistics. I argued that increasing land abandonment at stopover sites in European Russia should lead to tree and shrub encroachment which with time will make these sites unsuitable for migrating geese. I used ring recoveries and neckband observations to assess signs of a response of migrating geese to the changing habitat suitability of their stopover sites in European Russia.

\section{Research objectives}

I employed a multidisciplinary approach that combined descriptive statistics with GIS and remote sensing techniques. I analysed and interpreted data from multiple sources: officially reported census statistics on human population and agriculture, acquired metal ring recoveries and neckband observations, GPS tracks of migrating birds, landcover data from MODIS and Landsat satellite images as well as extensive data from own field observations. 
The main research objective of this thesis is to assess the impact on the migration ecology of greater white-fronted geese of the sweeping reorganisation of agriculture in European Russia that followed the break-up of the USSR. To fulfil the research objective the following research questions are addressed:

1. What are the land use changes and their drivers that define ongoing changes in landscapes of European Russia? (Chapter 2)

2. Where are the potential stopover sites in European Russia that migrating geese could use for spring staging located? (Chapter 3).

3. What are the landcover changes around stopover sites used by migrating geese in 1990 - 2014? Do these changes lower the availability and quality of potential stopovers? (Chapter 4).

4. Does ever-increasing land abandonment increase distances between remaining suitable stopover sites? Do these changes lead to reduction of stopover sites utilization by migrating geese? (Chapter 5 ).

\section{Thesis Outline}

This thesis contains six chapters: an introductory chapter, four data chapters addressing the respective research questions, and a synthesis. This first chapter introduces the reader to key concepts of the migration ecology of greater whitefronted goose. In Chapter 2 I use official census data from 56 provinces and 350 municipalities of European Russia to describe agricultural land use and human population growth. To compare growth rates of human population in 1990 2015 to average annual temperature, population size of municipalities and difference between Soviet and post-Soviet era I use linear mixed-effects models. The same models are applied to explore the relationship between selected agricultural parameters in $1990-2015$ and annual temperature, municipal area, and the presence of an urban centre.

In Chapter 3 I use an automated classification model to detect potential stopover sites in European Russia used by migrating greater white-fronted geese. A total of 1931 potentials stopover sites are modelled within European Russia based on a set of pre-defined habitat attractiveness criteria. I also compare the identified potential stopover sites with Important Bird Areas of 
BirdLife International and collected recoveries for greater white-fronted geese. These results were validated in 2014 with field visits to 64 randomly selected sites in Russia.

In Chapter 4 I analyse landcover changes in 1990 - 2014 at previously identified stopover sites used by migrating greater white-fronted geese. I focus on spatiotemporal dynamics of three landcover classes (arable, grass and forest) to better understand how habitat of abandoned stopover sites evolved in 1990 - 2002 and 2002 - 2014. Changes in landcover classes are compared with reported changes in growth rates of area under cultivation, grains and number of cattle.

In Chapter 5 I test the hypothesis that increasing land abandonment at stopover sites in European Russia has contributed to a southward shift in migration routing of greater white-fronted geese. To test this hypothesis I located stopover sites from information contained from 2796 metal ring recoveries and field observations, using a kernel density estimator grid of recovery locations. To account for known factors I examined the effects of latitude, distance to nearest waterbody and settlement and period on the relative density of stopover sites which we used as a proxy for stopover site usage.

In Chapter 6 I summarise the results from four main chapters and discuss the implication of these results to understanding of migration ecology of geese in Anthropocene. I present the contribution of this study to understanding of landuse change impact on wildlife, study's limitations and areas for future research. 


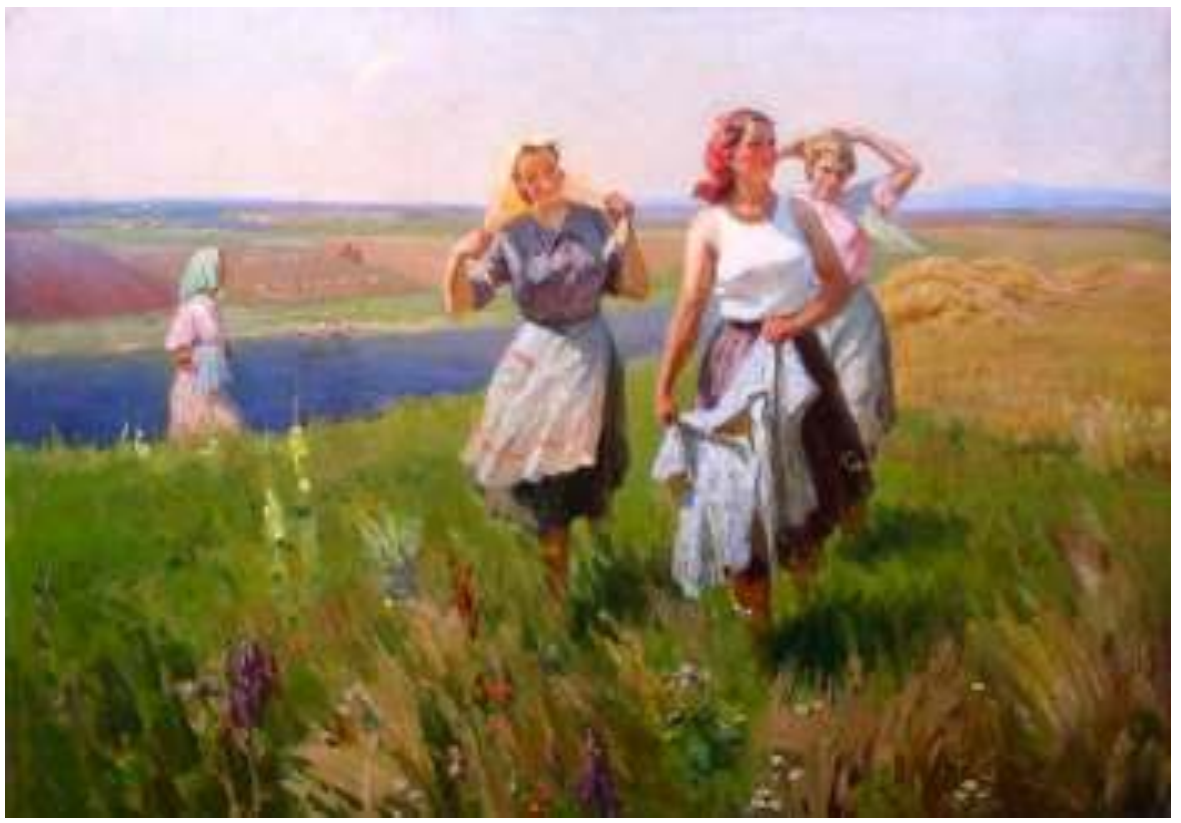

M. Bozhyi "End of the workday" (1950s)/ Михаил Божий. "Конец рабочего дня". 


\title{
Chapter 2
}

\section{Large-scale landscape change in European Russia after the break-up of the USSR}

Mikhail Grishchenko, Herbert H.T. Prins, Ronald C. Ydenberg, Michael E. Schaepman, Sip E. van Wiere, Willem F. de Boer, Henrik J. de Knegt

\begin{abstract}
We describe human population growth and agricultural land use in Russia, based on census data. From each of six censuses (1959, 1970, 1979, 1989, 2002 and 2010), we compiled the population size in 56 provinces and 350 municipal districts in European Russia. From data collected in 1990 - 2015, we compiled agricultural statistics such as the area devoted to crops, and the number of livestock. We used linear mixed-effects models to analyse the relationship of rates of change in these metrics to population size, average annual temperature, municipal area, and the presence of an urban centre, in the USSR vs. post-USSR 'eras'. We found that the rate of human population growth has fallen throughout the entire $50+$ year record. Larger (by population) provinces and municipal districts had higher growth, but over successive censuses positive growth was maintained only in ever larger districts, as smaller districts drained of people. In the post-USSR era, only a few large urban centres had positive growth. Factors such as low average annual temperature, geographic location (northern $v s$. southern region), the distance to an urban centre, and the dissolution of the USSR all exacerbated this effect. These processes are ongoing and strongly altering the rural landscape of European Russia, as reforestation of abandoned agricultural areas is occurring on a large scale, currently estimated at more than $20,000 \mathrm{~km}^{2} / \mathrm{y}$. This will have impacts for wildlife. We anticipate, for example, that these land use changes are playing an important role in newly emerging migration patterns of waterfowl.
\end{abstract}

Keywords: agriculture, human population decline, land abandonment, land use, political ecology, Russia. 


\section{Introduction}

In this Chapter, we document extensive land use changes in European Russia that occurred since the 1950s. Much has been written about the economic changes that occurred in Russia over recent decades (Ahrend 2005; Ickes and Ofer 2006) but much less is known about the vast changes taking place in land use (Ramankutty and Foley 1999; Prishchepov et al. 2013). These changes reflect changes in Russian political economy, and have implications for human well-being and for biodiversity in European Russia. For example, though much contemplated elsewhere, rewilding (Pereira and Navarro 2015) is progressing steadily in much of Russia - but has gone nearly unnoticed outside the country. These economically driven land-use changes over the vast Russian territory need to be understood for the international community to better recognize and appreciate regional and global trends in important processes such as the carbon budget and avian migration.

The vegetation of European Russia has been studied for many years (Keller 1927; Sukachev 1928; Liubimtseva and Defourny 1999). Progressing from south to north, steppe, forest steppe, broad-leaved forest, mixed forest, taiga and tundra zones lie in broad bands across the country, with the boundary between the naturally-occurring steppe and forest zones lying approximately from Lvov, to Kiev, Belgorod and from there to Samara. Forest clearing began in the Neolithic, first in the broad-leaved forest zone about 5500 BCE (Williams 2000; Bradshaw 2004). During the Iron Age people began to move arable agriculture into the coniferous zone. As the human population grew, the demand for provisions climbed (Goldewijk 2001), which stimulated further conversion of natural landscapes into cropland and grassland, as the most productive way to boost supply given existing technologies. This process was centrifugal, spreading from around settlements to outer, marginal areas. Forest clearance reached its zenith around 1914 (Tsvetkov 1957) when most broad-leaved forest had been cleared and agriculture reached its greatest extent (Strakhov et al. 2001). Thereafter, growth in agricultural production required technology such as mechanization and fertilizers, and large-scale works such as drainage and reservoirs (Avakyan and Sharapov 1970). 
Since its 1914 peak several factors in turn worked to reverse the expansion of the land area devoted to agriculture. For example, the area required for the upkeep of horses (grazing, growing fodder) was reduced with farm mechanization in the 1930s as the number of horses declined from $35 \mathrm{M}$ in 1929 (Bobyliov et al. 1984) to $5.3 \mathrm{M}$ in 1986 (Kalashnikov 2001). After the dissolution of the USSR (Strayer 1998), collective farming at many places within the Russian Federation ceased as farm subsidies were halted (Wegren 1995). Much land was privatised, but in many places agriculture was no longer profitable because the economy of scale achieved under collective farming was not possible under private management (Lerman 1998; Ioffe 2005). These trends were most prominent at the economic periphery of the country, where the climate mitigated against agriculture (Ioffe 1991; Ioffe et al. 2004). Small and medium cities lost their economic importance and started shrinking, while larger cities became the new engines of the economy, and grew (Wegren 2012).

This sweeping reorganization of the Russian economy resulted in widespread development of secondary forest in areas where in the 1950s there had been agricultural areas (Ramankutty and Foley 1999; Grishchenko and Prins 2016). Comparisons of detailed land use maps from 1857 (EtoMesto 2018) with the age of forests in northern Russia demonstrates that forest patches started springing up in 1950s (Ramankutty and Foley 1999; Brovkin et al. 2006). Shvidenko et al. (1997) estimated the rate of natural reforestation in European Russia at more than $20000 \mathrm{~km}^{2} /$ year.

In this Chapter, we describe these land use changes, and some of their drivers, to better understand ongoing change on the landscape of European Russia. We compiled human population census data from 1959 through 2015, and agricultural statistics from 1990 through 2015. Based on data aggregated at the municipal district and provincial levels (these are the smallest administrative units), we analyse patterns of human population growth and agricultural performance. We show that measures of growth in agricultural output and human population size have slowed in tandem over the past six decades or longer, and that these declines were exacerbated by (a) factors such as low average annual temperature and geographic location (northern vs. 
southern region) that make agriculture more challenging; (b) by the distance to an urban centre; and (c) by the dissolution of the USSR.

\section{Materials and Methods}

In Russia, national censuses have been conducted at approximately ten year intervals (1959, 1970, 1979, 1989, 2002 and 2010). These census data form the basis of our analysis. European Russia currently comprises 56 provinces, most of which were established in 1950s. Provinces are further subdivided into municipal districts. We compare the 56 provinces, as well as 350 municipal districts in 15 of these provinces (Table 2.1). Municipal districts are much smaller than provinces and therefore more homogeneous, and represent the smallest $\left(\sim 2000 \mathrm{~km}^{2}\right)$ administrative unit in which agricultural statistics have been consistently recorded since 1990 . They thus provide a convenient and finescale statistical record.

Census data were acquired at the Russian Federal Statistics Services (Moscow). Statistics for 350 municipalities were obtained from provincial branches of the Federal Statistics Services, provided as hard copy, photocopy, or digitally in spreadsheets. These data record the human population size of each municipal district since the 1959 census. Agricultural data have been recorded since 1990 and include the area under cultivation (ha), area under grains (ha), the number of cattle, and number of goats and sheep. We report 'shoats' (i.e., goats and sheep together) because the data often do not distinguish between them. The majority of the 350 municipal districts provide a complete record from 1990 through 2015.

Spatial data for provinces and municipal districts of European Russia were obtained in vector format from open access OpenStreetMap (GISLab 2015). The surface area of provinces and municipalities was calculated, and attribute tables with agricultural and demographic data linked to the spatial data. The latitude and longitude of a municipality was taken as those of the administrative centre of each municipality. We obtained for the administrative centre of each municipality an estimate of the average annual temperature reported in the world climate database (WorldClim 2015). Municipal districts with predominantly 'black earth' (Keller 1927, Ioffe and Nefedova 2004) and thus high agricultural 
potential are here termed 'southern' regions, and include Kursk, Lipetsk, Tula and Ryazan in the Central Federal district. All other municipal districts have predominantly 'non-black' earth and have lower agricultural potential, and are here termed 'northern' regions.

Table 2.1. An overview of 15 selected provinces in European Russia. Given are province name, federal district, number of municipal districts, capital, area and human population in 2015.

\begin{tabular}{|c|c|c|c|c|c|}
\hline Province & $\begin{array}{l}\text { Federal } \\
\text { District }\end{array}$ & $\begin{array}{l}\text { Number of } \\
\text { municipal } \\
\text { districts }\end{array}$ & Capital & $\begin{array}{l}\text { Area, } \\
\text { km }^{2}\end{array}$ & $\begin{array}{l}\text { Human } \\
\text { population, } \\
2015\end{array}$ \\
\hline Vladimir Oblast & Central & 16 & Vladimir & 29000 & 1406000 \\
\hline Ivanovo Oblast & Central & 21 & Ivanovo & 21000 & 1037000 \\
\hline Kostroma Oblast & Central & 24 & Kostroma & 60000 & 654000 \\
\hline Kursk Oblast & Central & 28 & Kursk & 30000 & 1117000 \\
\hline Lipetsk Oblast & Central & 18 & Lipetsk & 24000 & 1158000 \\
\hline Ryazan Oblast & Central & 25 & Ryazan & 40000 & 1135000 \\
\hline Smolensk Oblast & Central & 25 & Smolensk & 50000 & 965000 \\
\hline Tver Oblast & Central & 36 & Tver & 84000 & 1315000 \\
\hline Tula Oblast & Central & 23 & Tula & 26000 & 1514000 \\
\hline Yaroslavl Oblast & Central & 17 & Yaroslavl & 36000 & 1272000 \\
\hline Republic of Karelia & Northwestern & 16 & Petrozavodsk & 181000 & 633000 \\
\hline Republic of Komi & Northwestern & 19 & Syktyvkar & 417000 & 864000 \\
\hline Arkhangelsk Oblast & Northwestern & 19 & Arkhangelsk & 590000 & 1183000 \\
\hline Novgorod Oblast & Northwestern & 21 & V. Novgorod & 55000 & 619000 \\
\hline Perm Krai & Volga & 42 & Perm & 160000 & 2637000 \\
\hline Total: 15 & 3 & 350 & & 1803000 & 17509000 \\
\hline
\end{tabular}

The growth rate of the human population between successive censuses in each administrative unit is calculated as:

$$
\frac{\operatorname{Ln} N_{t+n}-\operatorname{Ln} N_{t}}{n}
$$

where $L n N_{t}$ is the natural log of the census statistic in year $t$, and $L n N_{t+n}$ is the natural $\log$ of the census statistic in year $t+n$ (i.e., $n$ years later). We used linear regressions to examine the growth rate in relation to the human 
population size of provinces and of municipal districts, and compared these relationships between the successive census periods.

We used linear mixed-effects models (LME) to analyse the relationship of the growth rates of municipal districts with absolute human population size, average annual temperature, and their interactions, including 'era' (pre- and post-USSR) as a factor. To account for spatial autocorrelation we included 'province' as a random factor in all LMEs. We also used LMEs to analyse patterns in agricultural land use (total area under cultivation; area under grains; number of cattle; and the number of shoats). We used the software packages (ESRI, ArcGIS v. 10.5) for spatial analysis and data visualisation, and $R$ (v. 3.2.2, $R$ Core Team 2016) for all statistical analyses.

\section{Results}

Human population growth in most provinces of European Russia was positive and strong in the USSR era, with higher growth rates in smaller provinces (Figure 2.1). Only a few provinces reported negative growth during this time. But in the post-USSR era the majority had shrinking populations, and the biggest rate declines were recorded in the smaller provinces. The human population in northern regions grew slightly from 1959 to 1989, but shrank thereafter from $15.5 \mathrm{M}$ to $12.4 \mathrm{M}$ by 2015 . Population in southern regions fell from $6 \mathrm{M}$ in 1959 to $5 \mathrm{M}$ in 2015.

Aggregating the data by municipal district in place of province gives a slightly different picture. While small provinces had high positive growth rates in the USSR era (Figure 2.1, left panel), this was not true of small municipalities (Figure 2.2, left panel). In fact, municipalities with the smallest human population size had negative growth in all decades. Even in the 1960s, more than $75 \%$ of municipal districts with human population size smaller than 100,000 were declining, and in the post-USSR era nearly all municipal districts declined. Only a few of the most populous districts maintained positive population growth.

In the post-USSR era the pattern of growth in provinces and municipalities was similar (compare right panels of Figures 2.1 and 2.2). Presumably, in the USSR high growth rate was sustained by state-sponsored industry in one or a 
few municipalities that inflated the overall growth rate of small provinces - an effect that disappeared after the dissolution of the USSR.
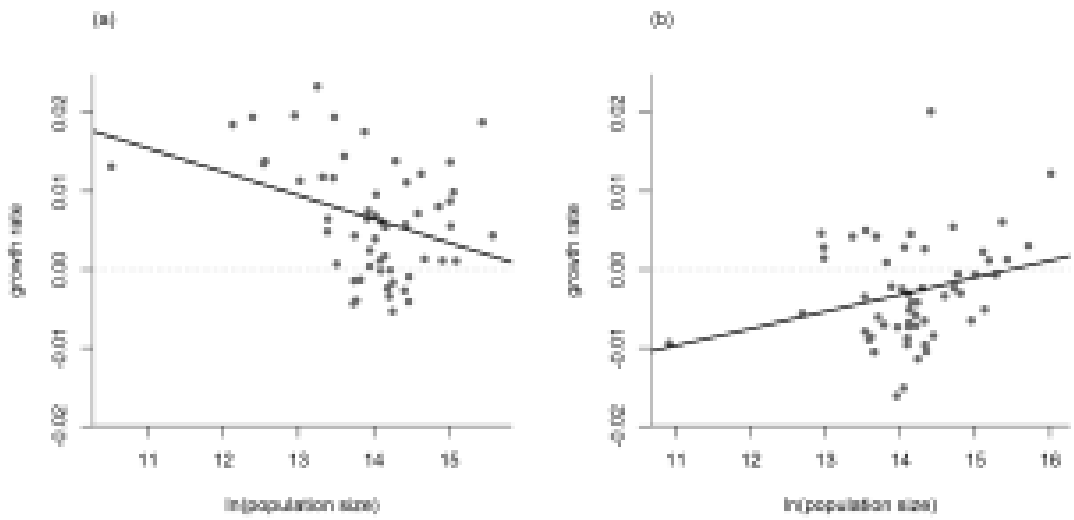

Figure 2.1. Human population growth rate in 56 provinces of European Russia in the USSR era (1959 -1989, left panel) and the post-USSR era (1990 - 2015, right panel), in relation to their population size in 1959 (left panel) or 1989 (right panel). The solid line shows the prediction of a linear regression model, with a slope of -0.003 (SE 0.001, $t=-2.779, p=0.0075$ ) for the USSR era, and a slope of 0.002 (SE $0.001, t=2.058, p=0.0444$ ) for the post-USSR era.
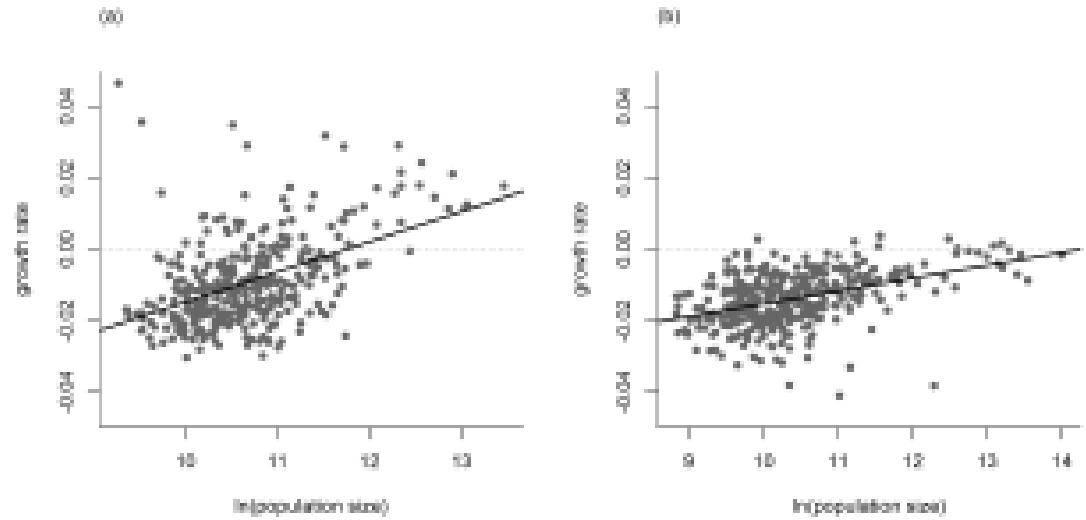

Figure 2.2. Human population growth rates in 350 municipal districts of 15 selected provinces of European Russia in the USSR era (1959 -1989, left panel) and the post-USSR era (1990 2015, right panel), in relation to their population size in 1959 (left panel) or 1989 (right panel). Summary of the linear models (solid lines) in Table 2.2. 
The correlations between growth rate and municipal population size are portrayed for each of the six census decades in Figure 2.3, and a statistical summary is given in Table 2.2 . The correlations are highly significantly positive in each decade, with the average municipal growth rate flattening and shifting downward in successive decades.

Table 2.2. Summary statistics (univariate linear regression) for the relations between population growth rate and (natural logarithm of) population size in 350 municipal districts, in each of six decades, divided into two eras (USSR era 1959 - 1989; post-USSR era 1990 - 2015). The data for each decade are portrayed in Figure 2.3.

\begin{tabular}{llllllll}
\hline Period & df & b & SE & $\mathbf{r}^{\mathbf{2}}$ & F & $\begin{array}{l}\text { Weighted } \\
\text { adj. }\end{array}$ & \multicolumn{3}{l}{ p-value } \\
& & & & $\mathbf{0 . 2 2}$ & $\mathbf{9 6 . 9 2}$ & $\mathbf{1 0 . 2 3}$ & $<\mathbf{0 . 0 0 1}$ \\
\hline $\mathbf{1 9 5 9 - 1 9 8 9}$ & $\mathbf{3 4 4}$ & $\mathbf{0 . 0 0 8}$ & $\mathbf{0 . 0 1 1}$ & $\mathbf{0 . 2 3}$ & \\
$1959-1970$ & 344 & 0.010 & 0.015 & 0.18 & 75.12 & 10.13 & $<0.001$ \\
$1971-1979$ & 346 & 0.011 & 0.013 & 0.29 & 140.55 & 10.06 & $<0.001$ \\
$1980-1989$ & 349 & 0.005 & 0.011 & 0.16 & 65.85 & 9.64 & $<0.001$ \\
\hline $\mathbf{1 9 9 0 - \mathbf { 2 0 1 5 }}$ & $\mathbf{3 5 0}$ & $\mathbf{0 . 0 0 4}$ & $\mathbf{0 . 0 0 7}$ & $\mathbf{0 . 1 9}$ & $\mathbf{8 2 . 8 4}$ & $\mathbf{1 0 . 1 8}$ & $<\mathbf{0 . 0 0 1}$ \\
$1990-2002$ & 350 & 0.002 & 0.007 & 0.06 & 23.51 & 10.27 & $<0.001$ \\
$2003-2010$ & 350 & 0.006 & 0.008 & 0.32 & 163.66 & 9.98 & $<0.001$ \\
$2011-2015$ & 350 & 0.005 & 0.008 & 0.27 & 132.47 & 9.71 & $<0.001$ \\
\hline
\end{tabular}

We used linear mixed-effect models to examine the effects of population size, temperature, and era on human population growth rate in municipal districts. Model results are summarized in Table 2.3 and the data are portrayed in Figure 2.4. All main effects and interactions are highly significant. The effects of population size and era are described above. Figure 2.4 illustrates the interactions, showing that that growth increases with temperature in populous municipalities, but falls with temperature in small municipalities. This arises because there are relatively many small municipalities (with on average low growth) with low average temperature, while the few very large municipal districts (with higher growth) are all relatively warm (Moscow 5.80, St. Petersburg $6.3^{\circ}$, Kiev $7.7^{\circ}$ ), and populous municipalities with relatively low temperature are absent. Comparing the two panels in Figure 2.4 shows that the plane fitted to the points retains its shape between eras, but has shifted downward. 

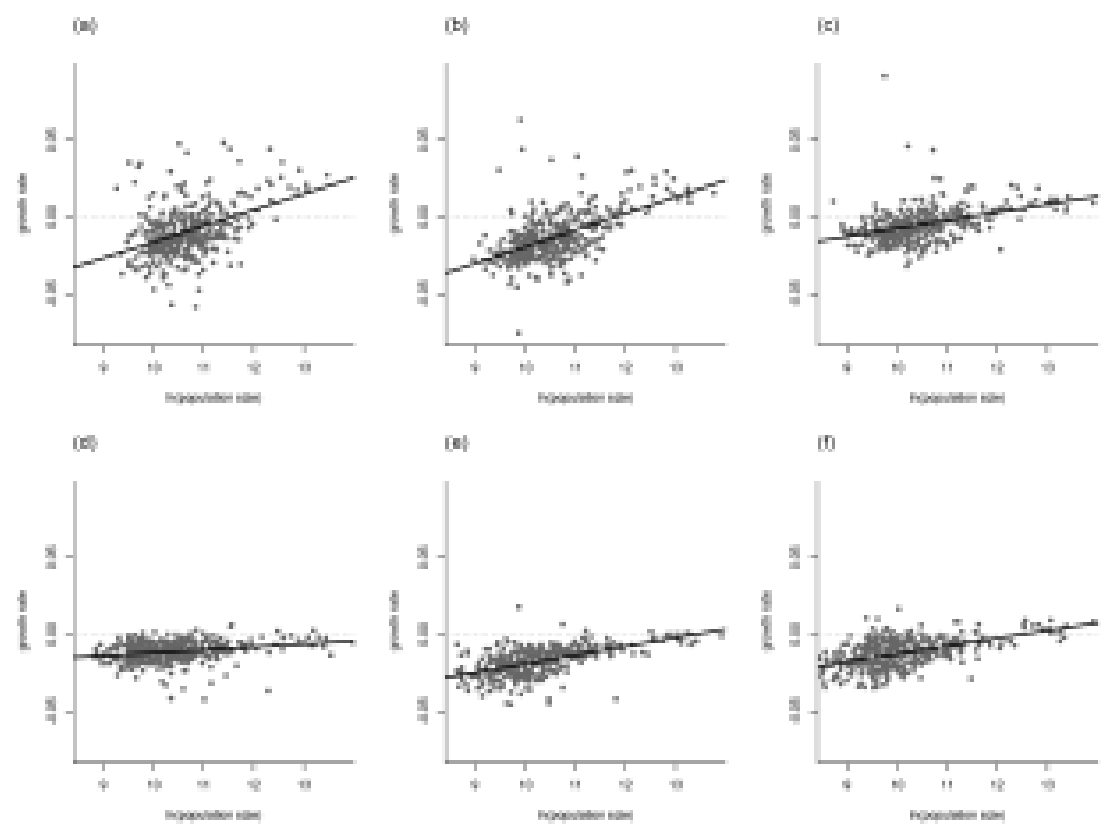

Figure 2.3. Population growth rate in 350 municipal districts of 15 selected provinces of European Russia in decades between successive censuses, in relation to the population size at the start of each decade (census year given in parentheses): panel a, 1959 - 1970 (1959); panel b, 1971 - 1979 (1970); panel c, 1980 - 1989 (1979); panel d, 1990 - 2002 (1989); panel e, 2003 - 2010 (2002); panel f, 2011 - 2015 (2010). The USSR era extends $1959-1989$, and the post-USSR era 1990 - 2015. Summary of the linear models (solid lines) in Table 2.2.

Table 2.3. LME model results, relating the growth rate of municipal districts to (natural logarithm of) human population size, temperature and era (USSR/post-USSR), with all pairwise interactions included. Province was entered as random factor to control for spatial autocorrelation. Given are regression coefficient b, standard error SE, DF, t statistic, and $\mathrm{p}$ value.

\begin{tabular}{llllll}
\hline Predictor & b & SE & DF & t statistic & p-value \\
\hline human population & 0.003 & 0.001 & 2066 & 2.774 & $<0.001$ \\
temperature & -0.025 & 0.005 & 2066 & -4.775 & $<0.001$ \\
era & -0.003 & 0.001 & 2066 & -5.352 & $<0.001$ \\
human population:temperature & 0.025 & 0.005 & 2066 & 4.611 & $<0.001$ \\
human population:era & -0.004 & 0.001 & 2066 & -7.521 & $<0.001$ \\
temperature:era & 0.005 & 0.001 & 2066 & 11.050 & $<0.001$ \\
\hline
\end{tabular}



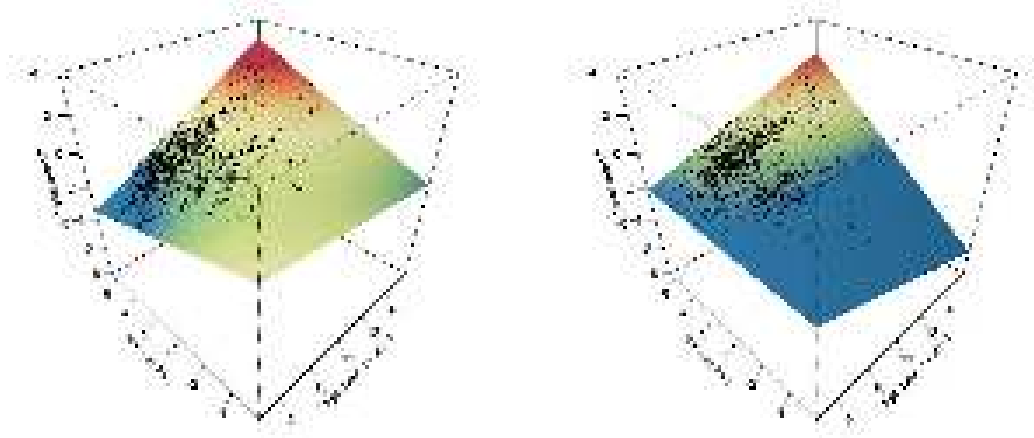

Figure 2.4. Model predicted population growth rate (see Table 2.3) in 350 municipal districts of European Russia in relation to population size (1959 left panel; 1989 right panel) and average annual temperature, in the USSR era (1959 -1989, left panel) and the post-USSR era (1990 2015 , right panel). Dots represent the location of the municipal districts, warmer colours depict higher growth rates.

Agricultural statistics comparing northern and southern regions of European Russia are portrayed in Figure 2.5. All measures (total area under cultivation, area under grains, number of cattle, number of shoats) decline sharply, and differ between the two regions. The total area under cultivation dropped by more than half in northern areas, falling from $8 \mathrm{M}$ ha in 1990 to 3 $M$ ha in 2015, while in southern regions the initial decrease from 6.5 $\mathrm{M}$ ha reversed in 2010 and reached $4 \mathrm{M}$ ha in 2015. The area under grains tumbled in municipal districts in northern regions, falling from $3 \mathrm{M}$ ha in 1990 to just 0.6 $\mathrm{M}$ ha in 2010 when its decline stabilised. In contrast, municipal districts in the south experienced only a moderate decline in area under grains, which stopped in 2000 and recovered to $3 \mathrm{M}$ ha in 2015, though still less than the $3.5 \mathrm{M}$ ha in 1990. Grain production virtually disappeared from the majority of municipal districts in northern areas. 
a

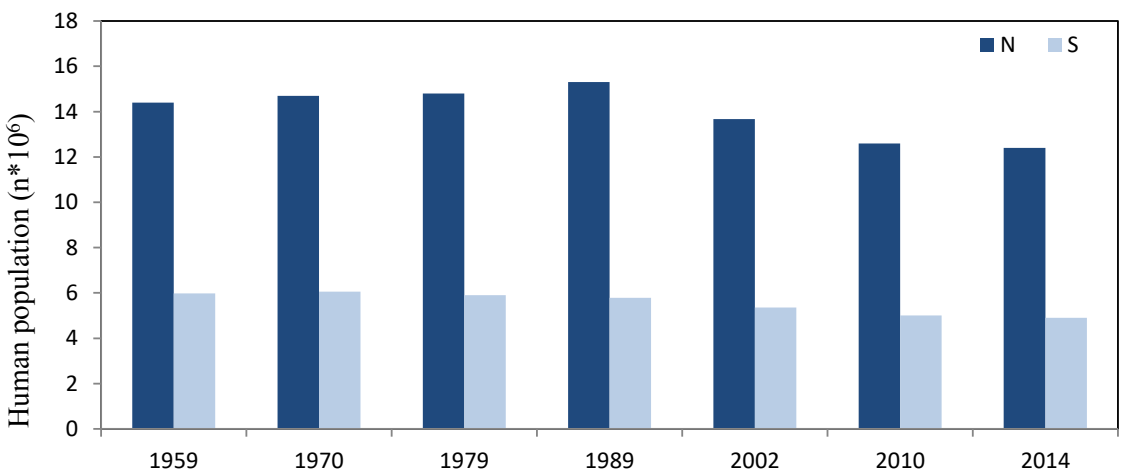

b
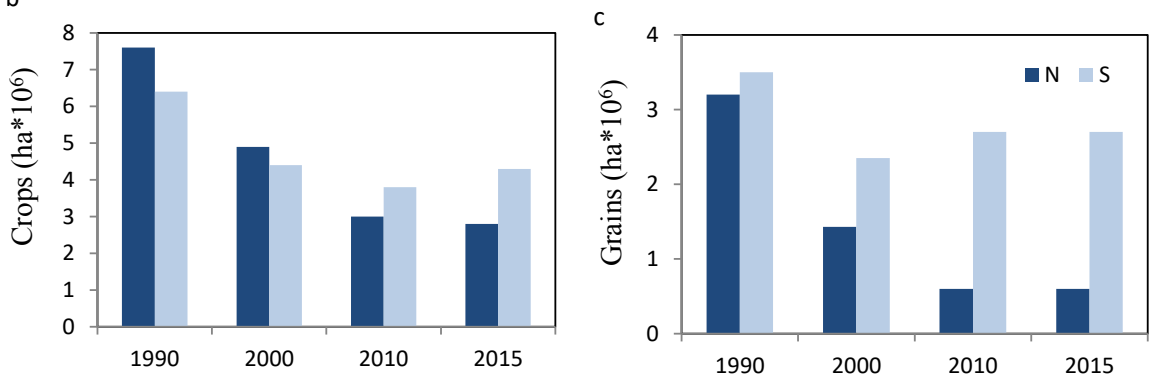

d
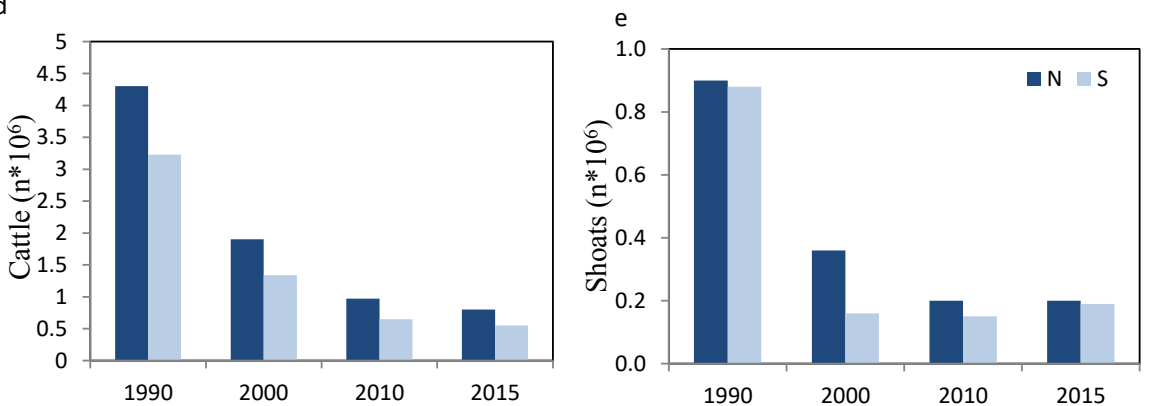

Figure 2.5. Agricultural statistics in 350 municipal districts of 15 provinces in the northern (dark blue) and southern (light blue) portions of European Russia. The axis gives the census year. Panel a) Total area under cultivation (ha. north: 239 districts, south: 94 districts); b. Area under grains (ha. north: 187 districts, south: 93 districts); c. Number of cattle (north: 218 districts, south: 94 districts); d. Number of shoats (north: 141 districts, south: 66 districts). 
Table 2.4. Summary of LMEs of the growth rates (1990 - 2015) of four agricultural measures in relation to the area of the municipal district, annual average temperature, the presence of an urban centre, and the absolute area or number of the measure in each district. Area of municipal district, population size, area under cultivation, area under grains, number of cows and number of shoats are In-transformed. Given are the regression coefficient b, standard error SE, degrees of freedom $\mathrm{df}$, the $\mathrm{t}$ statistic and the $\mathrm{p}$ value.

\begin{tabular}{|c|c|c|c|c|c|c|}
\hline $\begin{array}{l}\text { Land use } \\
\text { (growth rates) }\end{array}$ & Predictor & $\mathbf{b}$ & SE & df & t statistic & p-value \\
\hline \multirow{6}{*}{$\begin{array}{l}\text { total area under } \\
\text { cultivation }\end{array}$} & area of municipal district & 0.003 & 0.002 & 308 & 1.130 & N.S. \\
\hline & population size & -0.003 & 0.002 & 308 & -2.031 & 0.04 \\
\hline & population growth rate & 0.093 & 0.151 & 308 & 0.616 & N.S. \\
\hline & mean temperature & -0.004 & 0.002 & 308 & -3.323 & 0.02 \\
\hline & urban centre & 0.005 & 0.003 & 308 & 1.378 & N.S. \\
\hline & area under cultivation & 0.024 & 0.01 & 308 & 22.188 & $<0.001$ \\
\hline \multirow{6}{*}{$\begin{array}{l}\text { area under } \\
\text { grains }\end{array}$} & area of municipal district & -0.010 & 0.003 & 258 & -3.779 & $<0.001$ \\
\hline & population size & 0.001 & 0.001 & 258 & 0.385 & N.S. \\
\hline & population growth rate & -0.157 & 0.134 & 258 & -1.172 & N.S. \\
\hline & mean temperature & -0.008 & 0.003 & 258 & -3.177 & $<0.01$ \\
\hline & urban centre & 0.001 & 0.003 & 258 & 0.376 & N.S. \\
\hline & area under grains & 0.030 & 0.001 & 258 & 50.626 & $<0.001$ \\
\hline \multirow[t]{6}{*}{ number of cattle } & area of municipal district & 0.001 & 0.001 & 288 & 1.118 & N.S. \\
\hline & population size & 0.012 & 0.001 & 288 & 13.118 & $<0.001$ \\
\hline & population growth rate & -0.205 & 0.081 & 288 & -2.530 & 0.01 \\
\hline & mean temperature & -0.003 & 0.001 & 288 & -2.784 & $<0.01$ \\
\hline & urban centre & 0.003 & 0.002 & 288 & 1.690 & N.S. \\
\hline & number of cattle & -0.001 & 0.001 & 288 & -0.745 & N.S. \\
\hline \multirow{6}{*}{$\begin{array}{l}\text { number of } \\
\text { shoats }\end{array}$} & area of municipal district & -0.000 & 0.001 & 188 & -0.291 & N.S. \\
\hline & population size & 0.004 & 0.001 & 188 & 6.526 & $<0.001$ \\
\hline & population growth rate & -0.103 & 0.059 & 188 & -1.757 & N.S. \\
\hline & mean temperature & 0.001 & 0.001 & 188 & 0.673 & N.S. \\
\hline & urban centre & 0.003 & 0.001 & 188 & 2.288 & 0.02 \\
\hline & number of shoats & 0.001 & 0.001 & 188 & 0.923 & N.S. \\
\hline
\end{tabular}

The number of cattle and shoats showed staggering downturns in both regions. The northern cattle herd shrank by more than $80 \%$, from $4.3 \mathrm{M}$ in 1990 to $0.8 \mathrm{M}$ in 2015 , and in southern regions plunged from $3.3 \mathrm{M}$ in 1990 to $0.5 \mathrm{M}$ in 2015. The number of shoats (Figure $2.5 \mathrm{~d}$ ) in the north shrank five-fold from $1 \mathrm{M}$ in 1990 to $0.2 \mathrm{M}$ in 2015 , while in the south it shrank six-fold from $0.9 \mathrm{M}$ in 
1990 to $0.15 \mathrm{M}$ in 2010. Major declines in the number of shoats (Figure $2.5 \mathrm{~d}$ ) occurred in the north (Karelia and Arkhangelsk) and individual municipal districts of Tver, Smolensk and Ryazan provinces.

Table 2.4 summarizes the LME models analysing these trends. The rate of change is negative and highly significant for each of the four agricultural measures, but the significant factors differ. For the growth rate in the area under crops, the only strongly significant factor $(b=0.024)$ is the absolute area. For the growth rate in the area under grains, the significant factors are the area of the municipality $(b=-0.105)$ and the absolute area of under grains $(b=0.030)$. For growth in the number of cattle, the significant factors are the population size $(b=0.012)$ and the human population growth rate $(b=-0.205)$. For growth in the number of shoats, the only strongly significant factor is the human population $(b=0.004)$. The slope estimates also differ in direction and strength between the four measures.

\section{Discussion}

The data compiled here show that the growth rates of the human population in provinces and municipalities of European Russia have fallen over the last six decades, especially in smaller municipal districts and areas with lower average annual temperature. Growth became negative in all but the very largest cities. This population decline is associated with strong reductions in agricultural production of grain, cattle, crops and sheep and goats.

The analysis signposted two distinctive stages in the population development of municipal districts: the USSR era and the post-USSR era. Changes in population started in the 1950s, but their speed and magnitude increased after 1991. With the dismantling of the planned economy in the early 1990s, the government experienced a severe shortage of funds and minimised its involvement in the economy, which contributed to major fall in growth rates (Milanovic 1998; Andrienko and Guriev 2004; White 2007). The structure of local economy and its adaptability to changes were among major factors to mitigate or to exacerbate this decline (Yavlinsky and Braguinsky 1994; Tikhomirov 2000). In the market environment, populous municipal districts had more diverse human resources and more funds based on manufacturing, and so 
were better able to adapt than smaller centres, which were hampered by economies based solely on forestry, mining or agriculture (Tikhomirov 2000; Guriev and Vakulenko 2015).

During the USSR-era, small municipal districts declined rapidly, while populous centres grew even larger. Post-WWII industrialisation and rapid urbanisation were the major drivers of this process (White 2007). The industrial centres of European Russia destroyed during the Second World War quickly recovered: old factories were rebuilt, and larger more efficient factories were added. The increased demand for labour fuelled rapid urbanisation, attracting people to larger industrialised districts and away from smaller rural districts (Rowland 1998). The construction of new factories by the government culminated in the 1960-1970s, spurring the decline of smaller municipal districts (Rowland 1998; Wegren 1998). To counter this decline the government initiated large development programs in the 1970 s to support agriculture and smaller urban settlements (Johnson and Brooks 1983; Wegren 1998). Such effects were typical for all countries with planned economies (Henderson and Wang 2007; Bettencourt et al. 2007). In North America and Western Europe, smaller urban areas also experienced major downturns due to declines in heavy industrial production and migration to large urban areas (Bongaarts 2009). This type of industrial migration 'following factories' was common in many developed countries (Canada, Sweden, Japan) in early 20th century (Koser and Lutz 1998; Traphagan and Knight 2003; Sandow 2008; Teitelbaum 2013) followed by backmigration at its end (Tikhomirov 2000, Teitelbaum 2013). Russia experienced similar trend but to less extent (Malakoff 2016).

Municipal districts with smaller areas under cultivation, smaller areas under grains, lower numbers of cattle and shoats in colder areas declined faster than other municipal districts. Negative correlations with area and temperature for number of cattle and number of shoats are might be associated with different ownership of livestock: in warmer municipal districts most livestock belonged to collective farms and vanished together with them; in colder municipal districts livestock belonged to locals who kept it for personal use. Total area under cultivation, number of cattle and shoats are positively correlated with presence of urban centre. This indicates that demand for crops, dairy and livestock is local 
and depends on location of processing facilities (Bezlepkina et al. 2005; Douphrate et al. 2013), in contrast to area under grains, which is highly influenced by the international market (Trostle 2008; Trostle et al. 2011; Lioubimtseva and Henebry 2012; Lioubimtseva et al. 2013).

Both temperature and the interaction 'human population*temperature' show a positive effect on growth rates. This pattern could emerge from high growth rates of northern municipal districts in the USSR era due to government's effort (Lewis and Rowland 1979). In the post-USSR era temperature showed stronger positive effect on all agricultural parameters. This is indicated by strong positive correlations of the interaction 'area*temperature' for total area under cultivation, number of cattle and number of shoats. In all LMEs temperature showed a strong negative correlation except for area under grains where it was positive. This outcome might be biased by selection of municipal districts: area under grains shows a positive correlation with temperature because analysis covered almost no northern municipal districts (no grain production). In colder municipal districts agriculture was affected by the dissolution of the USSR stronger than in warmer areas, though some effects were serious there. We are not familiar with similar findings in international literature, but our results tally with other studies which show that land use is harder hit in economically peripheral areas than in areas where demand is maintained by higher population densities (Ioffe and Nefedova 2004; Prishchepov et al. 2013).

The significant negative effect of temperature on total area under cultivation, number of cattle and number of shoats might be linked to increased costs of doing agriculture, particularly surge in prices of commodities (Wegren 1998). These include electricity to light buildings, natural gas to heat barns and warehouses, petrol and oils to run machinery. With lower temperatures, shorter vegetative period and shorter day length the North is prone to larger demand for commodities and, consequently, higher expenditures on production factors. Additionally, shorter field season contributes to higher costs of labour and machinery, which stayed inactive during winter. Since the increased costs were not balanced out by subsidies any longer (Wegren 1998), the negative effect of temperature clearly manifested itself in our results. The land abandonment did not necessarily lead to increased productivity (Ioffe and Nefedova 2004) as it 
was expected in a wake of reforms in early 1990s (Wegren 1995). Hence, we do not expect that the observed downward spiral in agriculture was somewhat compensated with higher productivity or quality of food. On the contrary, food quality remains rather low (Grishchenko and Prins 2016) with a high percentage of market shared by imported foodstuff mainly from the EU, Belarus and Central Asia. However this appears to reverse after imposed in 2014 counter-sanctions which stimulated development of Russian agriculture.

Abandoned fields are usually overtaken by encroaching shrubs and trees (Prishchepov et al. 2013; Grishchenko and Prins 2016). This results in large increase of disturbed landscapes, and thus heavily impacting biodiversity. Even though this may be positive for much wildlife other species are negatively affected. European Russia forms part of the East Atlantic Flyway which is used by a number of migrating waterfowl. Goose species (e.g., greater white-fronted goose Anser albifrons) spend much time at stopover sites on the trip between their breeding and wintering grounds. These species may have been affected most by changes in land use at the stopover sites which have become progressively unsuitable. The overall number of the sites in European Russia and along the Flyway may have decreased too. Migrating waterfowl might adjust their migration behaviour which can potentially result in reshaping of existing migration networks of the East Atlantic Flyway.

Grain production and cattle farming have declined precipitously after the dissolution of the USSR especially in European Russia which resulted in either different land use or in land abandonment. Given the overall decline, the number of abandoned fields is expected to increase in the near future. Wide-spread land abandonment will increase shrub and tree encroachment which, we think, will result for many years in the accumulation of standing biomass thus fixing significant amounts of $\mathrm{CO}_{2}$ from atmosphere and changing the carbon budgets in Russia. This then is perhaps an unexpected positive legacy of a near unprecedented political upheaval. Our study may also provide a sound framework for understanding processes of land abandonment in the EU and North America. 


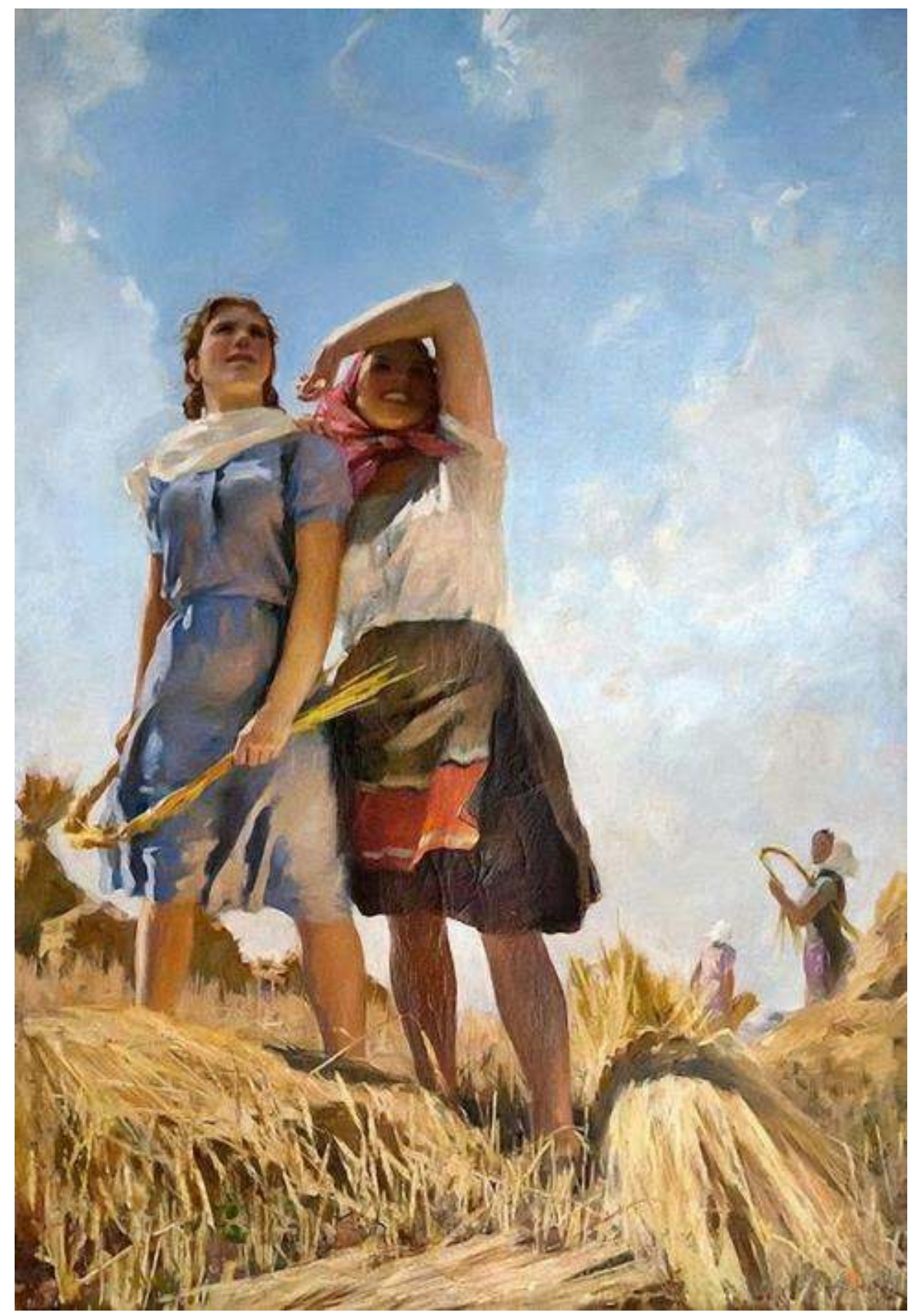

F. Malaev "Flying airplanes" (1950) / Ф. Малаев "Летящие самолёты". 


\title{
Chapter 3
}

\section{Automated identification of potential stopover sites of migratory geese in European Russia}

Mikhail Grishchenko, Herbert H.T. Prins, Ronald C. Ydenberg, Michael E. Schaepman, Henrik J. de Knegt

\begin{abstract}
The migration ecology of geese in Russia has been explored to a limited extent, with the majority of research activities concentrated on breeding grounds. The main purpose of this paper is to identify potential stopover sites used by migrating geese in the European part of Russia. We developed an automated classifier to model habitat suitability of goose stopover sites. We used a reductionist spatial model with a pre-defined set of rules. These rules were based on an evaluation of mainly foraging and roosting attractiveness of selected areas in the vicinity of water bodies. We identified 1931 locations in European Russia that could potentially be used by greater white-fronted geese as migratory stopover sites. We were able to visit 64 randomly-selected stopover sites to validate our classification approach. Results of automatic classification were compared with ground data and analysis of nutrients present in vegetation. Our findings will contribute to a better understanding of migration ecology of geese in Russia and their behaviour at stopover sites.
\end{abstract}

Key words: automatic classifier, greater white-fronted goose, migration, Russia, stopover sites

\section{Introduction}

Migration ecology of the Western Palaearctic populations of geese along the East Atlantic Flyway was thoroughly studied based on field observations in Western Europe (Drent and Prins 1987; Ebbinge 1991; Mooij 1997; Eichhorn et al. 2006). During migration, geese make use of several stopover sites where they rest and recover their depleted energy reserves (Hübner et al. 2006; Drent et al. 2007). Further along the East Atlantic Flyway, in European Russia, the migration 
ecology of geese has been explored less, with most research activities concentrated on the Arctic breeding grounds (Mooij 1997; Kölzsch et al. 2016). European Russia forms part of the East Atlantic Flyway. This flyway is used by a number of goose species (Table 3.1) with greater white-fronted geese Anser albifrons the most numerous at about $1.3 \mathrm{M}$ individuals (Koffijberg and van Winden, 2014). Some species pass through the flyway quickly (e.g., barnacle geese Branta leucopsis) but others (e.g., greater white-fronted goose) take many weeks on the passage between their breeding- and wintering grounds, and spend much time at stopover sites in European Russia (Figure 3.1). Of their annual cycle, greater white-fronted geese may spend altogether more than 55 $\%$ of their time (Table 3.1) in the flyway.

Table 3.1. Goose species on the East Atlantic Flyway. Data extracted from Wetlands International (2012), Arzel et al. (2006), and Madsen and Cracknell (1999).

\begin{tabular}{|c|c|c|c|c|c|c|c|}
\hline Name & Latin name & $\begin{array}{l}\text { Estimated } \\
\text { number in } \\
2012\end{array}$ & $\begin{array}{l}\text { Average } \\
\text { period } \\
\text { flying } N\end{array}$ & $\begin{array}{l}\text { Average } \\
\text { period } \\
\text { flying } \mathbf{S}\end{array}$ & $\begin{array}{l}\text { Average } \\
\text { number } \\
\text { of days } \\
\text { flying } N\end{array}$ & $\begin{array}{l}\text { Average } \\
\text { number } \\
\text { of days } \\
\text { flying } S\end{array}$ & $\begin{array}{l}\text { Total } \\
\text { proportion of } \\
\text { the year on } \\
\text { migration }\end{array}$ \\
\hline $\begin{array}{l}\text { Greater } \\
\text { White-fronted } \\
\text { goose }\end{array}$ & $\begin{array}{l}\text { Anser } \\
\text { albifrons }\end{array}$ & $1,334,000$ & 4 months & 2.5 months & 135 & 75 & $55 \%$ \\
\hline Bean goose & Anser fabialis & 620,000 & 3.5 months & 2 months & 120 & 60 & $49 \%$ \\
\hline Brent goose & $\begin{array}{l}\text { Branta } \\
\text { bernicla }\end{array}$ & 330,000 & 2 months & 2 months & 60 & 60 & $33 \%$ \\
\hline $\begin{array}{l}\text { Pink-footed } \\
\text { goose }\end{array}$ & $\begin{array}{l}\text { Anser } \\
\text { brachyrhynch } \\
\text { us }\end{array}$ & 455,000 & 2 months & 2 months & 60 & 60 & $33 \%$ \\
\hline $\begin{array}{l}\text { Barnacle } \\
\text { goose }\end{array}$ & $\begin{array}{l}\text { Branta } \\
\text { leucopsis }\end{array}$ & $1,100,000$ & 1.5 months & 1 months & 40 & 30 & $19 \%$ \\
\hline
\end{tabular}

The clearance of forests in European Russia since the Neolithic by humans to make room for livestock and crops created landscapes over which geese found it easier and easier to move (Ankney 1996; Gauthier et al. 2005, van Eerden et al. 2005; Alisauskas et al. 2011; Jankowiak, 2015). As the human population increased, agriculture spread to even remote and marginal areas. By early 20th century almost all areas of European Russia suitable for agriculture were in use, and further growth in food production required increases in productivity by the use of machinery, fertilizer and large-scale land improvement works. The latter 
resulted in improved drainage of wet fields of Central and Northwestern Russia, and the creation of thousands large and small water reservoirs all over European Russia (Berka 1990). This extensive conversion of forest to agricultural lands created a landscape ideal for goose migration, with thousands of large and small stopover sites for migrating geese and extensive grazing areas. In other words, geese have been beneficiaries of the Anthropocene (Moss and Erlandson 2013; Hatvany et al. 2015) since it began about 8,000 years ago.

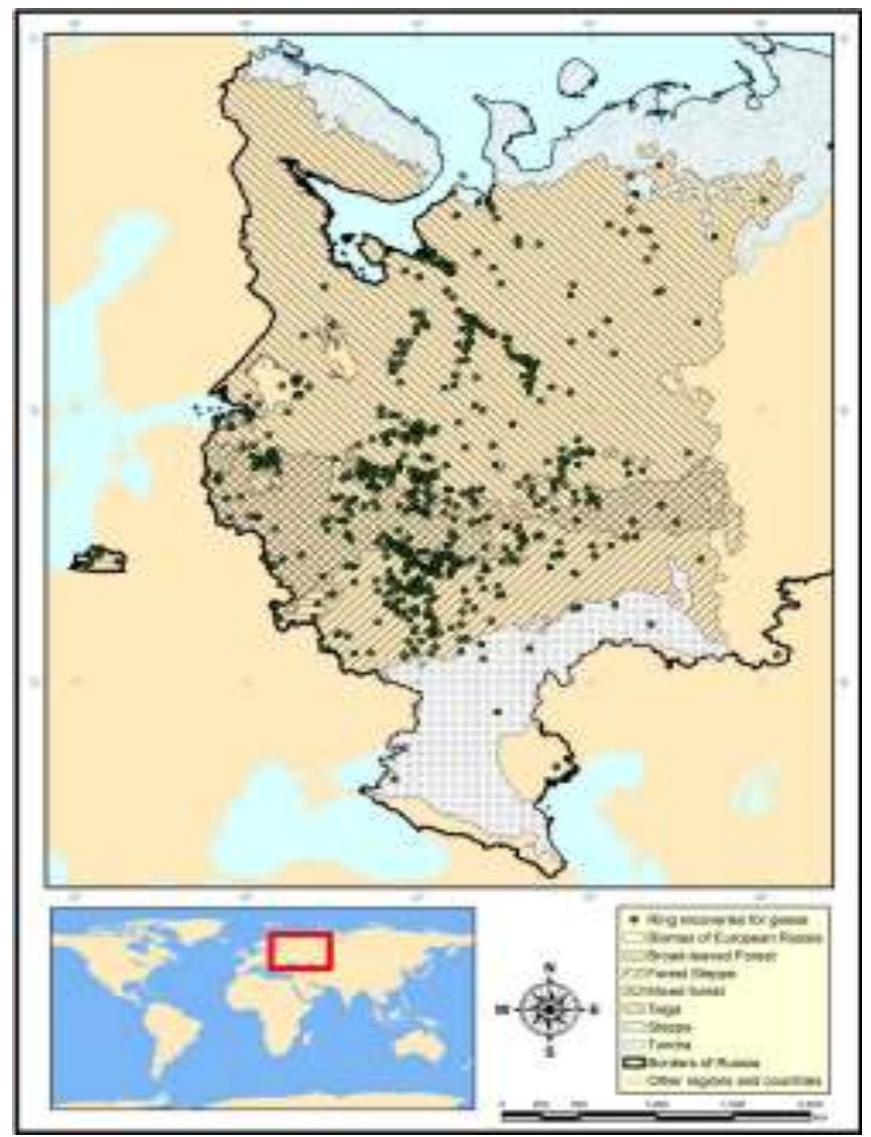

Figure 3.1. A map of European Russia, showing all greater white-fronted goose stopover sites used between 1955 and 2015 (Chapter 3). Superimposed are natural vegetation zones (stippled: steppe; simple hatch: forest steppe; horizontal hatching: broad-leaved forest; cross-hatching: mixed forest; reverse hatch: coniferous forest or taiga; to the North of the taiga lies the tundra), based on Olson \& Dinerstein (2002). Borders reflect the situation when the data were collected and do not imply a political viewpoint. 
However, the land is beginning to revert to forest, after the major restructuring of agriculture that followed the dismantling of the USSR in 1991 (Chapter 2). Removal of state subsidies for collective and individual farming (Wegren 1995) exacerbated the already poor financial performance of farms and led to their massive bankruptcy and termination of agricultural activities in the vast areas of European Russia. Since most Russian farms were located in the boreal zone, abandoned fields were quickly overtaken by natural vegetation, shrubs and trees, leading to full reforestation in 25-30 years after abandonments (Kümmerle et al. 2015; Grishchenko and Prins 2016). Such vegetation succession reduces open areas of fields used as stopover sites used by migrating geese. With less input of fertilizers and reduced mowing, the quality of forage on the remaining open fields decreases. This land abandonment developed initially in the economic periphery (i.e., Russian North and smaller municipalities) and progressed towards the centre of European Russia. The landscape that offered migrating geese so many stopover locations has as a result become less suitable.

Advances have been made due to the use of modern techniques such as remote sensing (e.g., Si et al. 2015a) and applying satellite data (e.g. Papi and Gudmundsson 1993). Also for the study of migrating geese, these modern techniques could be applied with much success (van Wijk et al. 2012; Si et al. 2015a). The first attempts to use remote sensing data to study migrating geese were made in 1970s when first Landsat 3 images became available. First studies focused on fixed habitat where nesting success (Heyland 1976) was assessed, a land survey of goose habitat was performed (Wickware et al. 1980) and a goose census (Best et al. 1982) was carried out using satellite images. Later these studies focused on habitat selection (Morrison 1997; Naugle 1997) and factors that affect decisions of migrating waterfowl or shorebirds to choose particular staging sites. With low temporal resolution it was difficult to obtain multitemporal series of images to evaluate dynamics of landcover changes. In addition, remote sensing techniques were first widely used for remote areas and breeding habitat (Heyland 1976, Gadallah 2002, Gadallah and Csilling 2002) that was isolated, had limited data availability, which made satellite imagery the only source of information about landscapes. 
More integrated approaches to studying goose migration ecology emerged about 20 years ago (Drent and Mehlum 1998) with advances in analyses of remote sensing data, higher reliability of signals and adoption of GPS-tracking technology to monitor their movements. This allowed a multidisciplinary approach to habitat suitability modelling (Kushawa and Roy 2002) and first multitemporal analysis (Jano et al. 1998; Travaini et al. 2007) based on spatial decision rules. While virtually all studies before focused on breeding grounds, Tombre et al. $(2005,2010)$ performed a habitat suitability assessment for pinkfooted geese (Anser brachyrhynchus) on their stopover sites. But these observations are limited to a relatively small number of sites, and the proportional recovery of marked geese is low. Determining the full extent of stopover sites in such a vast area as European Russia $\left(\sim 4 \times 10^{6} \mathrm{~km}^{2}\right)$ requires another approach. For the later, no large-scale habitat suitability modelling of their stopover sites, particularly in Russia, has been done to date. This is related with its inaccessibility for validation as well as need for a more integrated approach (Soininen at al. 2015; Guo et al, 2017) that combines remote sensing, GIS and analysis of socio-economic data. Similar assignments were done for site assessment for wetlands where potentially suitable areas were identified and prioritised (Dong et al. 2014; Li et al 2017). A more land-based approach with ground data collection was done to better understand staging habitat ecology of migrating Canada geese (Branta canadensis, McAlister et al. 2017). High predictive power of potential stopover site identification of such expert-based modelling was shown with the study on barnacle geese (Shariari et al. 2017) which suggests its potential effectiveness for greater white-fronted geese whose migration routes, breeding, wintering and stopover sites partly overlap.

In this Chapter we develop a classification approach to identify potential stopover sites in European Russia that migrating geese could use for spring staging. We report on the number of these stopover sites that could be used by migrating geese in European Russia. We validate the outcome of this work with the set of identified stopover sites from ring recoveries. Our purpose then is to verify whether the relatively low number of identified stopover sites in European Russia (Chapter 5) tallies with those that were identified though remote sensing. This is of importance for further understanding the migration ecology of these 
geese, but also for estimating the loss of stopover sites due to the sweeping reorganisation of Russian agriculture after the dissolution of the USSR in 1991.

\section{Materials and Methods}

We developed an automated classification model to identify the habitat suitability of goose stopover sites across European Russia. The pre-defined spatial rules were based on knowledge derived from previous studies of the wintering sites in the Netherlands (Koffijberg et al. 1997; Kleijn et al. 2012), Denmark (Madsen 1985a), Germany (Mooij 1993), Sweden and Norway (Kölzsch et al. 2015). These studies were performed every winter for several decades and recorded information in particularly for the greater white-fronted goose, bean goose (Anser fabalis) and pink-footed goose. These goose species share much of the same wintering habitat and show similar migration behaviour. A wintering site constitutes a wetland with associated grasslands of sufficient nutritional quality ( $\mathrm{Si}$ et al. 2011) which is rather similar to a stopover site in European Russia. Thus, we decided to use the observations of all three species to generate the spatial rules of habitat utilisation (Speed et al. 2009) at the migration stopover sites in Russia.

During stopping over geese were sighted mostly on agricultural lands or on nearby waterbodies. Therefore, our first assumption was that a stopover site comprises at minimum a 20 ha waterbody with associated fields (Koffijberg et al. 1997; Si et al. 2011). These fields could be cereal fields (wheat, barley, oats, rye), stubble fields (Nilsson and Persson 1998; Rosin et al. 2012), fields with leftovers from potato or sugar beet from the previous fall (Ely and Raveling 2011), meadows or grasslands (with grass shorter than seven cm: Heuermann et al. 2011; Si et al. 2011) between which we do not discriminate because geese use them all. We assumed that nutritional quality of grasses in spring was sufficient for geese, which was previously confirmed by the study of grass greenup (Ydenberg and Prins 1981; Si et al. 2011). Secondly, we assumed that waterbodies were exclusively used for roosting while associated fields were exclusively used for foraging. This assumption was supported by extensive studies of the diet composition of the above mentioned species (Madsen 1985a; Madsen 1998; Arzel 2006). Thirdly, we assumed that there were no significant 
fluctuations in the level and extent of the surface water. Water levels were considered at their peak due to rapid snowmelt as we investigated the spring migration.

From field observations we expect geese to stay within a distance of $5 \mathrm{~km}$ from roosting site (Madsen and Cracknell 1999; Kleijn et al. 2012; Baveco 2013; $\mathrm{Si}$ et al. 2015b). Thus, we used a $5 \mathrm{~km}$ buffer from the waterbody to foraging fields in our automatic classifier for potential stopover site selection. Within selected areas we then excluded buffers with disturbance caused by adjacent settlements (Table 3.2), railways (Table 3.3) and roads (Table 3.4). Based on Ortega (2012) we could not obtain any definite numbers for noise disturbance zone which was previously measured for pink-footed geese (Madsen 1985b). Therefore we made an estimate of the distance. We used the MODIS landcover product (Land Cover Type/Dynamics, MCD12Q1 reprocessed version 5, accessed on 01-12-2017) for discriminating between forest and suitable stopover habitat (arable land, pastures and meadows). Potential stopover sites were identified by overlaying techniques with an output pixel sizes of $500 \times 500$ meters. This is comparable with an average field area of collective farm in Russia at the end of the 1980s (Prishchepov et al. 2013; pers. obs.), though we acknowledge the difference in shape. It also tallies well with geese selecting fields in areas where hunting is important (Kalchreuter 1991; Ebbinge pers. comm.).

We selected water bodies and rivers with a flow speed of less than 0.5 $\mathrm{m} . \mathrm{sec}^{-1}$. Flow speed is usually not contained in satellite or openstreetmap data, thus we assumed that all polygon feature classes representing rivers had a low flow speed. We selected waterbodies with surface area larger than 100 ha from MODIS Landcover product (Land Cover Type/Dynamics, MCD12Q1 reprocessed version 5, Accessed on 01-12-2017) and with area smaller than 100 ha from OpenStreetMap (Accessed on 01-12-2017). We selected only fresh-water bodies. We did not include predation in the analysis since no data for European Russia are available. Two provinces (Nenets Autonomous Okrug and Murmansk Oblast) were excluded because they largely overlap with the breeding grounds and, hence, contain few stopover sites. 
Table 3.2. Distance from settlement's centroid (radius of a circle). "Locality" is a type of settlement with fewer than 10 inhabitants that do not live permanently at that locality (SanPiN, 2003).

\begin{tabular}{llll}
\hline $\begin{array}{l}\text { Type of rural } \\
\text { settlement }\end{array}$ & Village & Hamlet & Locality \\
\hline North & $600 \mathrm{~m}$ & $300 \mathrm{~m}$ & $50 \mathrm{~m}$ \\
Middle & $900 \mathrm{~m}$ & $600 \mathrm{~m}$ & $100 \mathrm{~m}$ \\
South & $1500 \mathrm{~m}$ & $1000 \mathrm{~m}$ & $150 \mathrm{~m}$ \\
\hline
\end{tabular}

Table 3.3. Disturbance zones from the railway lines (radius of a circle, SanPiN, 2003); the number of trains per day are used to classify traffic intensity.

\begin{tabular}{llllll}
\hline $\mathbf{N}$ & Number of lines & Electrification & $\begin{array}{l}\text { Traffic } \\
\text { Intensity }\end{array}$ & $\begin{array}{l}\mathbf{N} \\
\text { trains.day }^{-1}\end{array}$ & $\begin{array}{l}\text { Distance } \\
(\mathbf{m})\end{array}$ \\
\hline 1 & 2 lines & electrified & Very heavy & $>100$ & 150 \\
2 & 2 lines & non-electrified & Heavy & $50-100$ & 100 \\
3 & 1 line & electrified & Moderate & $10-50$ & 70 \\
4 & 1 line & non-electrified & Rare & $1-10$ & 50 \\
5 & Side lines & non-electrified & Occasional & $<1$ & 30 \\
\hline
\end{tabular}

Table 3.4. Disturbance zones from the roads (radius of a circle) (SanPiN, 2003); the number of motor cars per day are used to classify traffic intensity.

\begin{tabular}{llllll}
\hline $\begin{array}{l}\text { N } \\
\text { of lanes }\end{array}$ & Number & Class & Traffic Intensity & N cars.day & $\begin{array}{l}\text { Distance } \\
(\mathbf{m})\end{array}$ \\
\hline 1 & 4 & M roads & Very heavy & $>30,000$ & 200 \\
2 & 2 & P roads & Heavy & $15,000-30,000$ & 150 \\
3 & 2 & A roads & Heavy & $5,000-15,000$ & 100 \\
4 & 2 & Primary & Heavy & $1,000-5,000$ & 50 \\
5 & 2 & Secondary & Moderate & $500-1,000$ & 30 \\
6 & 2 & Tertiary & Moderate to rare & $100-500$ & 20 \\
7 & 1 & Unclassified & Rare & $10-100$ & 10 \\
8 & 1 & Service and & Occasional & $<10$ & 5 \\
& track & & & \\
\hline
\end{tabular}

In April and May 2014, we visited 64 stopover sites that had been identified as stopover sites on basis of the automatic classifier. We verified whether the site (a) was close to water, (b) was covered by open non-forested vegetation, and (c) if it was covered by grassy vegetation. We collected approximately 20 gram of green grass which was air dried. For 40 sites of these 
grass samples, chemical analyses were conducted at the laboratory of the Resource Ecology Group at Wageningen University where we measured N, P and $\mathrm{K}$ concentrations in these samples.

We conducted a sensitivity analysis, to gauge the effect of the selection of the parameter values of our assumptions, by calculating the resulting number of potential stopover sites as a function of (a) varying the minimum size of the water body from 20 ha up to 100 ha in steps of 20 ha each; (b) varying the width of the maximum buffer function between the roosting site and the maximal foraging site by decreasing it to $4 \mathrm{~km}$ instead of $5 \mathrm{~km}$ and by increasing it from $5 \mathrm{~km}$ to $10 \mathrm{~km}$ and to $15 \mathrm{~km}$; and (c) by doubling the disturbance distances from Table 3.3 and 3.4.

Finally, we confronted the outcome of our automatic classifier with 6207 recoveries (metal rings, neck collars and satellite tracks) for greater whitefronted geese and 470 Important Bird Areas (IBA's; BirdLife International, accessed on 26-01-2018) in European Russia. The dedicated reporting by hundreds of hunters who shot geese and returned metal rings with which geese had been fitted mainly in the Netherlands, (West) Germany and Belgium has provided some information about stopover sites in European Russia. This makes a recovery of a metal ring unique to an individual goose. In addition, geese have been fitted with coloured neck collars, and a small group of devoted observers have been reporting their sightings from European Russia over the last two decades or so. These neck collars could potentially yield multiple records. Both datasets (data courtesy B.S. Ebbinge) were acquired through www.geese.org (a joint initiative of Alterra, SOVON and NIOO). Each record had goose ID, geographical coordinates of ringing site and recovery sites, date and time of ringing, date and time of recovery. The GPS satellite tracks were sourced through a joint project of NIOO and Alterra (data courtesy B.S. Ebbinge) on monitoring the migration of greater white-fronted geese and bean geese in 2005 through 2010. Each record had goose ID, geographical coordinates of catching site and stopover site, date and time of a track, speed, course and altitude. We selected only those records that showed a ground speed zero and had their altitudes close to absolute altitudes. 


\section{Results}

Potential stopover sites. Number and spatial distribution.

The automated spatial model detected 1931 potential stopover sites across European Russia (Figure 3.2).

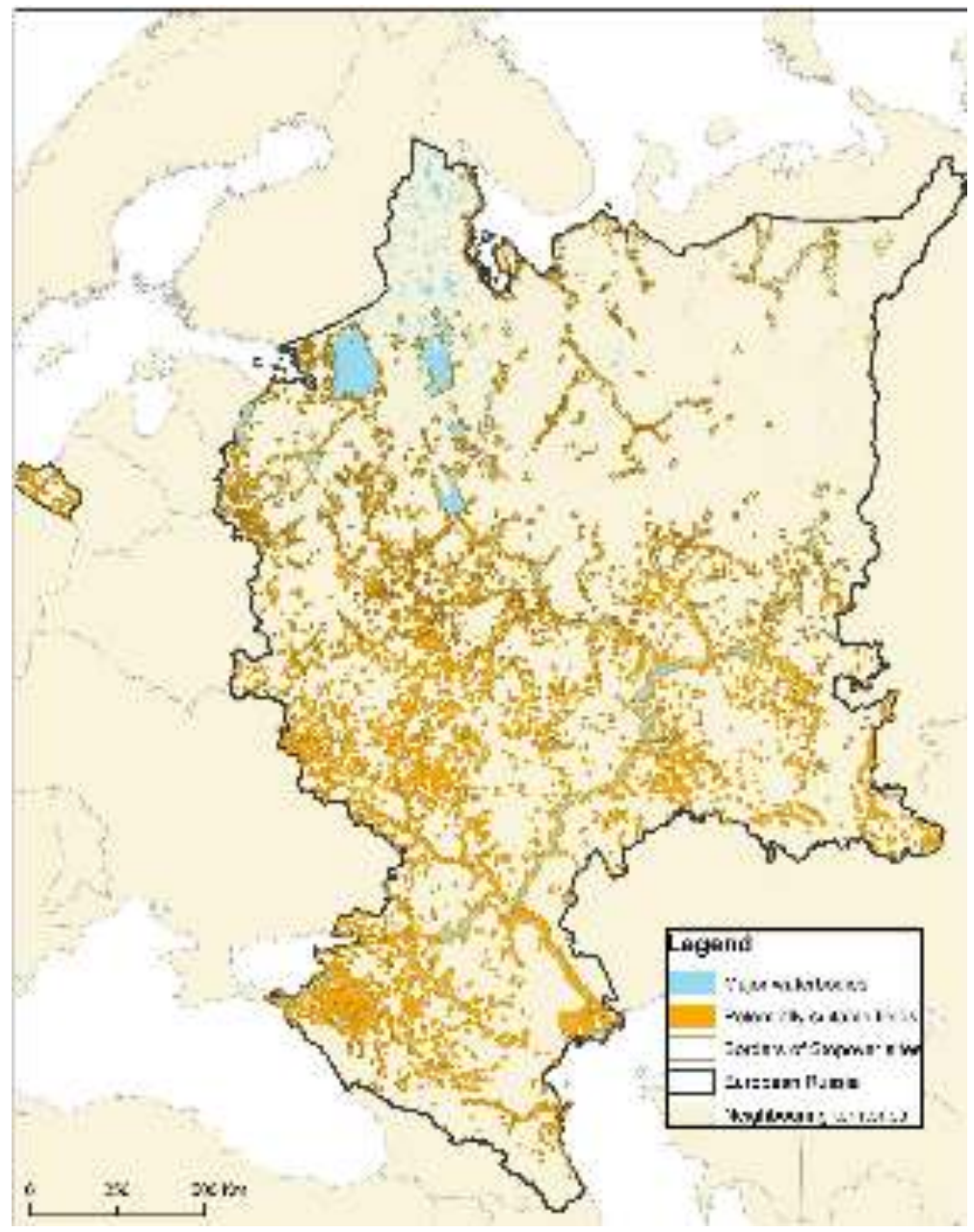

Figure 3.2. Map of potential stopover sites of greater white-fronted geese (Anser albifrons) in European Russia as model outcome.

These potential stopover sites were associated with over 26,500 waterbodies ranging in area size between 20 ha and $138,000 \mathrm{~km}^{2}$. These waterbodies were unequally distributed across the study area, concentrating in 
the north-west of Russia and in the Volga basin. The majority of waterbodies were represented by small lakes and ponds with sizes between 20 and 100 ha. The 200 largest waterbodies all had sizes above $100 \mathrm{~km}^{2}$ and included the large lake systems of the Russian Northwest (Ladoga and Onega lakes), and riverine systems of the Volga basin, the Northern Dvina basin and the Don basin (Figure 3.3). The later included a large number of water reservoirs artificially created in 1930s - 1970s (e.g., Rybinsk reservoir, Kuibyshev reservoir).

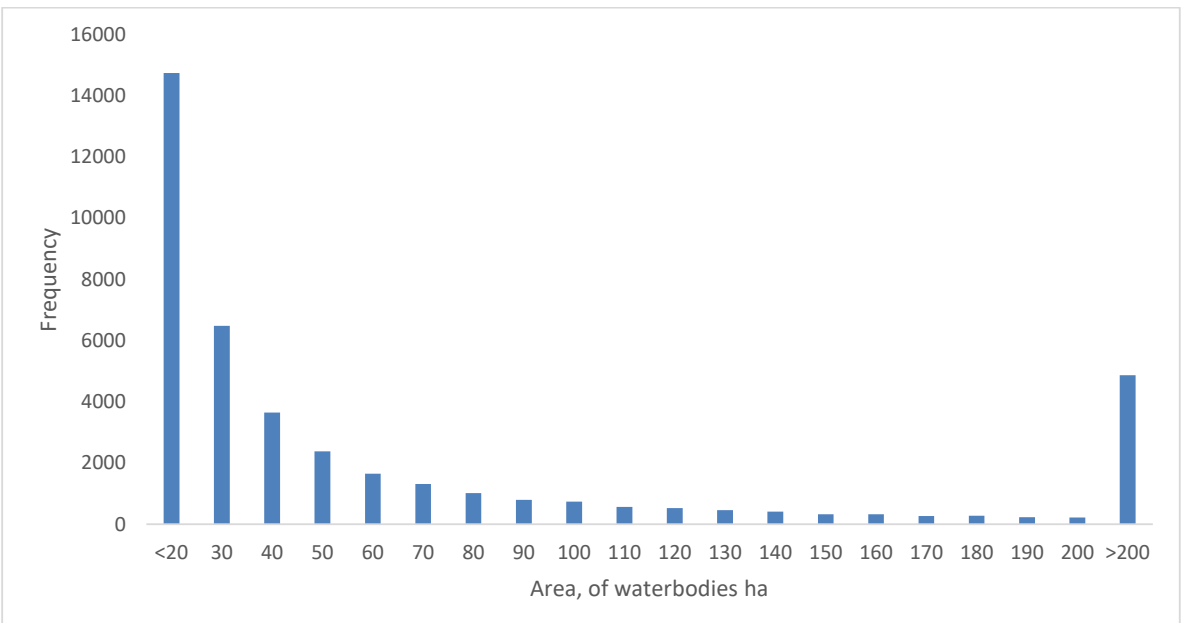

Figure 3.3. A histogram with size classes on the X-axis and frequency on the $Y$-axis conforming to a geometric distribution.

The landcover of foraging sites was integrated from four landcover classes of MODIS (Land Cover Type/Dynamics, MCD12Q1 reprocessed version 5). We discerned tundra (of no significance for our study because we concentrate on geese migrating in autumn and spring and do not focus on potential summer migration or moulting sites), taiga (which is coniferous forest and thus unsuitable for geese foraging in the study area), grasslands (both meadows and pastures; which are deemed suitable according our assumptions), cropland (also suitable), and finally semi-desert (unsuitable for migrating geese) (see Table 3.5). MODIS landcover classes 10 (grassland, 12 (cropland) and 14 (natural grassland) shaped the foraging suitability of potential stopover sites limiting their total number to 1931 . 
Table 3.5. MODIS image land cover classification (Land Cover Type/Dynamics, MCD12Q1 reprocessed version 5 ).

\begin{tabular}{|c|c|c|}
\hline Class name & $\begin{array}{l}\text { Initial class } \\
\text { code }\end{array}$ & Reclassification \\
\hline Savanna & 9 & 4 \\
\hline Grassland & 10 & 3 \\
\hline Cropland & 12 & 1 \\
\hline $\begin{array}{l}\text { Cropland/natural } \\
\text { vegetation mosaic }\end{array}$ & 14 & 2 \\
\hline
\end{tabular}

Goose sightings and IBA's.

To understand how the classified stopover sites correspond to real geese sightings we overlaid the potential stopover sites with available data on goose sightings (metal bands, neck-collar observations and satellite tracks combined) and IBA's. About $87 \%$ of geese sightings were recovered within $5 \mathrm{~km}$ distance from detected stopover sites (Figure 3.4) which is within a flying distance between a roosting and a foraging are at a stopover site. The $13 \%$ of sightings outside of detected stopover sites were located in the Don basin (cropland) and in the northern part of European Russia (natural grasslands). About $80 \%$ of IBA's were within the detected stopover sites (Figure 3.5) but only about $69 \%$ of detected stopover sites were in the vicinity of the IBA's. This finding suggests that about $31 \%$ of stopover sites in European Russia are outside of protected areas. These stopover sites are located in the northern (Komi, Arkhangelsk), south-eastern (Samara, Orenburg) and western parts (Kursk, Belgorod) of European Russia. 


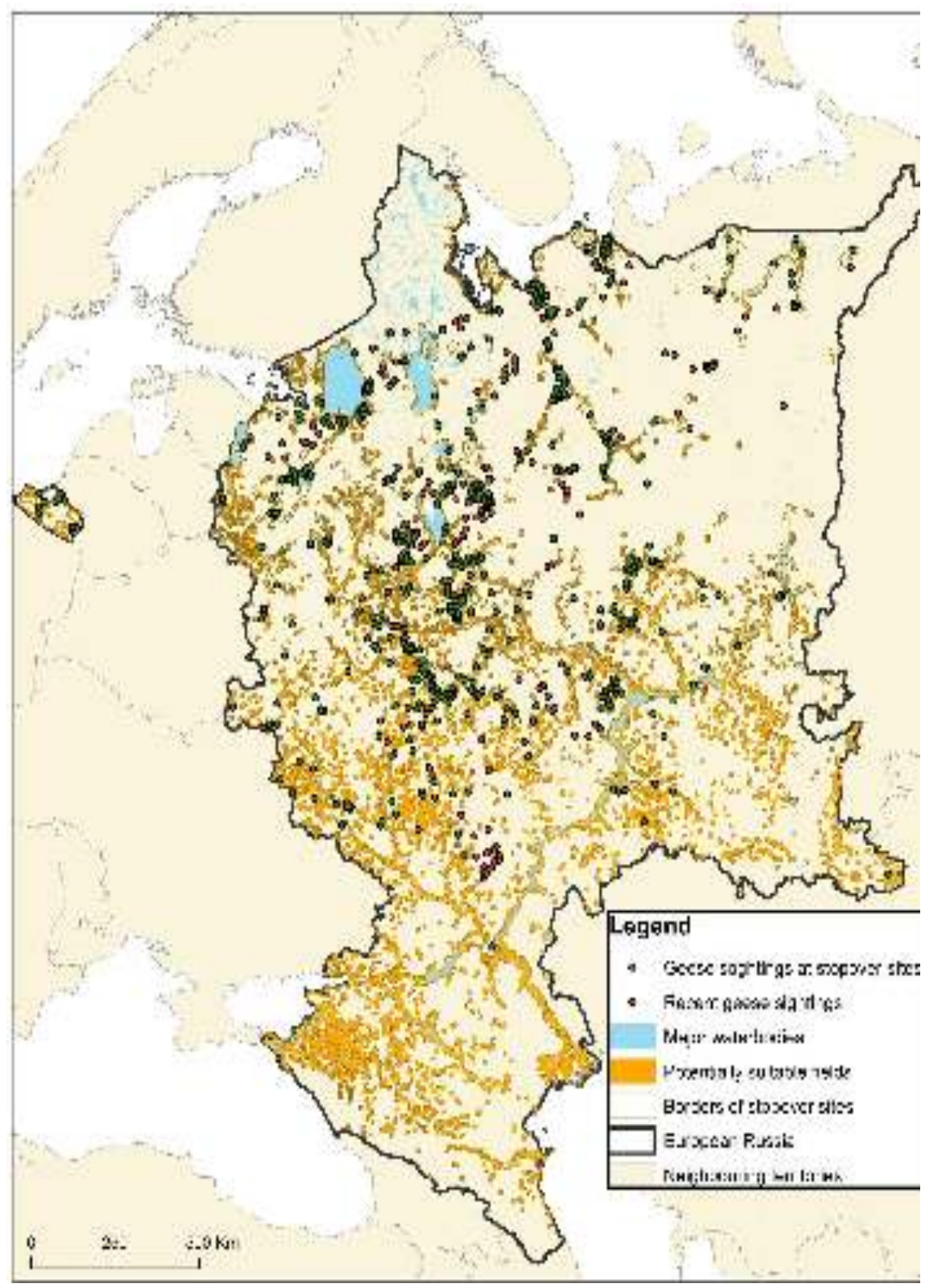

Figure 3.4. A map of modelled stopover sites and available recent geese sightings. These sightings include metal ring recoveries, observations and satellite tracking data collected between 2010 and 2014. 


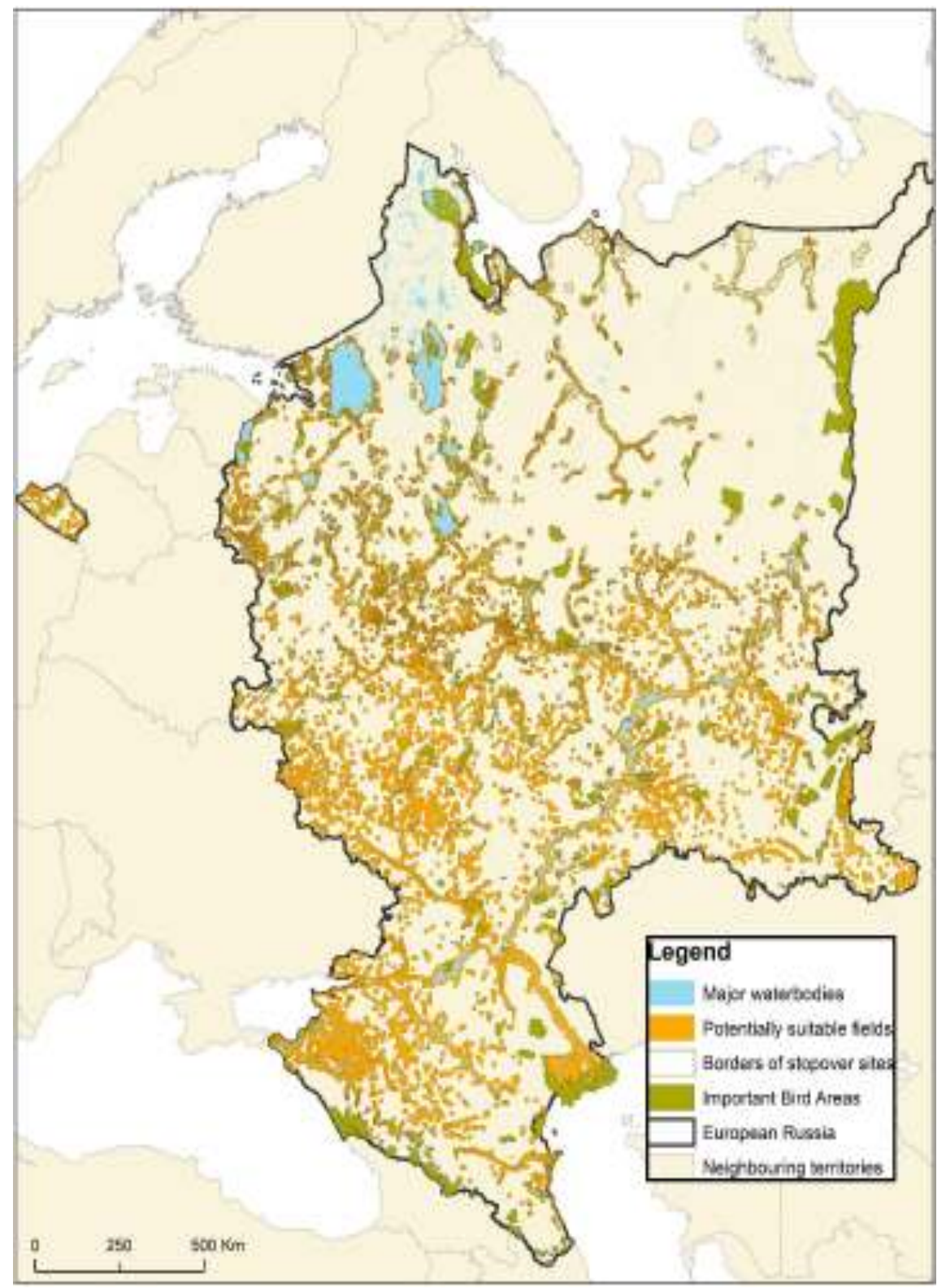

Figure 3.5. A map of identified stopover sites and IBA's in European Russia (BirdLife International). 
Validation and sensitivity analysis

To validate the accuracy of classification we randomly selected 150 points within 15 provinces with available agricultural statistics (see Chapter 2). Out of 150 randomly selected potential stopover sites, we were able to visit 64 sites in April and May of 2014 (Figure 3.6); many of the other sites we could not reach because thaw-up and snow melt made country roads impassable. With an overall accuracy of $89 \% 7$ of those sites were misclassified. Three of the misclassified sites were at the outskirt of villages, and four were old fields from which agriculture had disappeared between 2 and 5 years. The time of abandonment was based on vegetation composition estimate with the fields being dominated by grass species with $20-30 \%$ proportion of herbs and almost no shrub/tree encroachment. From collected 19 vegetation samples from visited stopover sites, only four showed a nitrogen content slightly below $4 \%$. This confirms our assumption about sufficient nutritional quality of grasses for geese in spring (Heuermann et al. 2011; Si et al. 2011). The visual examples (digital photographs) of visited stopover sites and their vegetation are given in the appendixes (Figure S3.7).

The sensitivity analysis was conducted by varying the default values for minimum sizes of waterbodies and respective distances to foraging fields (Table 3.6). The automatic classifier did not react to changing of the width of disturbance zones. Minimal variations were observed when changing distances gees fly from roosting to foraging sites. However the minimum size of waterbodies appeared to have large influence on the outcomes of the automatic classifier. This effect was especially pronounced when the minimum size was increased from 20 ha to 40 ha and 60 ha while the further increase led to moderate changes. With an increase of minimum size from 20 ha to 40 ha, the classifier wielded 1325 stopoversites versus 1931 . With an increase of minimum size to 60 ha the automatic classifier detected 1103 stopover sites. However, a further increase to 80 ha and 100 ha yielded 945 and 859 stopover sites respectively. 


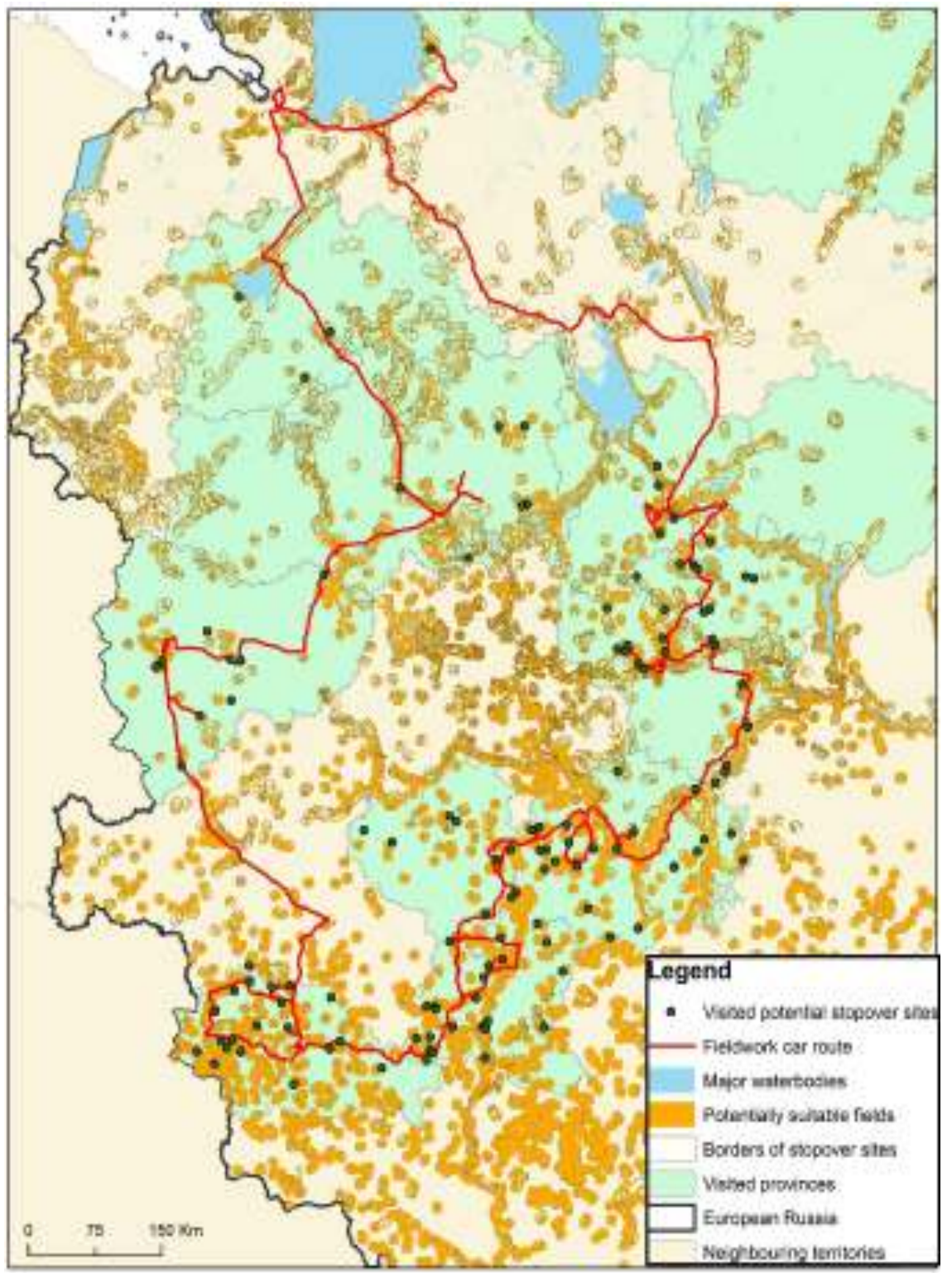

Figure 3.6. A map of potential stopover sites visited in Spring 2014 for validation of the automatic classifier developed prior to the fieldwork. 
Table 3.6. The effect of varying the default values in the model for waterbodies and disturbance.

\begin{tabular}{|c|c|c|c|c|c|}
\hline $\begin{array}{l}\text { Minimum size } \\
\text { of waterbodies }\end{array}$ & $\begin{array}{l}\text { Number } \\
\text { identified }\end{array}$ & $\begin{array}{l}\text { Distance } \\
\text { roosting to } \\
\text { foraging }\end{array}$ & $\begin{array}{l}\text { Number } \\
\text { identified }\end{array}$ & $\begin{array}{l}\text { Width of } \\
\text { disturbance } \\
\text { zone }\end{array}$ & $\begin{array}{l}\text { Number } \\
\text { identified }\end{array}$ \\
\hline & & $4 \mathrm{~km}$ & 1908 & & \\
\hline 20 ha (default) & 1931 & 5 km (default) & 1909 & Default see text & 1931 \\
\hline 40 ha & 1325 & $10 \mathrm{~km}$ & 1929 & Double default & 1931 \\
\hline 60 ha & 1103 & 15 km & 1931 & & \\
\hline 80 ha & 945 & & & & \\
\hline 100 ha & 859 & & & & \\
\hline
\end{tabular}

\section{Discussion}

In this Chapter we developed a spatial method to estimate the number and spatial distribution of potential stopover sites for migrating greater whitefronted geese across European Russia. A stopover site was defined as a waterbody larger than 20 ha with associated fields larger than $500 \times 500 \mathrm{~m}$ located within a flying distance of $5 \mathrm{~km}$. A total of 1931 such sites were located within European Russia. As expected, most are located along major riverine systems and lakes. Of the combined 6207 goose sightings collected through satellite tracking, metal rings and field observations, $87 \%$ fell within the generated stopover sites, though these collectively comprise less than $4 \%$ of the total area of European Russia. About $69 \%$ of IBAs fell within modelled stopover site network, but $31 \%$ of the stopover sites did not match an IBA. These findings indicate that the automatic classification gives an overall correct result for location of stopover sites for migrating geese in European Russia.

The 1931 potential stopover sites are unequally distributed across the study area, with a density gradient from northwest Russia (with a high density) to southeast (with a low density). Stopover sites are often located around small to medium-sized lakes or floodplains surrounded by fields with small-scale agricultural activities (Ioffe and Nefedova 1997). Because most potential stopover sites are detected within $5 \mathrm{~km}$ from over 25,000 waterbodies, their overall spatial distribution will correlate with areas with higher density of waterbodies. These areas are located in the Russian North and along the large riverine systems (e.g., the Volga, the Don). These large waterbodies along with 
groups of smaller one had shaped the network of stopover sites used by migrating geese. The systems of lakes in the Russian North were formed after the last Ice Age ended about 12,000 years ago. High number and density of stopover sites are typical for boreal landscapes of moraine origin that have been exposed to intensive human activities, particularly agriculture in the last two thousand-odd years. These heterogeneous landscapes in the North consisting of mixed forests, waterbodies, pastures and cropland were heavily transformed in the past 200 years with greater progress in melioration and technology. In contrast, low numbers and density of 12 stopover sites $/ 200 \mathrm{~km}^{2}$ are typical for homogenous steppe landscapes of elevated planes that have been used for extensive grazing and grain production. These stopover sites appear not be natural because they are usually found around big water reservoirs created in 1930 - 1970s and small ponds constructed for both irrigation and fishery. Agriculture is represented by large scale grain production mixed with small scale sheep herding (Ioffe and Nefedova 1997).

We analysed potential stopover sites with a pre-defined set of spatial rules. These rules were mainly based on the evaluation of foraging and roosting attractiveness of selected locations in the vicinity of waterbodies. We did not however include other listed factors that might potentially affect the migration behaviour of geese (Shariati et al. 2017). These factors are commonly based on hunting pressure (Ebbinge 1991; Prop 1994), current conservation regime and predation (Jonker et al. 2010). Hunting is the major disturbance for migrating geese (Ebbinge 1989) because hunting is widespread across the study area. The only viable measurement of hunting is reported metal ring recoveries of geese that were tagged in Western Europe and shot dead in European Russia. The overlay of detected stopover sites with metal ring recoveries and additional recoveries from satellite tracking and field observations showed an $87 \%$ match. Only $13 \%$ of total recoveries were collected further than $5 \mathrm{~km}$ from the detected stopover sites. The location of these recoveries (Russian North) suggest that the geese could have been hunted elsewhere but reported from a settlement where hunter lives. Another source of underreporting might come from inability of hunters/observers to deduce the exact coordinates of location which results in erroneous recording in ring database. 
If migrating geese experience high hunting pressure, which is suggested by Ebbinge (1991), this should drive them towards protected areas. In case of birds, IBA's of BirdLife International are a universal measure of protected areas. Indeed, about $80 \%$ of IBA's in European Russia overlap with detected stopover sites suggesting that migrating geese make use of these areas. However, IBA's cover only $69 \%$ of detected stopover sites while the remaining $31 \%$ are located outside the protected areas. Thus, IBA's alone do not define spatial distribution of stopover sites in European Russia. Therefore, to avoid potential underestimation of suitable stopover site, its detection could not be based only on hunting pressure and inclusion of protected areas.

Predation is another widely discussed impact factor that shapes goose migration. It was shown that migration of geese can overlap with migration of big raptors which cause the distress and force birds to change their migratory behaviour (Jonker et al. 2010). We did not include this factor in our analysis because no consistent data of raptors numbers are available for the study area. Moreover, we believe that the impact of predation pressure varies considerably across the study area. Perhaps, it plays a major role at the Baltic Sea shore and along the large rivers such as the Volga and the Ob where high numbers of white-tailed eagles (Haliaeetus albicilla) occur (pers. obs.), while it might have a lower influence impact in inland Russia.

Using landcover data from MODIS restricted the number of landcover classes we could use for foraging suitability assessment in the automatic classifier. Only grasslands and croplands were classified as suitable landcover classes while no further distinction in quality of foraging could be made. This could be acceptable to study ecology of staging sites for migrating geese on a large-scale because MODIS offers better temporal resolution and requires less computations compared to Landsat TM. However, Landsat TM products would be more applicable, if better distinction between landcover classes is needed when assessing foraging quality at a finer scale. MODIS has a better temporal resolution than Landsat TM This should include grass height/biomass, crop rotation, and field wetness. Although the minimum field size of the MODIS landcover products output $(500 \times 500 \mathrm{~m})$ is quite large, is should not have affected the results of the automatic classification because smaller fields in the 
boreal zone are usually surrounded by forest which makes them unsuitable for geese.

The automatic classifier showed high sensitivity to waterbody area size while it did not react on varying other parameters. This observation was expected as the basis for a stopover site definition is a roosting site, i.e., a waterbody. Since the majority of waterbodies in European Russia are between 20 ha and 60 ha in size, they affect the number of detected stopover sites. The overall accuracy of classification was $89 \%$ based on the ground through collected from the randomly selected point. This high accuracy rate was affected by rather broad classification rules applied and a large scale of the study area. Of the $11 \%$ misclassified points, three belonged to settlements and four to old fields. While preparing the dataset for the automatic classifier, some settlements turned out not to be digitised properly. To include these settlements in the analysis, a circular buffer of a standard size was build depending on the location of settlement. However, this simplification omitted real shapes of those settlements which caused some of their outskirts to be included in stopover site habitat. Thus, the final classification was done with increased radius of centroid for settlements. Four points misclassified as old fields were abandoned in recent 3-5 years. This time of abandonment is somewhat a grey zone (pers. obs.) because recently abandoned fields can still be used by migrating geese. Moreover, these fields can be returned to agricultural use even after being abandoned for 3-5 years. To account for this type of misclassification it might be possible to consider recently abandoned fields suitable for geese and deduce them into a separate landcover class.

We conclude that most stopover sites in the North of Russia are on manmade grasslands in an area that naturally would have been covered by forest close to natural lakes, while in the Centre of Russia the stopover sites are on grasslands in areas that would have been naturally covered either by steppe or by broad-leaved forest close to man-made waterbodies. Because these grasslands easily disappear with changes in agricultural practices (as witnessed during the fast economic changes after the dissolution of the USSR), geese numbers may be sensitive to network collapse if a sufficient high number of stopover stop being attractive to staging geese. 
Appendix to Chapter 3
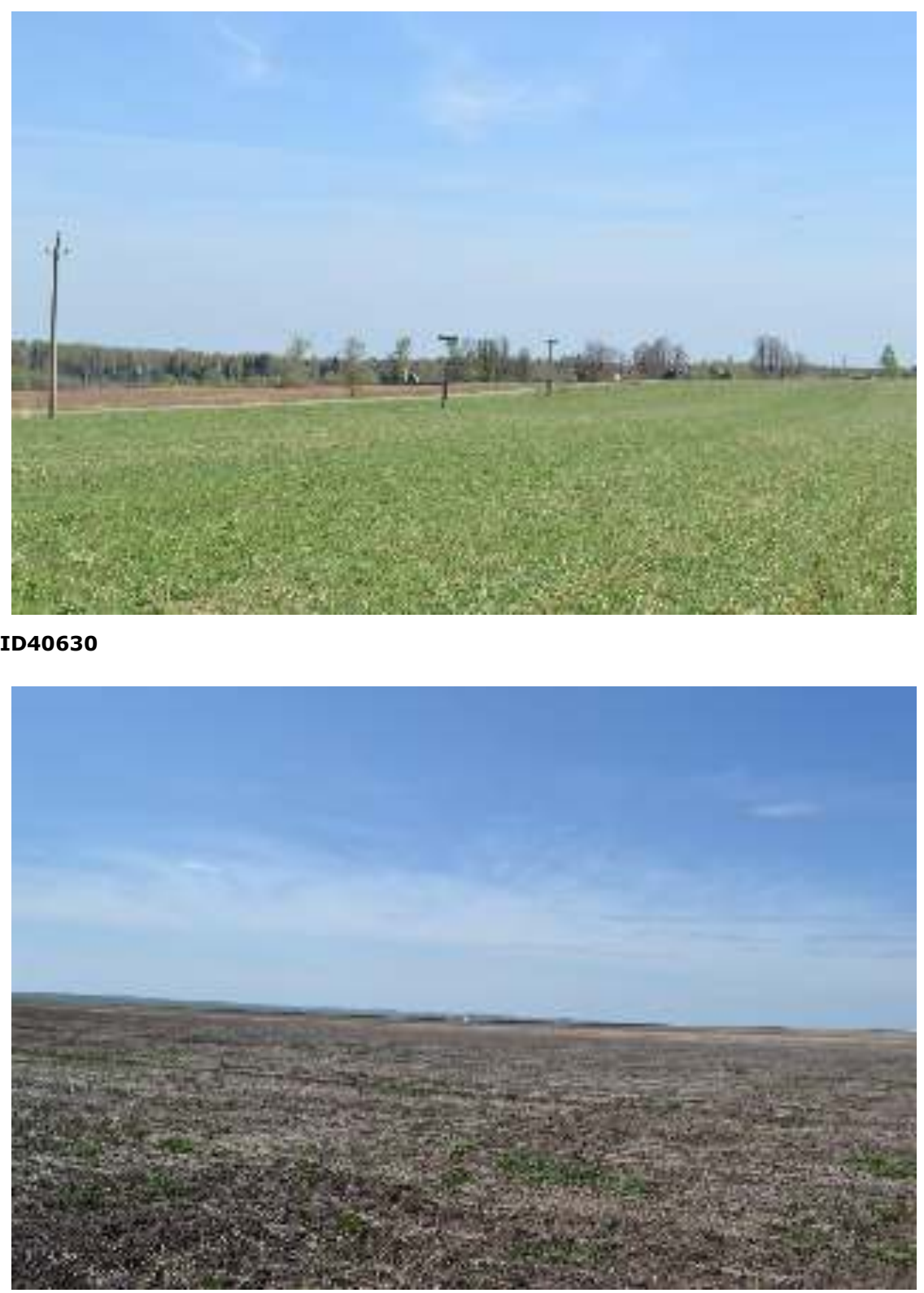

CID52335 


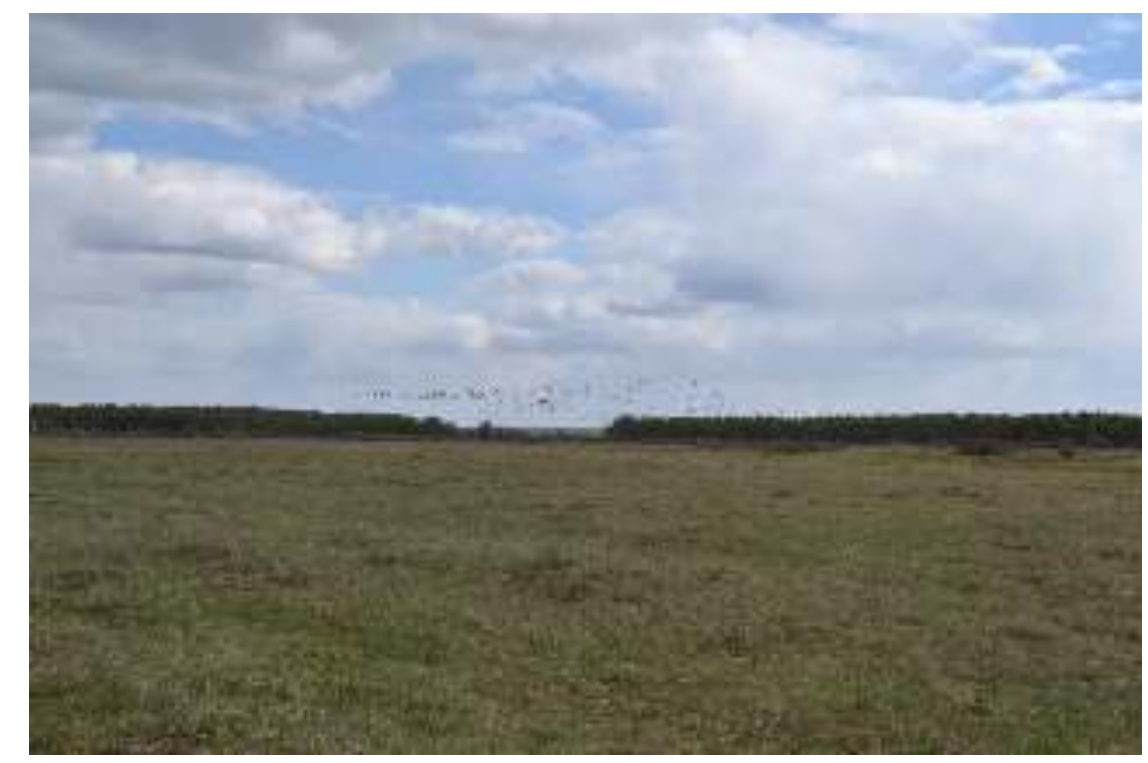

CID54783

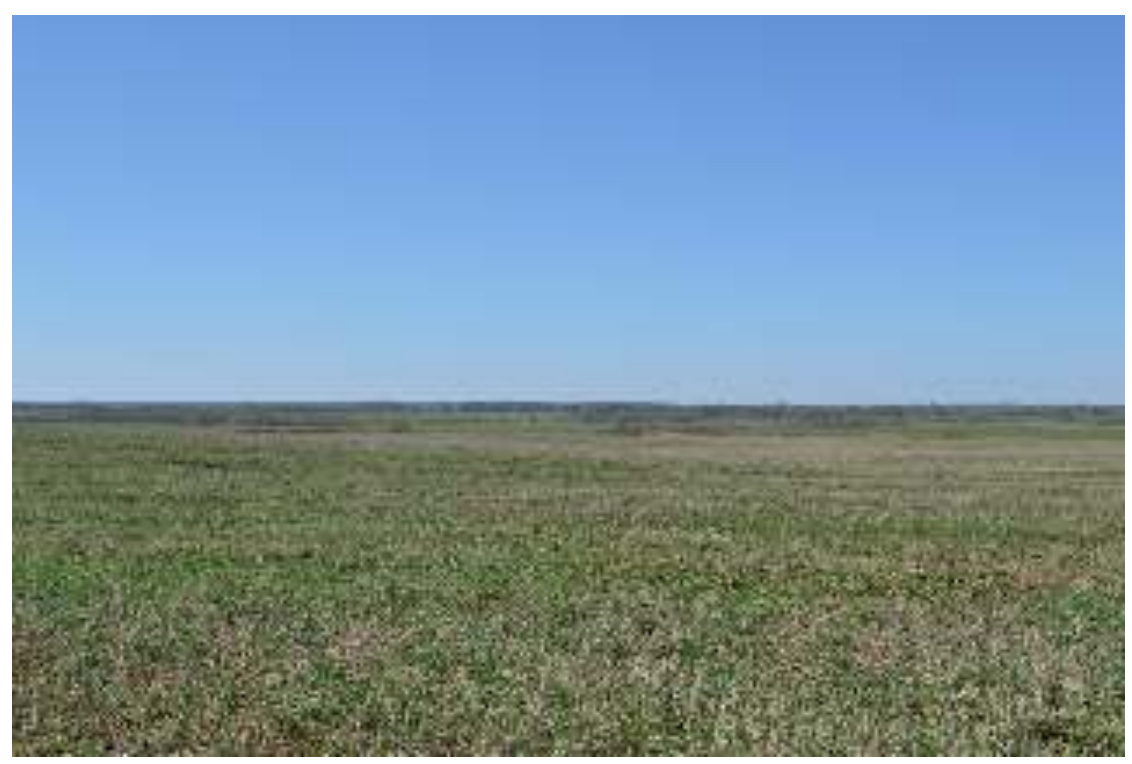

CID58863 


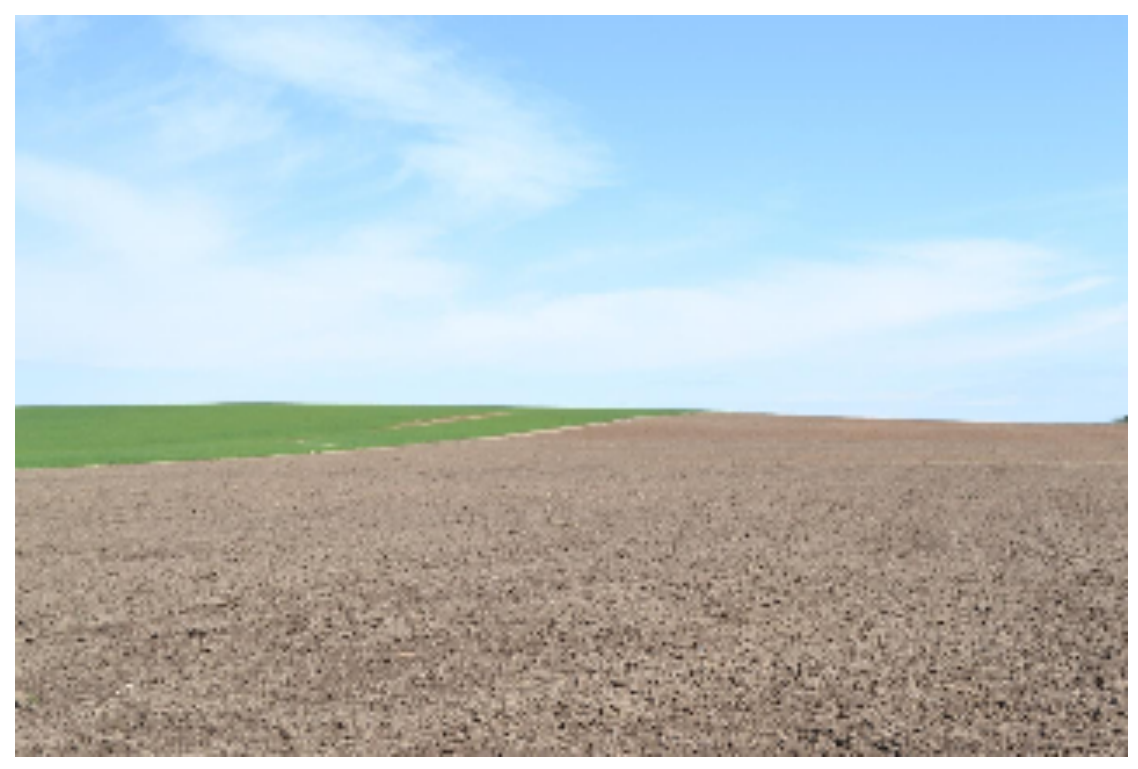

CID59592

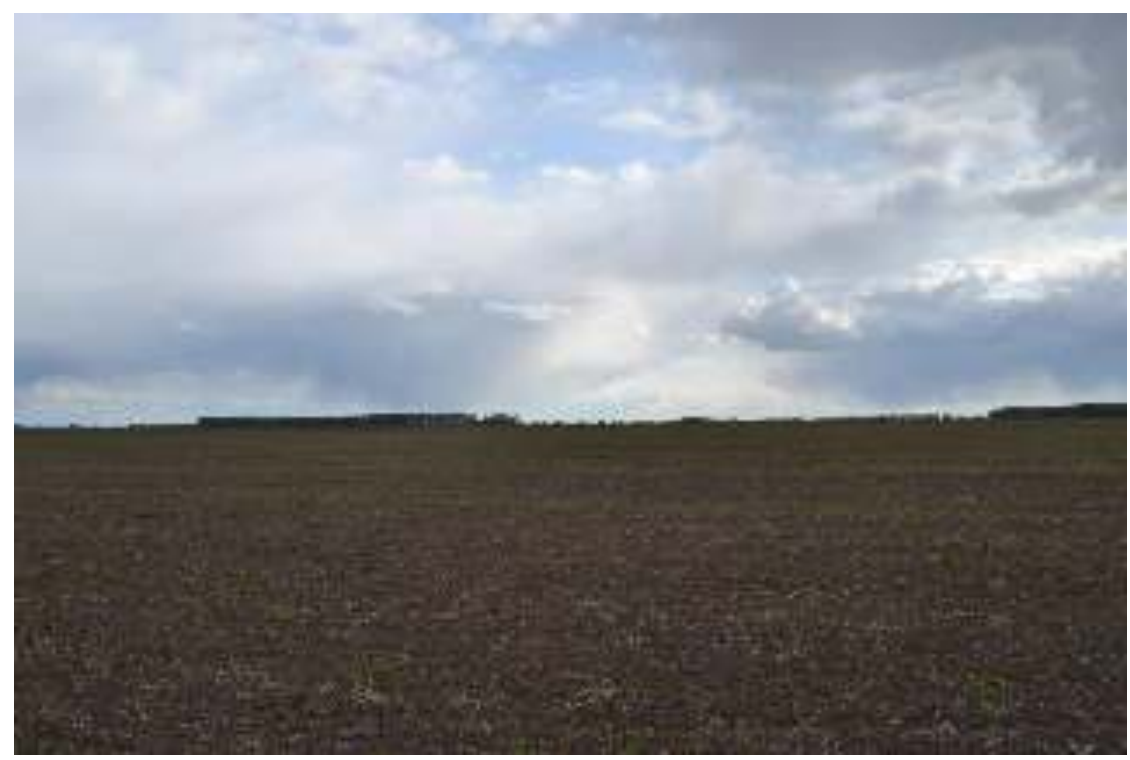

CID72218 


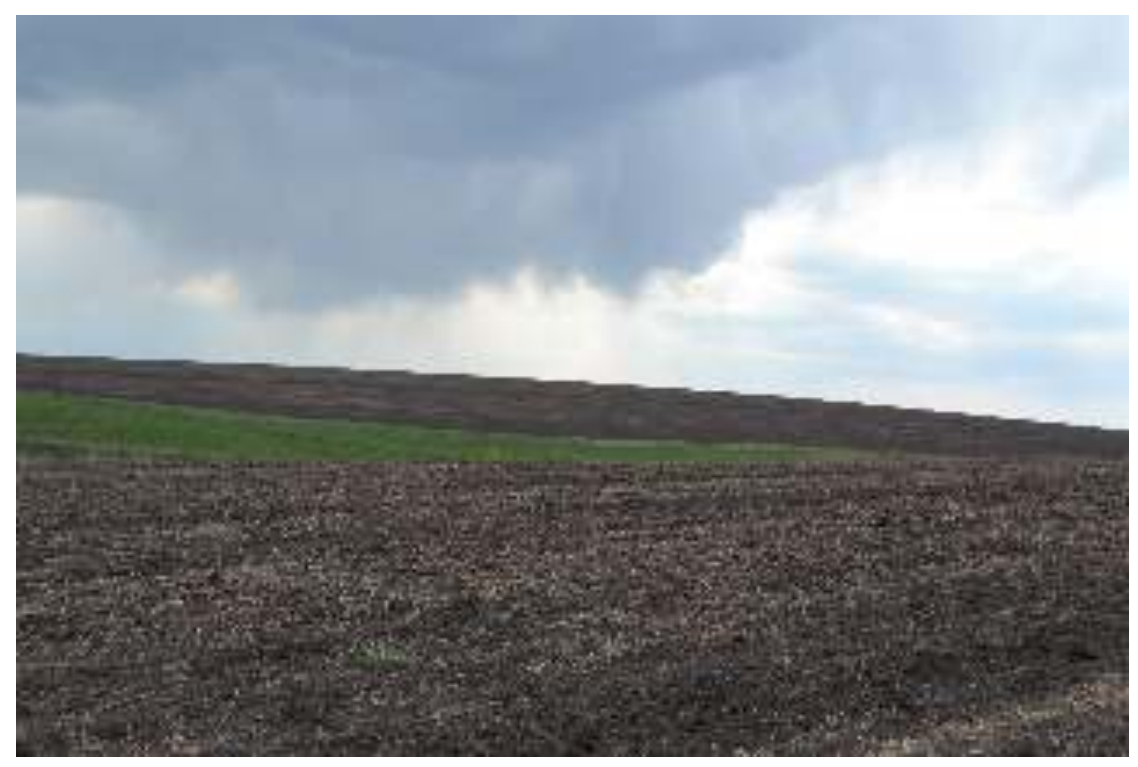

CID102693

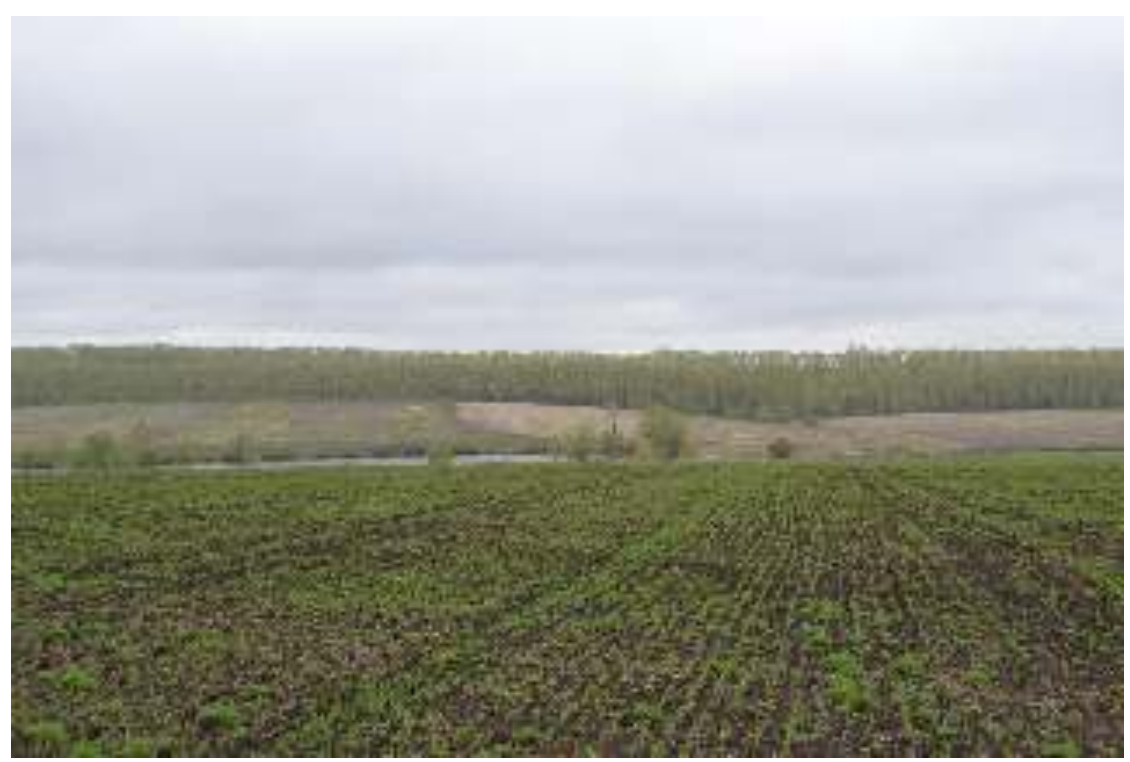

CID111261 


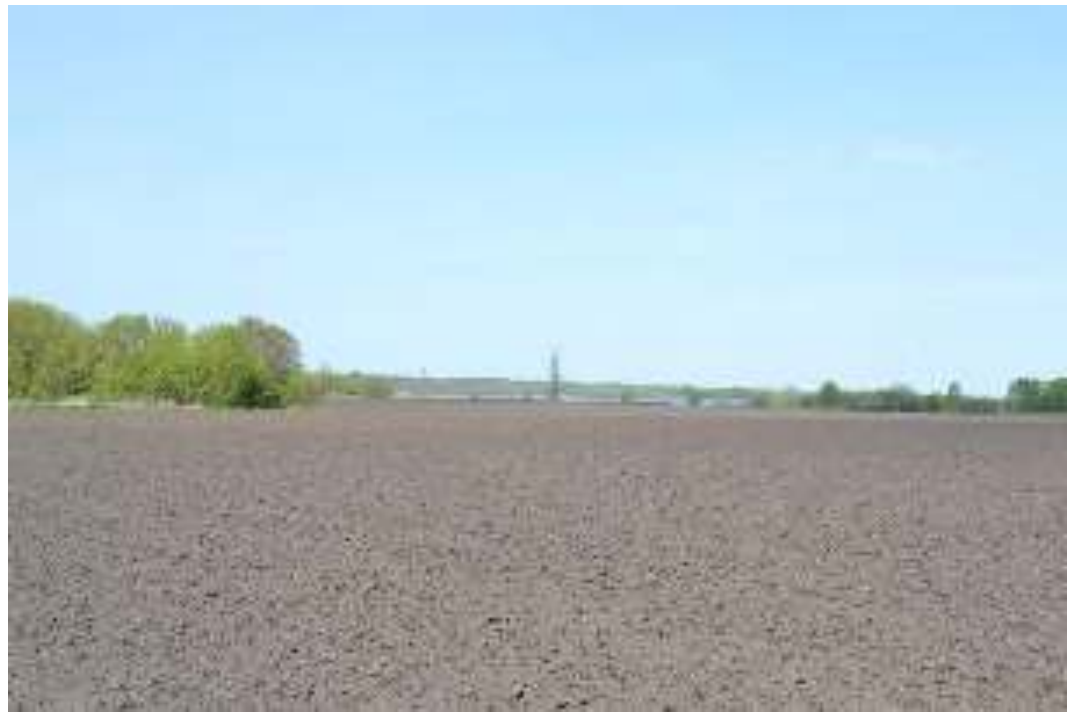

CID127493

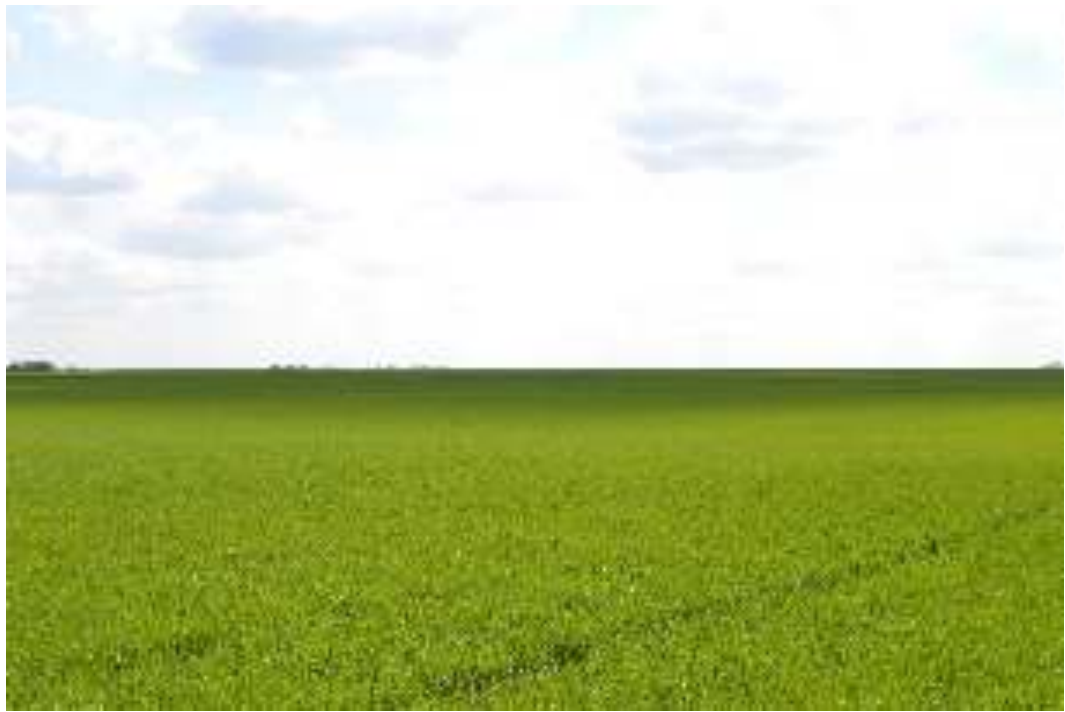

CID127749

Figure S3.7. Pictures from 10 visited stopover sites. 


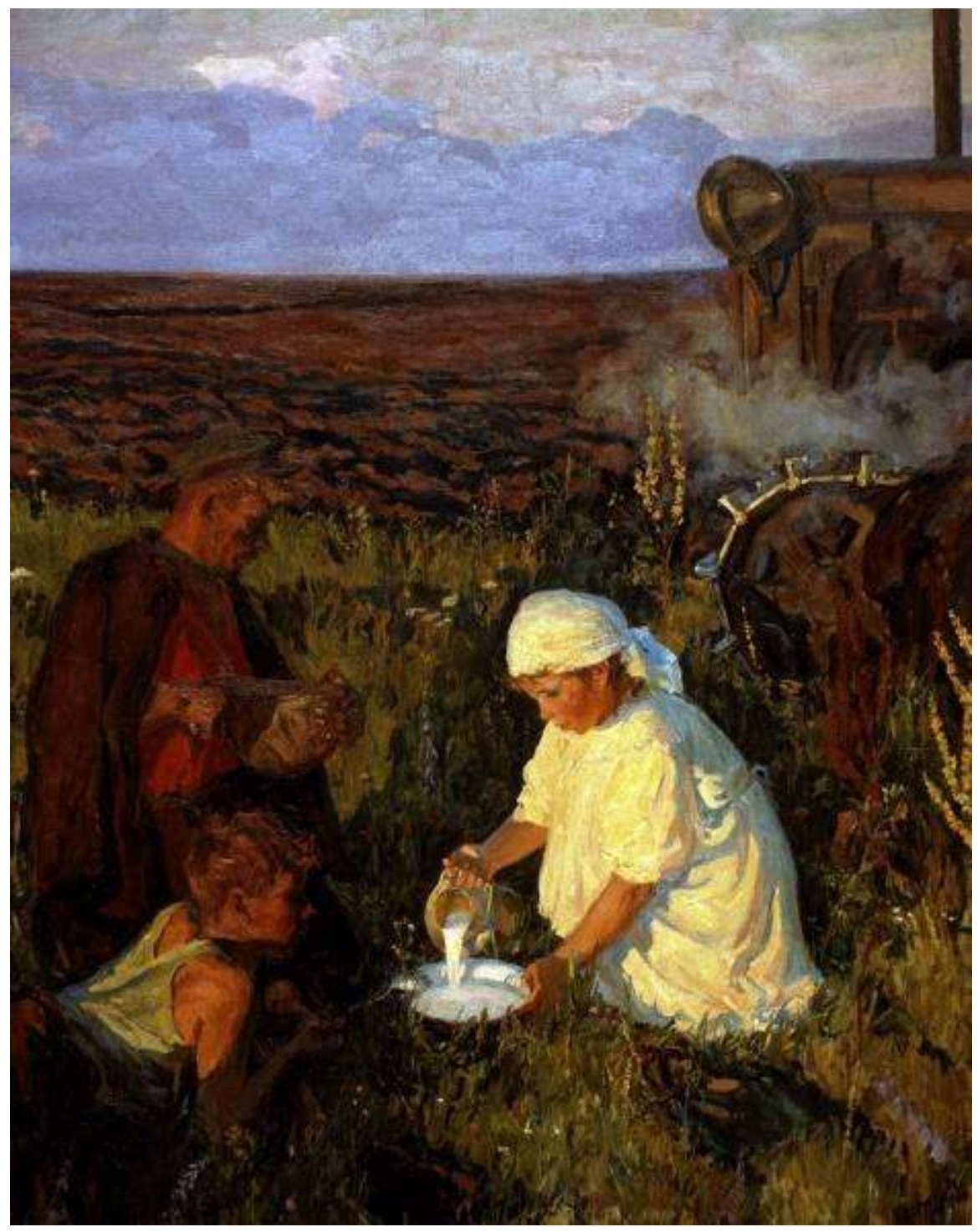

A. Plastov Tractor Drivers' supper (1961) / А. Пластов "Ужин трактористов". 


\title{
Chapter 4
}

\section{Changes in landcover at stopover sites confirm decline of agriculture in European Russia}

Mikhail Grishchenko, Herbert H.T. Prins, Ronald C. Ydenberg, Michael E. Schaepman, Henrik J. de Knegt

\begin{abstract}
After describing patterns of changes in landscape and modelling stopover sites in European Russia for migrating greater white-fronted geese, in this Chapter we study how those landuse changes and land abandonment transform stopover sites. We also provide a scale and illustrations to evaluate different stages of old-field development at stopover sites previously used by migrating geese. We use nine cloud-free Landsat scenes for 1990, 2002 and 2014 to analyse landcover changes in across the study area with majority of detected stopover sites where agricultural statistics were also available. In 1990 - 2014 number of arable pixels declines by $56 \%$, number of grassland pixels increased by $14 \%$ and number of forest pixels increased by $5 \%$. Similar changes occurred at stopover sites but increase of forest pixels was around $12 \%$. To verify performed classification we conducted a fieldwork visiting 84 ground truthing locations in June 2014. Our observations indicated that widespread reforestation is under way on abandoned agricultural fields used for grain production 10 to 20 years ago. Detected changes in arable, grass and forest landcover classes confirm vegetation succession recorded during fieldwork. These alterations in landscapes around stopover sites in European Russia used by migrating greater white-fronted geese, may affect their migration ecology in a near future.
\end{abstract}

Key words: agriculture, greater white-fronted goose, landcover changes, oldfield development, Russia, stopover site 


\section{Introduction}

The East Atlantic Flyway is used by many bird species for their annual migrations, including the greater white-fronted goose Anser albifrons, which at $\sim 1.3$ million individuals (Fox et al. 2010) is the most numerous Eurasian goose species. This species makes an annual return migration between breeding areas in the Russian Arctic and seaboards of the North Sea where it overwinters (Koffijberg \& van Winden 2014). There, like some other species (e.g., barnacle goose Branta leucopsis), it has changed from a species to be protected into a species that increasingly causes agricultural damage (Ankney 1996; Jefferies et al. 2004b). In this respect these species resemble snow goose Anser caerulescens, which in Canada and especially the United States has become a superabundant species that causes conflict with farmers (Owen \& Black 1991, Abraham et al. 2005), and may locally even damage the tundra of their breeding grounds (Kerbes et al. 1990; Gauthier et al. 2004).

In North America, snow geese benefit from the creation of vast grassland areas and rich agricultural spillage all along their flyway from Texas towards the Canadian boreal zone (Abraham et al. 2005) which contributed to the great growth in population numbers. They also receive ample protection, with a wellregulated hunt, (Jefferies et al. 2004a; Calvert et al. 2005) in contrast to that of the greater white-fronted geese in Eurasia where even spring hunt in Russia is still legal (Kokko et al. 1998; Rozenfeld \& Sheremetyev 2016). In European Russia, however, farming declined steeply after the former USSR was faced with that sweeping political upheavals that led to its dissolution in 1991 (Wegren 1995; Grishchenko \& Prins 2016). Farming over vast areas of northern Russia became unprofitable and was not maintained (Ioffe \& Nefedova 2004, Chapter 2), collective farms were privatised and broken up (Lerman 1998), and villagers left the small hamlets and concentrated in big cities (Ioffe 1991; Chapter 2). Across the Russian part of the East Atlantic Flyway, these land use changes are creating a landscape very different from that of 30 years ago, that may pose new challenges for migratory birds. The greater white-fronted goose population soon may face population limitation not on its winter grounds (Mooij 1997; Koffijberg \& van Winden 2014), or on its summer grounds (Kölzsch et al. 2016), but on its migration routes. 
Greater and lesser-white fronted geese $A$. erythropus, bean geese Anser fabalis, and red-breasted geese $B$. ruficollis all use specific places in the landscape for stopover and staging, where they rest and replenish fat reserves (Madsen 1999; Arzel et al. 2006). Such places are located near open water where they can safely roost, and lie within $\sim 5 \mathrm{~km}$ of arable land, pastures or meadows where they can forage (Kleijn et al. 2012; Baveco et al. 2013; Chudzińska 2015). The foraging sites are not directly surrounded by forest and should measure at least $500 \times 500 \mathrm{~m}$ (Baveco et al. 2013; pers. obs.). Note that to facilitate mechanized agriculture, the minimum size of collective farm fields prior to the USSR's collapse was greater than $500 \times 500 \mathrm{~m}$ (Kuemmerle et al. 2009; Stefanski et al. 2014).

Elsewhere we reported on land abandonment and the resultant patterns of land use change over the European part of Russia (Grishchenko \& Prins 2016; Chapter 2). This analysis was based on land use and population statistics gathered by municipal districts in Russia. These data confirm that the human population of municipal districts of European Russia has declined over the past six decades, accompanied by an even stronger decline in agricultural activities over the recent 25 years. These declines were largest in northern portions of European Russia, and smallest near big cities and in southern regions (Prishchepov et al. 2013; Chapter 2). This large-scale cessation of agriculture has led in turn to a massive expansion of forest, as abandoned fields were encroached upon initially by shrubs but in about two decades by trees, which leads to increase of disturbed landscapes, and thus affecting biodiversity (Grishschenko \& Prins 2016; Queiroz et al. 2014, Poschold et al. 2005).

In this chapter we ask whether these large-scale and profound alterations of the landscape in European Russia encompass to stopover sites, 1900 of which were identified in Chapter 3. We report in finer detail the changes when agriculture comes to a stop at locations previously used by migrating geese. Our expectations are that in European Russia, landcover changes 1990 - 2014 will reveal: (1) more pixels classified as forest; (2) more pixels classified as grass and (3) fewer pixels classified as arable. We attempt to define stages of land abandonment from our field observations. 


\section{Materials and Method}

We assessed landcover on three Landsat scenes (see below) in 1990, 2002 and 2014. The selected images selected lie along the migration route of greater white-fronted geese in northern European Russia, as substantiated by many recoveries of metal leg rings, colour rings and other tracking devices (Chapter 5 ). Each image contained known stopover sites that had been used at least sometimes in the recent past (Chapter 3). Each image also had complete municipally-collected agricultural statistics for the period 1990 - 2014 (Chapter 2) for comparison with our analyses on landcover.

We selected cloud-free Landsat images from dates during goose spring migration (May) in central and northern parts of European Russia. The imagery was centred on Novgorod Province, Tver Province and Yaroslavl Province (Figure 4.1). We recognised six land cover classes visually (urban, water, arable, grass, peat bog and forest) to establish a training set (Figure 4.2). The Landsat scenes were processed in Google Earth Engine (last accessed 05-01-2018) for supervised classification to compare the geo-referenced pixels over time, thus enabling us to assess the transition between land cover types (e.g., from meadow to shrub land) at a very fine scale (Landsat TM $30 \mathrm{~m}$ resolution). The reference years were selected based on data availability, quality, minimum required geometric corrections, and proximity to our field visits (2014; see below). The year 1990 preceded the break-up of the USSR (1991) but with low data quality and limited availability for that year, we used Landsat 5. To simplify the analysis and avoid additional correction for SLC-off, we used Landsat 7 scenes from 2002. We used Landsat 8 scenes to match landcover to our 2014 field observations. Due to a large overlap between the Landsat scenes for Yaroslavl and Tver, we merged them for reporting purposes.

For classification training, we selected 20 training sites for each land cover class from a 2014 Landsat 8 scene. We ran supervised classification with the 'Random Forests classification algorithm' (Pal 2005, Rodriguez-Galiano et al. 2012). The same heuristics was used for Landsat 7 and Landsat 5, from which we inferred land cover maps for 2002 and 1990, respectively. The classified raster scenes were exported in GeoTIFF format with a standardized pixel size of $30 \times 30 \mathrm{~m}$ (Pixel size differs between Landsat 5, 7 and 8). The nine rasters were 
imported to ArcMap (ESRI ArcGIS 10.5), reclassified to the six established classes, and clipped to the respective spatial extents of the three scenes (Novgorod, Tver and Yaroslavl).

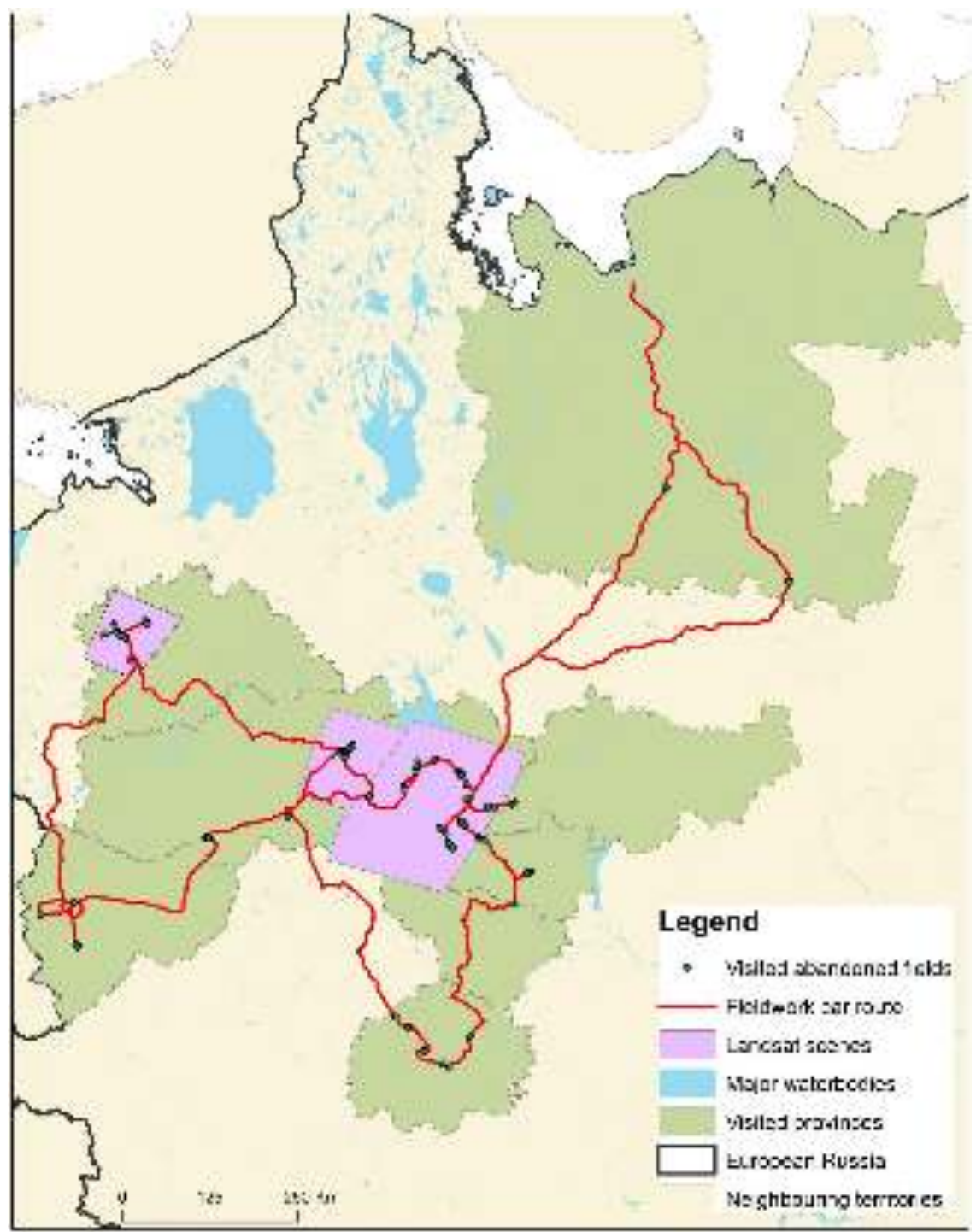

Figure 4.1. A map of the study area featuring the selected Landsat scenes in European Russia, the stopover sites visited for ground truthing, and the entire travel route in June 2014. 


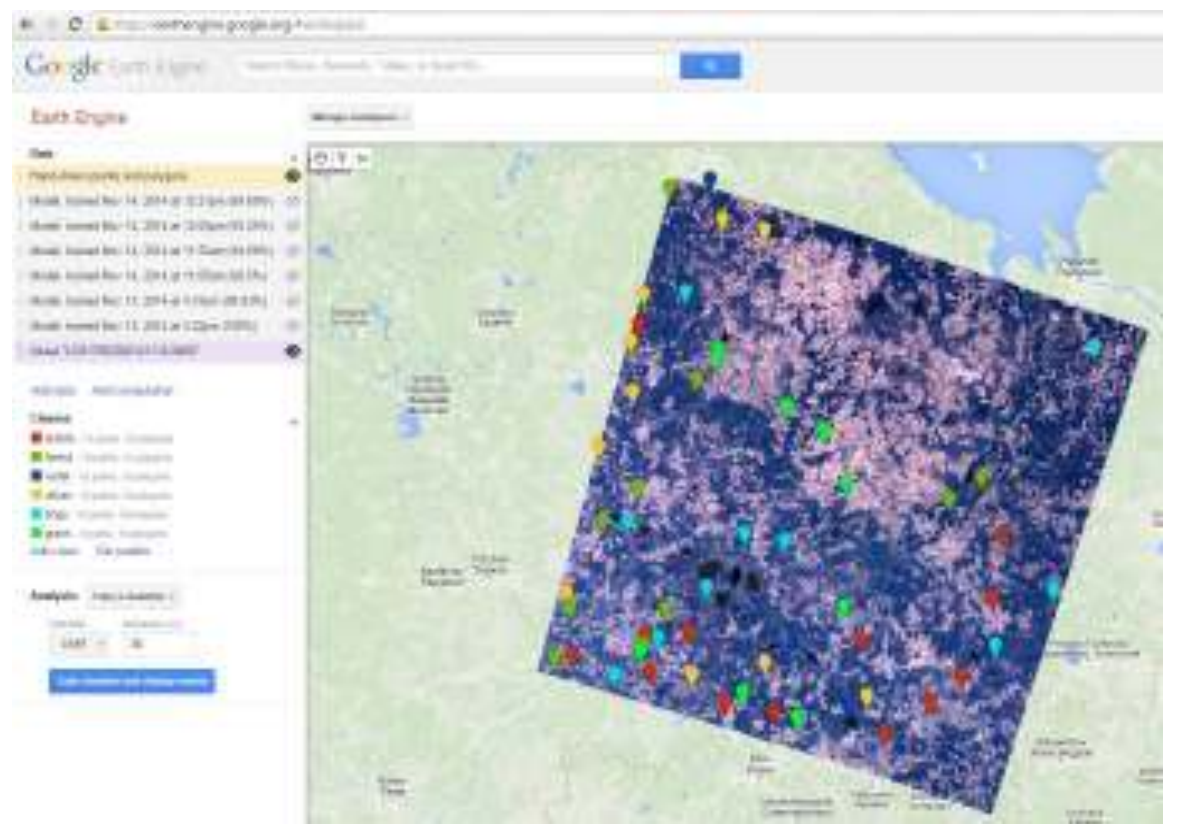

Figure 4.2. An example of the training set used to perform a supervised classification of the selected Landsat 8 scene in Tver Province.

Ground truthing was accomplished on a $7500 \mathrm{~km}$ trip by automobile (Figure 4.1) in June 2014, during which we collected field data to verify the supervised classification of land cover class (LCC) changes. We randomly selected 150 stopover sites in advance (see Chapter 3), restricting the selection to those lying within $5 \mathrm{~km}$ of the nearest road. We classified each site as 'recently used by geese' or 'not used in the previous decade', based on ring recoveries, neck collar sightings, and satellite tracks. We were able to visit 84 of these sites. At each site we took 360 degree digital photographs to assess vegetation composition and cover, and estimated the year of field abandonment based on vegetation composition, presence of formerly cultivated crop species and visual assessment of soil.

We constructed pixel-by-pixel 'difference maps', in which a comparison was made of LCC transitions between 1990 and 2014. The rasters were reclassified into 'arable only' and 'grass only' rasters for the year 1990, and subtracted from Landsat scenes for 2002 and 2014. 
The rate of change for each of the six land cover classes over three periods $(1990$ - 2002; $2002-2014 ; 1990-2014)$ was calculated as

$$
\underline{\operatorname{Ln} N_{t+n}-\operatorname{Ln} N_{t}}
$$

$n$

where $\mathrm{Ln} \mathrm{N}_{\mathrm{t}}$ is the natural log of the number of pixels in each land cover class in year $t$, and $L n N_{t+n}$ is the natural log of digital number in year $t+n$ (i.e., $n$ years later). We compared these growth rates with those previously calculated based on municipal statistics (Chapter 2), in which we estimated the area under cultivation, the area growing cereals, and the numbers of cattle. The statistical analysis was performed in R (v. 3.2.2, R Core Team 2016) and all spatial analyses and data visualisation were done in ArcMap (ESRI, ArcGIS v. 10.5).

\section{Results}

The LCC analysis is summarized in Table 4.1, showing the area (number of pixels) in each of the LCCs in 1990, 2002, and 2014, in the selected Landsat scenes (Novgorod, with Tver and Yaroslavl combined for presentation purposes). The results show that the overall number of pixels classified as arable land declined by $56 \%$ between 1990 and 2014, from 14,619,148 to 6,364,513 (a total of more than $8.25 \mathrm{M}$ pixels), amounting to an annual rate of -0.0347 . The annual rate of decline was stronger in the Yaroslavl scene $(-0.0369)$ than in Novgorod $(-0.0073)$. (The overall high rate is accounted for by the fact that Yaroslavl had 17.6 times as much arable land in 1990.) Table 4.1 also shows that the rate was not even across the periods $1990-2002$ and $2002-2014$.

In contrast, the area of grassland increased by $14 \%$, from $26,996,347$ to $30,775,179$ (about $3.8 \mathrm{M}$ pixels), amounting to an annual rate of 0.0055 , while the area of forest increased by $5.2 \%$, from $49,483,649$ to $52,043,661$ (about $2.6 \mathrm{M}$ pixels), amounting to an annual rate of 0.0021 . Together these increases almost equal (78\%) the loss in arable land. Large increase in the amount of water pixels and loss of peat bogs are perhaps affected by different area wetness at the time satellite images were taken. 
Table 4.1. Landcover in European Russia in 1990, 2002 and 2014. The scenes for Yaroslavl and Tver provinces are combined (see Methods). The number of pixels yielded by the supervised classification (GoogleEarth) for each landcover class is given for 1990, 2002 and 2014. The annual rates of change in landcover for the periods 1990 to 2002, 2002 to 2014, and 1990 to 2014 are given.

\begin{tabular}{lllllllll} 
Scene & Class & Type & $\mathbf{1 9 9 0}$ & $\mathbf{2 0 0 2}$ & $\mathbf{2 0 1 4}$ & $\mathbf{1 9 9 0}-\mathbf{2 0 0 2}-$ & $\mathbf{1 9 9 0}-$ \\
\hline Yaroslavl & 1 & Urban & 15045933 & 18124598 & 15917859 & 0.016 & -0.011 & 0.002 \\
& 2 & grass & 23077758 & 21493533 & 28816802 & -0.006 & 0.024 & 0.009 \\
& 3 & water & 4813363 & 3767952 & 6370096 & -0.020 & 0.044 & 0.012 \\
& 4 & forest & 40647962 & 41250119 & 41359365 & 0.001 & 0.000 & 0.001 \\
& 5 & Arable & 13833944 & 11724118 & 5705837 & -0.014 & -0.060 & -0.037 \\
& 6 & Peat bog & 10242523 & 11301163 & 9491524 & 0.008 & -0.015 & -0.003 \\
\hline Novgorod & 1 & Urban & 1708591 & 2385120 & 2882661 & 0.028 & 0.016 & 0.022 \\
& 2 & Grass & 3918589 & 2991226 & 1958377 & -0.023 & -0.035 & -0.029 \\
& 3 & Water & 2564714 & 2633760 & 2332718 & 0.002 & -0.010 & -0.004 \\
& 4 & Forest & 8835687 & 9800331 & 10684296 & 0.009 & 0.007 & 0.008 \\
& 5 & Arable & 785204 & 490752 & 658676 & -0.039 & 0.025 & -0.007 \\
& 6 & Peat bog & 1949477 & 1461073 & 1245534 & -0.024 & -0.013 & -0.019 \\
\hline
\end{tabular}

The analysis of changes around stopover sites is summarized in Table 4.2, again showing the area (number of pixels) in each of the LCCs in 1990, 2002, and 2014, in the selected Landsat scenes (Novgorod, with Tver and Yaroslavl combined for presentation purposes). The results are very similar. The overall amount of arable land (number of pixels) has declined by $56 \%$, from 4,050,355 to $1,802,122$ (about $2.2 \mathrm{M}$ pixels), amounting to an annual rate of -0.0337 . The decline was stronger in the Yaroslavl scene (-0.035) than in Novgorod (-0.017). Table 4.2 also shows that the rate was not even across the periods $1990-2002$ and $2002-2014$. In contrast, the area of grassland increased by $12.5 \%$, (from $7,633,861$ to $8,584,708$, or about $0.95 \mathrm{M}$ pixels), amounting to an annual rate of 0.0049 . The area of forest increased by $11.5 \%$ (from $11,578,250$ to $12,913,676$ or about $1.3 \mathrm{M}$ pixels), amounting to an annual rate of 0.0045 . Together these increases slightly exceed (by $2 \%$ ) the estimated loss in arable land around stopover sites. The two approaches (province scale and around stopover sites) thus give very similar results (Table 4.3 ). Note that the total 
relative loss and the rate of decline in arable land are an order of magnitude greater than those for any of the other five land cover classes.

Table 4.2. Landcover at detected stopover sites in European Russia in 1990, 2002 and 2014. The scenes for Yaroslavl and Tver provinces are combined (see Methods). The number of pixels yielded by the supervised classification (GoogleEarth) for each landcover class is given for 1990, 2002 and 2014. The annual rates of change in landcover for the periods 1990 to 2002, 2002 to 2014, and 1990 to 2014 are given.

\begin{tabular}{lcrrrrrrr} 
Scene & Class & Type & $\mathbf{1 9 9 0}$ & $\mathbf{2 0 0 2}$ & $\mathbf{2 0 1 4}$ & $\mathbf{2 0 0 2}$ & $\mathbf{2 0 1 4}$ & $\mathbf{2 0 1 4}$ \\
\hline Yaroslavl & 1 & Urban & 4025523 & 5400372 & 4256813 & 0.024 & -0.020 & 0.002 \\
& 2 & grass & 6334966 & 5591293 & 7862615 & -0.010 & 0.028 & 0.009 \\
& 3 & water & 2466121 & 2033422 & 2549259 & -0.016 & 0.019 & 0.001 \\
& 4 & forest & 9764423 & 10343745 & 10575787 & 0.005 & 0.002 & 0.003 \\
& 5 & Arable & 3766172 & 2880399 & 1613551 & -0.022 & -0.048 & -0.035 \\
\hline Novgorod & 6 & Peat bog & 3155772 & 3263746 & 2654952 & 0.003 & -0.017 & -0.007 \\
\hline & 1 & Urban & 535493 & 690619 & 977858 & 0.021 & 0.029 & 0.025 \\
& 2 & Grass & 1298895 & 1041829 & 722093 & -0.018 & -0.031 & -0.024 \\
& 3 & Water & 655130 & 688624 & 579575 & 0.004 & -0.014 & -0.005 \\
& 4 & Forest & 1813827 & 2071241 & 2337889 & 0.011 & 0.010 & 0.011 \\
& 5 & Arable & 284183 & 172374 & 188571 & -0.042 & 0.007 & -0.017 \\
& 6 & Peat bog & 523934 & 446775 & 305476 & -0.013 & -0.032 & -0.022 \\
\hline
\end{tabular}

Table 4.3. A comparison of the changes in land cover classes 1990 - 2014, measured on province scale and around stopover sites. Shown are the \% changes in area, and the rates. The two approaches give very similar results. Note that the decline of arable land exceeds all other changes by an order of magnitude.

\begin{tabular}{|c|c|c|c|c|}
\hline & \multicolumn{2}{|c|}{$\%$ change in area } & \multicolumn{2}{|l|}{ rate } \\
\hline & SCENE & STOPOVER & SCENE & STOPOVER \\
\hline Arable & -56.5 & -55.51 & 0.0346 & -0.0337 \\
\hline grass & 14 & 12.46 & 0.0055 & 0.0049 \\
\hline forest & 5.17 & 11.53 & 0.0021 & 0.0045 \\
\hline Urban & 12.21 & 14.77 & 0.0048 & 0.0057 \\
\hline water & 17.96 & 0.24 & 0.0069 & 0.0001 \\
\hline Peat & -11.93 & -19.55 & -0.0053 & -0.0091 \\
\hline
\end{tabular}

Results presented in Tables 4.3 and 4.4 are visualised with difference maps calculated from the Landsat scenes for both transitions from arable LCC 
to all other classes and from grass LCC to all other classes (Figures 4.3a and 4.3b). Most pixels showed no change between landcover classes in $1990-2002$, 2002 - 2014 and 1990 - 2014, but for arable difference maps fewer changes were observed. Most pixels that changed their values transitioned from arable to grass and forest LCC (Figure 4.4a) and from grass to forest and urban LCC (Figure 4.4b). This abnormally high transition to urban pixels is a result of misclassification between arable and urban LCC, which was common the analyses due to similar spectral reflectance produced by both LCC. This misclassification might pose a problem if an entire difference map should be analysed. However, our analysis targeted landcover changes around stopover sites (Chapter 4, Figures 4.5 a-b) which were modelled with urban areas clipped out as unsuitable for staging geese. Therefore, we considered erroneous transition from grass to urban LCC outside urban areas to mark a transition from grass to arable LCC which was confirmed with ground truthing.

Our field observations in Russia in June 2014 confirmed that following abandonment of a field, the succession from cropland to forest was well under way in under 20 years. We defined five stages of old-field development following abandonment (Table S4.6). Stage 1 old fields were abandoned no longer than two years previously. Such fields had been used for mostly grain cultivation. Grass coverage is $\sim 95 \%$, with herbs and shrubs accounting for less than $5 \%$. Such fields might be quickly returned into cultivation with low machinery and fertilizer inputs.

Stage 2 old fields were abandoned three to five years previously. Such fields had originally been used to grow grain, and were later turned into grassland. Grass coverage is up to $\sim 50 \%$, and herbs cover the remainder. These fields could be brought back to cultivation, but would require considerably more investment than at Stage 1 . Stage 3 old fields were abandoned up to a decade previously. Patches of grass still cover $\sim 10 \%$ to $30 \%$, but herbs dominate with $\sim 70 \%$ to $90 \%$ coverage, while trees and shrubs cover up to $5 \%$. Often these fields had originally been used for grain production, but had been used for haymaking prior to abandonment. Stage 4 old fields were abandoned 11 to 15 years previously. They are dominated by herbs (up to $90 \%$ ) but might still have up to $10 \%$ coverage by grass species. Trees and shrubs occupy up to $10 \%$ of a 
field. Stage 5 old fields had been abandoned 16 - 20. Herbs dominate vegetation cover, but trees and shrubs cover up to $30 \%$ of a field, especially along its edges.

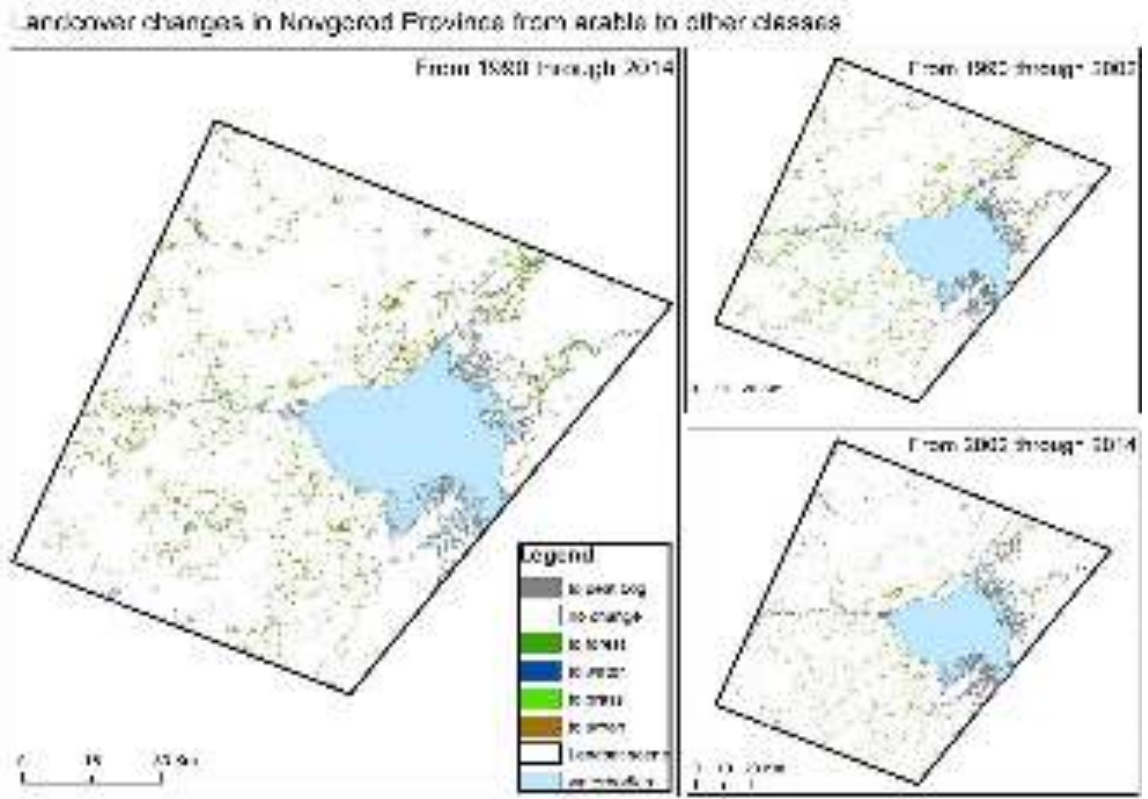

Figure 4.3a. Difference map calculated from the Landsat scenes in Novgorod Province. The map on the left features transition from arable landcover to all other classes, $1990-2014$. The two smaller maps on the right highlight similar transitions 1990 - 2002 (upper) and 2002 2014 (lower). The abnormally high number of urban pixels is a result of misclassification between arable and urban LCC. 


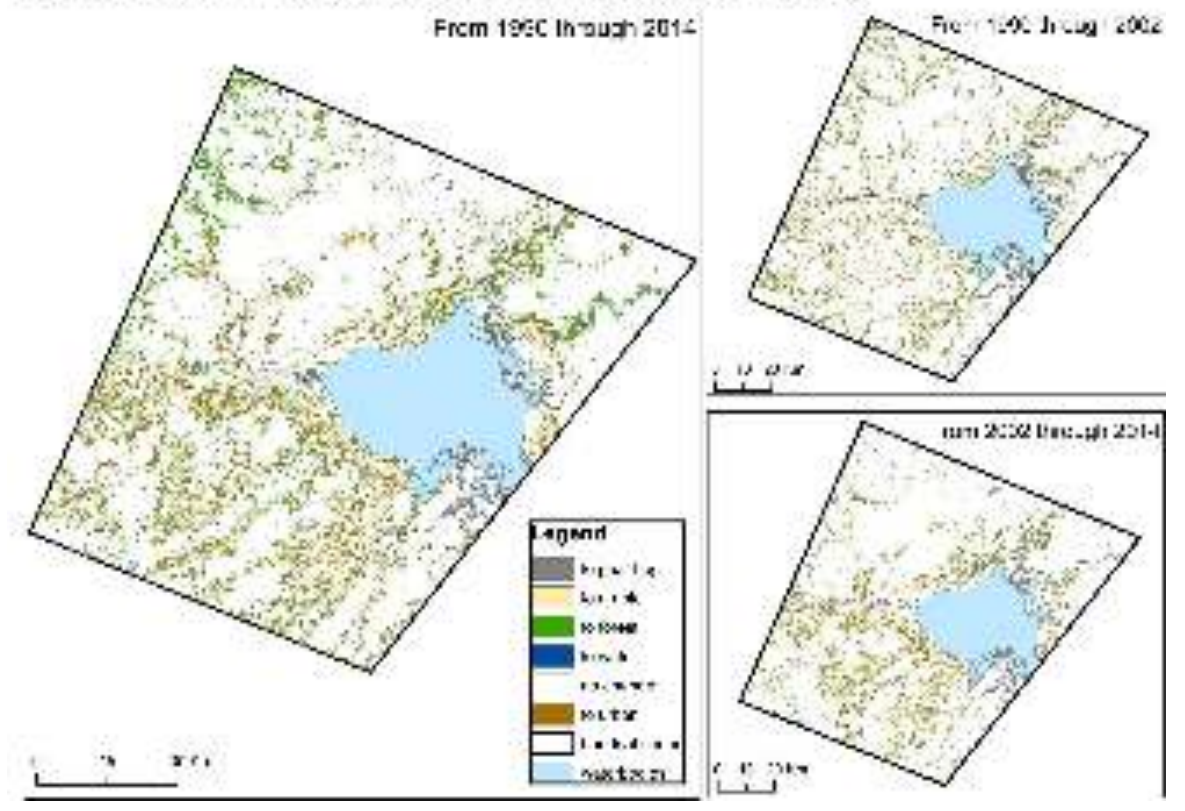

Figure 4.3b. Difference map calculated from the Landsat scenes in Novgorod Province. The map on the left features transition from grass landcover to all other classes, $1990-2014$. The two smaller maps on the right highlight similar transitions 1990 - 2002 (upper) and 2002 2014 (lower). The abnormally high number of urban pixels is a result of misclassification between arable and urban LCC. 


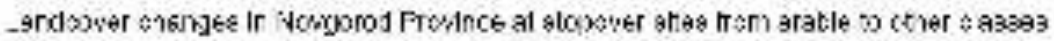

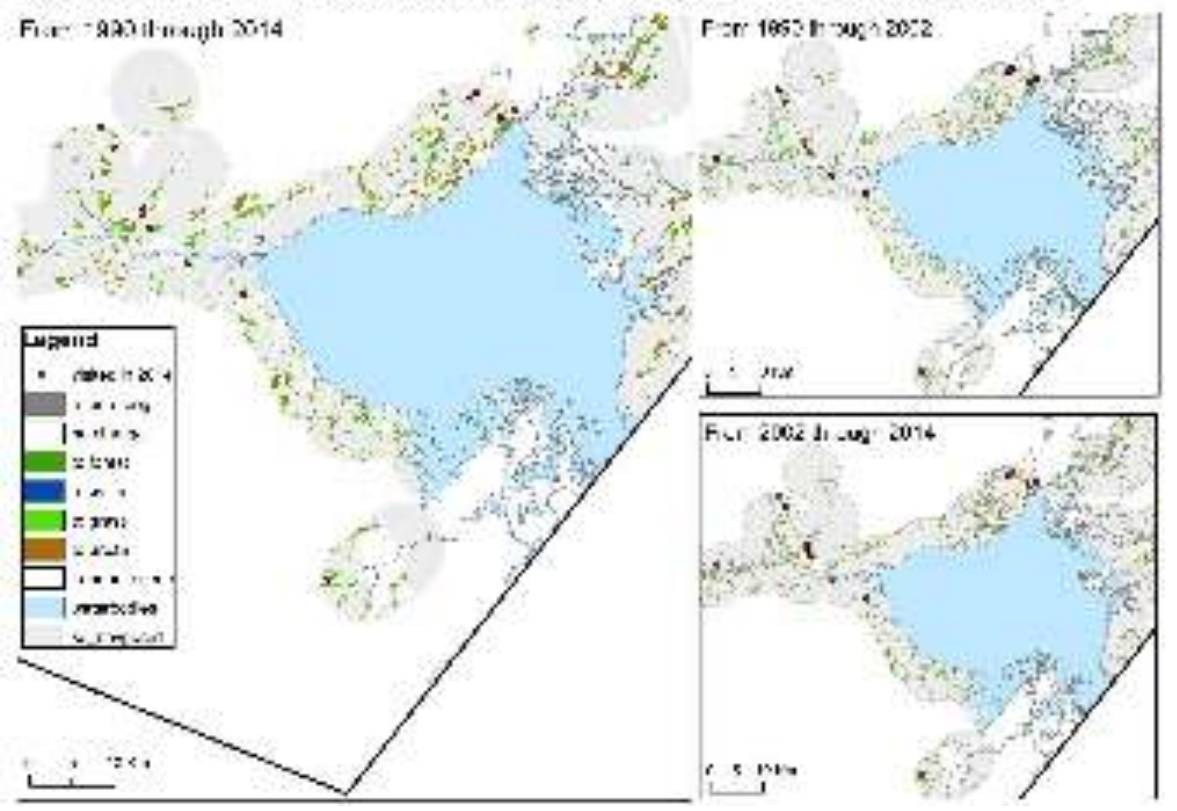

Figure 4.4a. Difference maps at stopover sites calculated from the Landsat scenes in Novgorod Province. The map on the left features transition from arable landcover to all other classes, 1990 - 2014. The two smaller maps on the right highlight similar transitions 1990 - 2002 (upper) and $2002-2014$ (lower). 


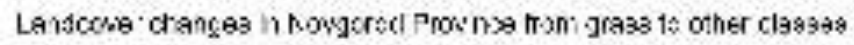

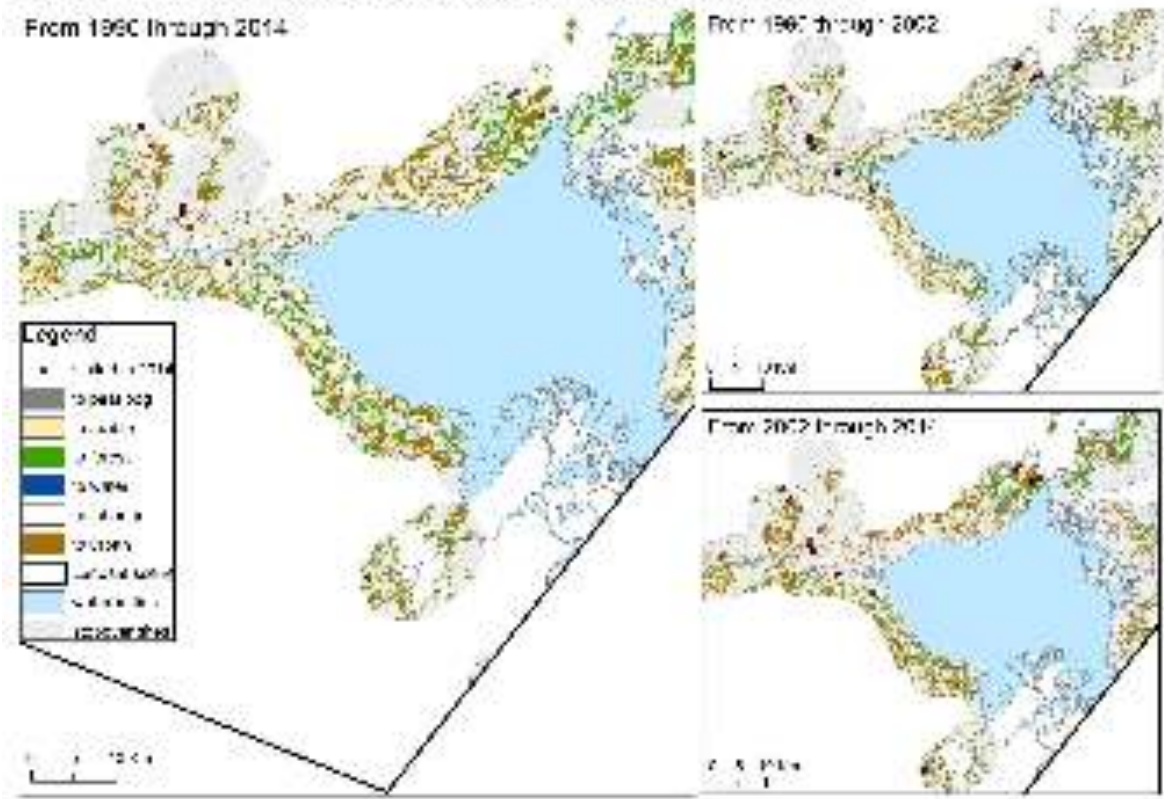

Figure 4.4b. Difference maps at stopover sites calculated from the Landsat scenes in Novgorod Province. The map on the left features transition from grass landcover to all other classes, 1990 - 2014. The two smaller maps on the right highlight similar transitions 1990 - 2002 (upper) and $2002-2014$ (lower).

\section{Comparison with municipal district statistics}

To relate detected landcover changes around stopover sites with previously studied changes of agriculture in European Russia (Chapter 2) a change in number of pixels in arable LCC was compared only with growth rates in area under cultivation and area under grains. A change in number of pixels in grass LCC was compared only with number of cows. For Yaroslavl scene a decline in number of pixels in arable LCC (annual rate of -0.037) matched with falling growth rates in area under cultivation (annual rate of -0.033) and area under grains (annual rate of -0.069) in $1990-2014$ (Table 4.4). Similar patterns were observed in $1990-2002$ and $2002-2014$. However, decline in number of pixels in arable LCC in 1990 - 2002 (annual rate of -0.014) was less than in area under cultivation (annual rate of -0.032 ) and grains (annual rate of -0.075 ) but it 
plummeted in 2002 - 2014 (annual rate of -0.060) along with decline in area under grains ( -0.060 and -0.062 respectively). Though both number of pixels in grass LCC (annual rate of -0.006) and cows numbers (annual rate of -0.062) declined in 1990 - 2002, they mismatched in $2002-2014$ and in $1990-2014$. In the two periods number of pixels in grass LCC recovered (annual rates of 0.024 and 0.009 respectively), but cow numbers continued to tumble (annual rates of -0.060 and -0.061 respectively). For Novgorod scene decline in number of pixels in arable LCC (annual rate of -0.007) was associated with similar decline in area under cultivation and area under grains (annual rate of -0.059) in 1990 - 2014. However in 2002 - 2014 number of pixels in arable LCC grew (annual rate of -0.025) while agricultural statistics demonstrated a decline (annual rate of -0.064). The number of pixels in grass LCC (annual rate of 0.029) declined along with the number of cows (annual rate of -0.105), which however shrank three times faster. Exploring landcover changes at a scale of stopover sites (Table 4.5) yielded results that were similar to those observed on the entire scenes.

Table 4.5. A comparison between growth rates for arable and grass landcover classes based on the analysis of Landsat images focussing on detected goose stopover sites. Changes in growth for arable class are compared with changes in growth rates for area under crops and area under grains.

\begin{tabular}{ccrrrr} 
Scene & Type & $\mathbf{1 9 9 0 - \mathbf { 2 0 0 2 }}$ & $\mathbf{2 0 0 2} \mathbf{- 2 0 1 4}$ & $\mathbf{1 9 9 0} \mathbf{- 2 0 1 4}$ \\
\hline Yaroslavl & Arable & -0.022 & -0.048 & -0.035 \\
& & -0.032 & -0.034 & -0.033 \\
& & -0.075 & -0.062 & -0.069 \\
\hline \multirow{2}{*}{ Novgorod } & Grass & -0.010 & 0.028 & 0.009 \\
& & -0.062 & -0.060 & -0.061 \\
\hline & & -0.042 & 0.007 & -0.017 \\
& & -0.054 & -0.064 & -0.059 \\
& Grass & -0.173 & -0.019 & -0.096 \\
\hline & & -0.018 & -0.031 & -0.024 \\
& -0.109 & -0.102 & -0.105 \\
\hline
\end{tabular}

Even though the overall accuracy of the classification was above $90 \%$ (based on GoogleEarth Engine outputs), we discovered some discrepancies 
between classified LCC and some visited points in the field, as well as between landcover classes themselves. Most misclassifications between LCC happened for landcover classes with similar reflectance. One of the validation points was an active field classified as recently abandoned. However, that error could not be avoided because the field was returned to agricultural use already after the classification. Other misclassified validation points were on the exurbs of cities where colonies of dacha's (second houses) expanded in 1990s (Ioffe and Nefedova 2004). Some classifications resulted in a large number of arable fields misclassified as urban. However, this misclassification had no impact on the results because we had already excluded urban areas while modelling stopover sites (Chapter 3 ) which implies that all 'urban' pixels could be treated as 'arable'.

\section{Discussion}

After analysing changes in agricultural practices in European Russia (Chapter 2) and generating a network of potential stopover sites (Chapter 3), in this Chapter we looked at the actual changes in landcover in 1990 through 2014 at stopover sites used by migrating geese. After analyses of landcover changes of three Landsat scenes, that cover the study area, for 1990, 2002 and 2014, we found three important trends for LCC arable, grass and forest. Over the past 25 years arable land continuously declined on all investigated scenes and especially at stopover sites. The decline of arable land across all scenes was stronger in 2002 - 2014 and matched the observed declines in area under cultivation and grains. For the same period area under grassland declined in Novgorod scene but showed mixed trends for Yaroslavl scene. For the later it declined between 1990 and 2002 but recovered in 2002 - 2014. While decline in grass in Novgorod scene matched a similar decline in cow numbers, this was not the case for Yaroslavl scene. In both areas forest cover had continuously increased in the past 25 years with greater re-forestation in Novgorod scene.

While most pixels showed no change when calculating the difference maps, nearly half of them transferred from one LCC to another. Arable, grass and forest were among three most dynamic LCC. While arable LCC was continuously declining, forest LCC was increasing and grass showed a rather mixed response. As decline in arable class matches well with declined in growth 
rates of area under cultivation and grains, we can conclude that changes in agricultural practices in European Russia after the break-up of the USSR in 1991 manifested themselves in observed landcover mainly in the form of increased shrub and forest cover. Prishchepov et al. (2013) observed similar trends in landcover across municipal districts of selected provinces in Central Russia with rates of agricultural abandonment up to $65 \%$ of their initial rates in 1990 . Their findings suggest that removal of over $90 \%$ of state subsidies to agriculture in European Russia played an important role in land abandonment, especially in more peripheral areas. Most grain production in the North of Russia was halted (Ioffe \& Nefedova 2004) which resulted in abandonment of arable fields or their use for other crops, particularly as meadows and grasslands (Ioffe 2005, Prishchepov et al. 2017).

In both Landsat scenes (Novgorod and Yaroslavl) arable LCC declined slower than reported area under cultivation and grains in 1990 - 2002, but in 2002 - 2014 it matched well with decline in area under grains. This observed delay in signal in 1990 - 2002 does not match earlier recorded number (Prishchepov et al. 2013) which might have to do with protracted restructuring of collective farms (Leerman 1998) resulting in their impeded restructuring and slower changes of agricultural practices. Land abandonment appeared to be stronger in 1990 - 2002 in Novgorod province while in Yaroslavl and Tver provinces together, the effect was stronger in 2002 - 2014. These differences might be related to adopted rural policies (Wegren 2012) and decline in rural population (Ioffe 2005) rather than to only area under cultivation and grains. Rural population in Novgorod province declined much faster than in Yaroslavl province, especially in 1990 - 2002 (Chapter 2), which could have an indirect impact on agricultural practices. Another explanation of differences between two scenes is the temperature gradient (Prishchepov et al. 2013) where Novgorod province has a colder climate and shorter vegetative period compared to Yaroslavl. Thus, temperature effects combined with decline in human population (Chapter 2) could have a strong effect on decline in arable fields in $1990-2002$ but had limited impact in $2002-2014$.

A widespread land abandonment confirmed with detected decline in arable LCC could result in a temporal increase of grass LCC in the study area. This 
increase was prominent on the Yaroslavl scene. To keep a field active for a longer period, a farm could use it as a grassland that requires less inputs and manipulations (Ioffe 2005, Wegren 2012). However, this solution is not sustainable in a long-term, because of dwindling demand for grass and hay indicated by lower number of cattle, goats and sheep (Chapter 2 ). It should be noted that maintaining grassland costs labour because maintenance in the absence of grazing either needs mowing or burning. Agricultural burning is very widespread in European Russia on both active and abandoned fields (Romanenkov et al. 2014) and has been done for decades despite official legal ban. Agricultural organizations believe that burning should prevent fields from being overgrown with shrubs and trees (on old fields) or that burning helps fertilizing soils (on active fields). Labour is getting scarce in the provinces that we studied (Korovkin et al. 2006; Leurelle 2007) but we observed incursions by "traditional" graziers from further south and east (Azeris, Armenians, Uzbeks: Laurelle 2007). Comparing changes in grass LCC with available cattle numbers (Chapter 2), we observed a faster decline of cattle numbers than of grass LCC. The 'new nomads' that appear to be entering these lands do not graze cattle very much but especially sheep; the numbers of these particular sheep do not appear to crop up in the data collected by municipalities though. Our results clearly indicate the political origin of induced land use changes: political decisions affected economic policies and, with a delay, manifested in changed landcover. Once cattle herds were reduced due to shortage of subsidized inputs (Wegren 1998) and falling demand for food (Ioffe \& Nefedova 2004), demand for grass and hay stalled which we observed in falling number of pixels of grass LCC.

In the Novgorod scene declining grass LCC followed falling cattle numbers in both 1990 - 2002 and 2002 - 2014. In the Yaroslavl scene cattle numbers shrank much faster than the grass LCC in 1990 - 2002 and continued their fall in 2002 - 2014 while the grass LCC showed an increase. A recent increase in grassland LCC could have two alternative explanations: (1) farming practices intentionally changed to pastures and meadows or (2) LCC classified as grassland are clear-cuts in reality. Both outcomes might lead to a misclassification of landcover classes. The first alternative explanation might be 
partly true because farms indeed changes their practices out of financial health reasons (Leerman 1998) but this was not intentional and we consider it a hidden land abandonment (Ioffe 2005), as these grasslands will be eventually abandoned (pers. obs.). However an immigration of new pastoral farmers with their herds of sheep or goats from the South and the East of the former USSR (Laurelle 2007) might indeed contribute to temporal increase of number of active grassland and pastures. The second alternative explanation seems more suitable for the Asian part of Russia and some districts in the Russian North where large-scale logging takes place (Alix-Garcia et al. 2016). However, such activities in the study area are rather limited (pers. obs.). Furthermore, we did not visit any single misclassified point on our fieldwork that represented a clearcut. Hence, both alternative explanations can be ruled out.

While arable and grass LCC declined in Novgorod and Yaroslavl scenes in 1990 - 2014, forest LCC had continuously increased. Both scenes showed an increase in forest cover in 1990 - 2002 and 2002 - 2014, but the increase was stronger in Novgorod scene. This reforestation amid declines in arable and grass LCC suggests that classification detects tree and shrub encroachment on abandoned agricultural fields. This is in line with finding of recent studies of landcover changes in Russia (Prishchepov et al. 2013) and Eastern Europe (Kuemmerle et al. 2015). The study area is located in the boreal forest zone where forests were cleared (Bradshow 2004) to give space to agricultural fields that supported growing human population (Chapter 2, Goldewijk 2001).

Our data are showing that both in Novgorod Province and in the Provinces of Tver and Yaroslavl forest cover has been increasing, and arable land has been decreasing. This is not only true for the general land use of these areas that straddle the migration routes of white-fronted goose, lesser white-fronted goose and bean goose, but is also true for the particular areas that are well-suited as stop-over sites for these geese. Even though much has been written about the "green wave" (van der Graaf et al. 2005, van Wijk et al. 2012; St et al. 2015b) that geese could utilize on spring migration, it appears that agricultural spillage (wheat, potato, maize) may be important (Nilsson and Persson 1998; Rosin et al. 2012). The same may apply in fall (Ely and Raveling 2011, Kölzsch et al. 2016). Since the geese do not use forests, the combination of declining arable 
lands and increasing forests do not bode well for migratory geese. Does the increase of grass cover compensate for the loss of arable fields? That depends on the species and quality of the grass cover.

Our fieldwork confirmed that many agricultural fields formerly used for grain production have been experiencing a succession to forest for the past three decades. Our five stages of succession are very similar to those that were recognised as old-field succession in North America (Core 1949; Odum 1960), and it reflects the vegetation succession from an arable field to forest in a course of 25 years. After grain cultivation was stopped, fields were often dominated by few grass species (Dactylis glomerata, Alopecurus myosuroides) and some crop species that germinated from spillage. These plant species are commonly present on active grain fields (Hubbard 1978) and, therefore, are able to quickly spread through a recently abandoned field (stage 1 ). Some of these species (e.g., Dactylis glomerata) could be also cultivated for haymaking and are very abundant in early stages of abandonment (stages 1-2). As the succession progresses, grass species are being crowded out with herb species (Anthriscus sylvestris, Galium odoratum, Angelica sylvestris, Heracleum sphondylium) that dominate abandoned fields on stages 2 to 4 . Limited evidence exists that these grass species are particularly well suited for geese grazing (Wink et al. 1993; Tombre et al. 2005) and the herbs are not used at all (pers. obs.). Already at stage 2 some tree species (Salix, Betula, Pinus) from nearby forests and woods invade abandoned fields. These tree species are not consumed at all, but visibility declines dramatically in such fields making them very dangerous for geese because of fox, wildcat, lynx and wolf predation. If no human intervention is made growth of these young trees and further seed dispersal result in complete reforestation (stage 5). However, seed dispersal might be constrained by local habitat conditions so that trees and shrubs need extra time to germinate (Tiebel et al. 2018). This delay might explain rather low observed forest growth rates. Hence, only few agricultural fields that were abandoned 15-25 years ago eventually turned into young forest. Afforestation could be an alternative explanation of detected increase in forest LCC. Foresters and NGO's usually execute afforestation programmes in Russia on clear-cuts (Vilen et al. 2016), but these were not likely to be present in the study area on a large scale. 
Our results suggests large-scale landcover changes around stopover sites used by migrating greater white-fronted goose and other goose species. At this point in time, it appears that there are still sufficient large scale arable fields and meadows available in north-central Russia for geese to successfully stage during migration but the situation appears to be much less favourable than 20 or 30 years ago. When extrapolating to the future, these changes might alter habitat availability and configuration for the species to such an extent though that finding suitable stopover sites will be hampered. Indeed, the results of Chapter 5 show that many stopover sites have been abandoned already. This in turn indeed will likely decrease functional landscape connectivity and thus will negatively impact the species. We suggest identifying key stopover sites where conservation bodies should concentrate their efforts to maintain a landscape conducive for staging geese. Indeed, without such actions, the greater whitefronted goose, as other migrating species that make use of agricultural landscapes in European Russia, may soon become rare again, as it was at the end of the 1900s. 


\section{Appendix to Chapter 4}

Table S4.6. Stages of old field succession observed at abandoned stopover sites in European Russia in June 2014. For each stage of succession we indicate approximate time of abandonment, vegetation composition and changes in landcover pattern between 1990, 2002 and 2014.

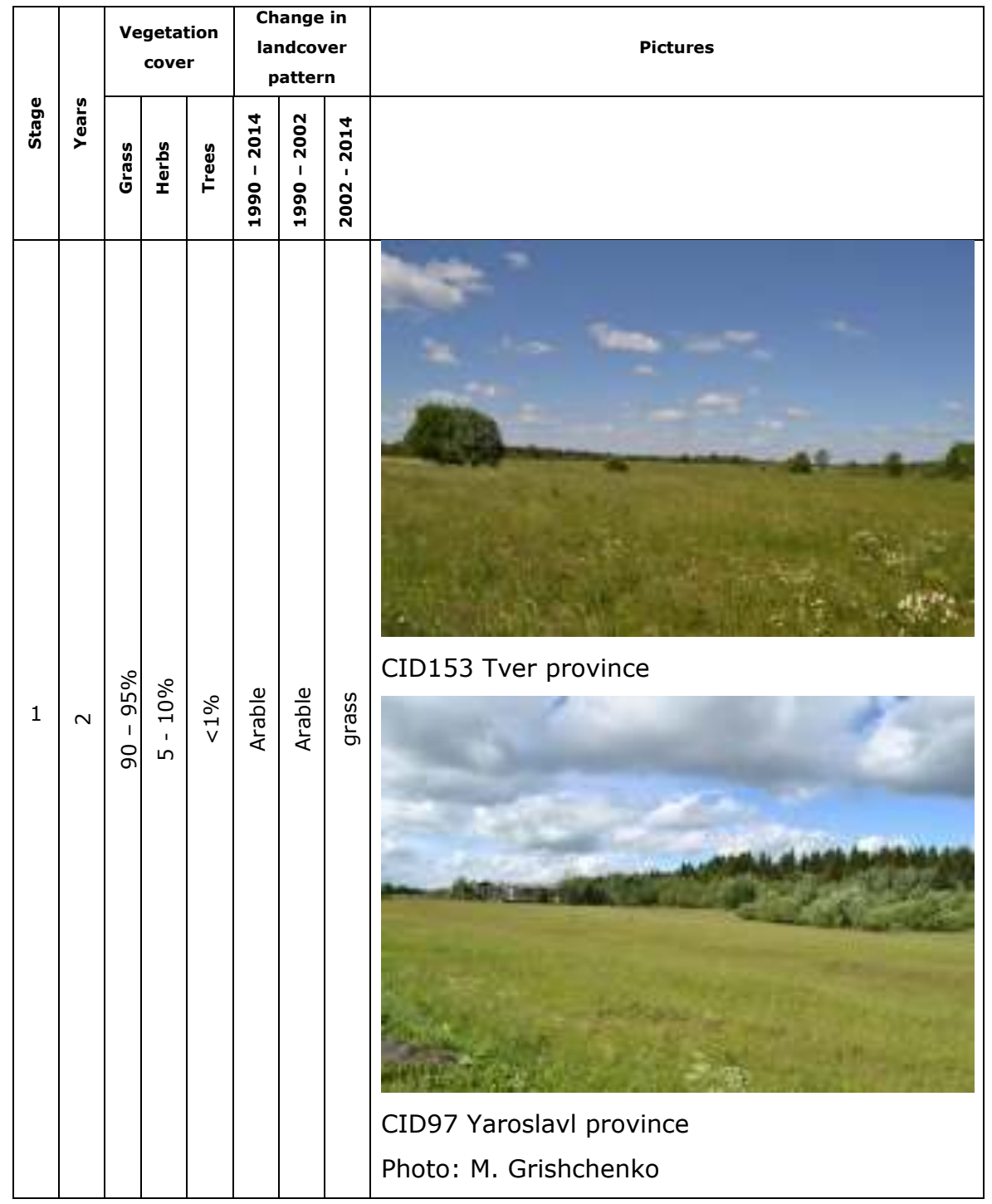




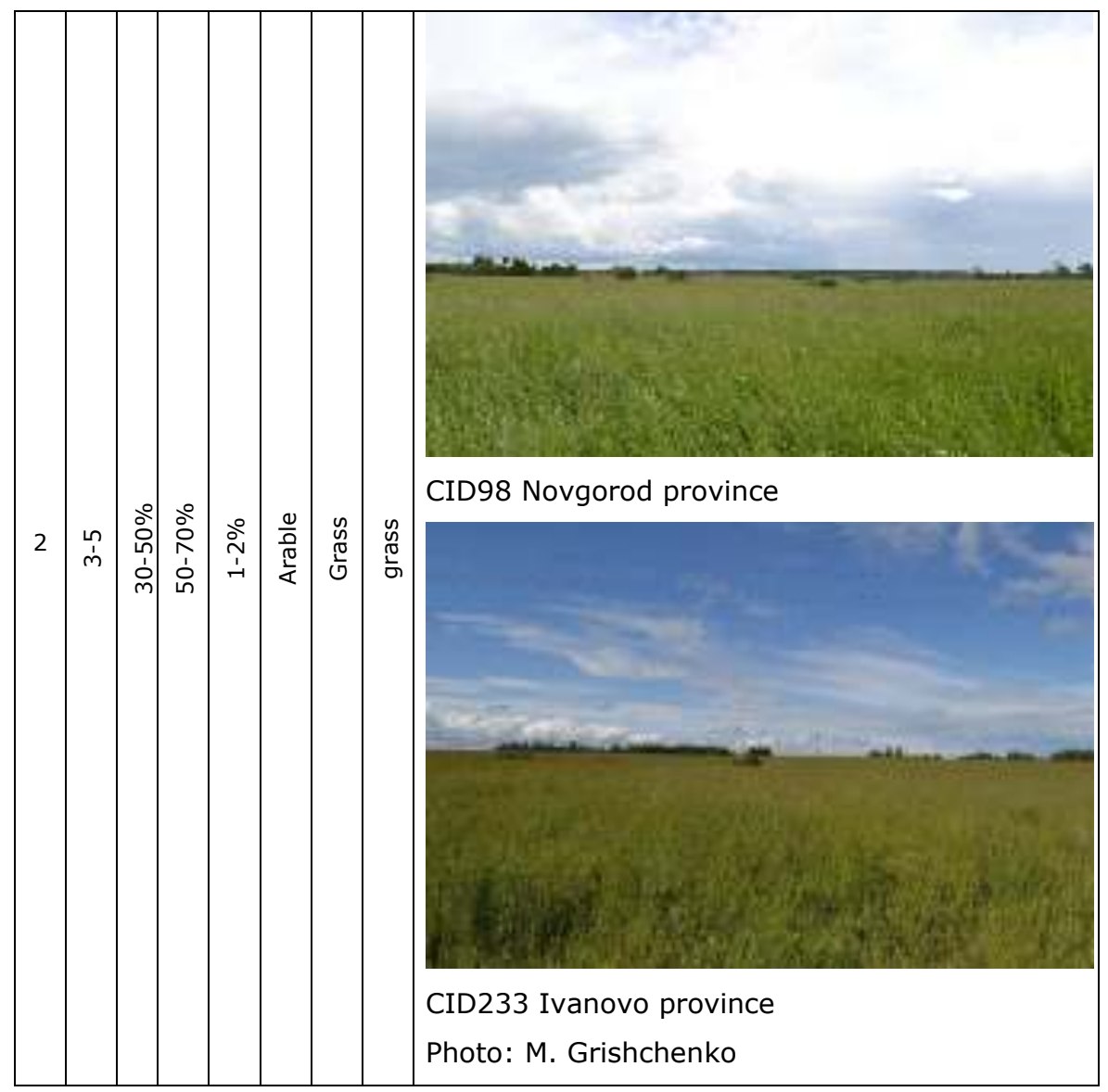




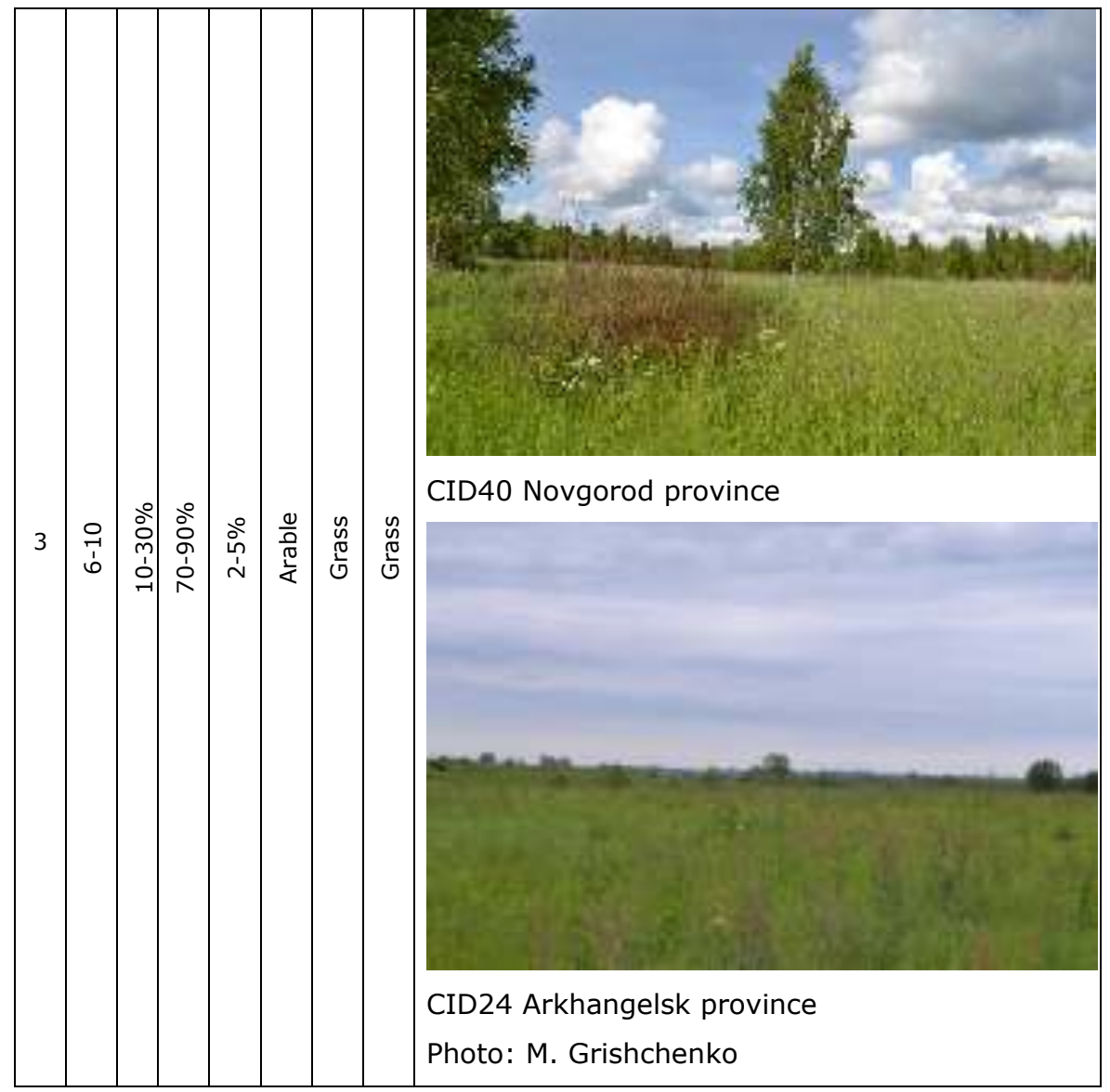




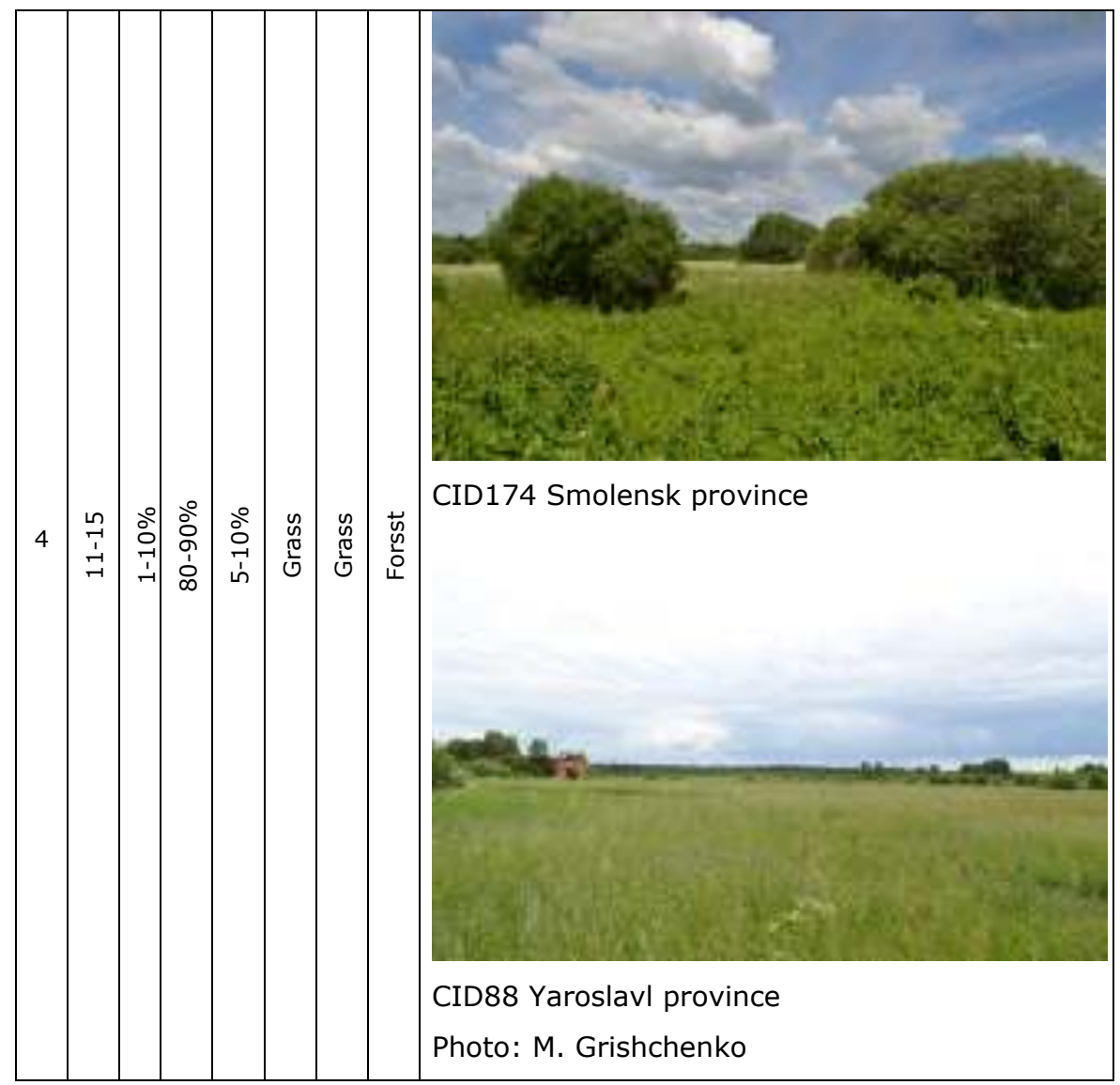




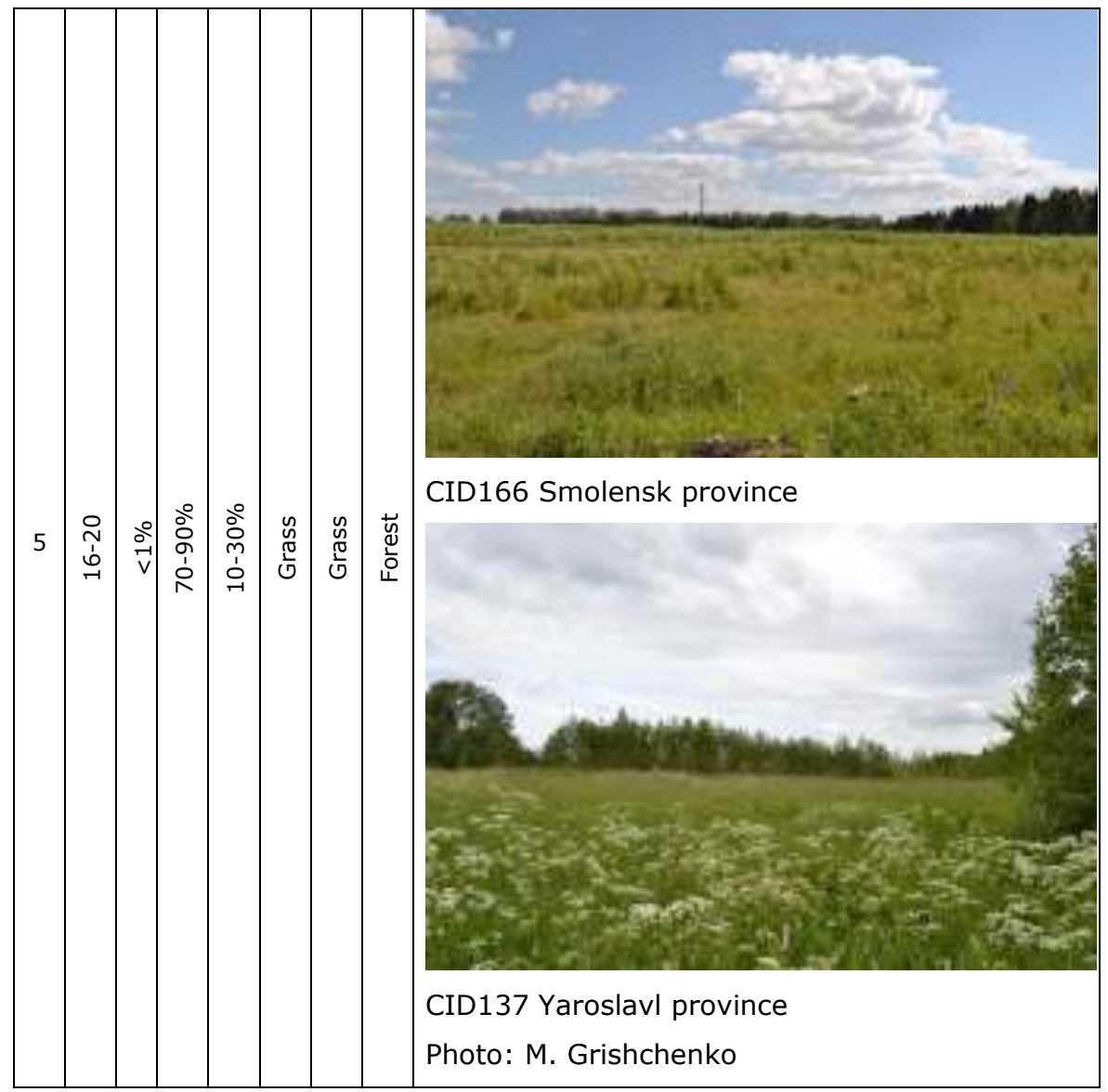




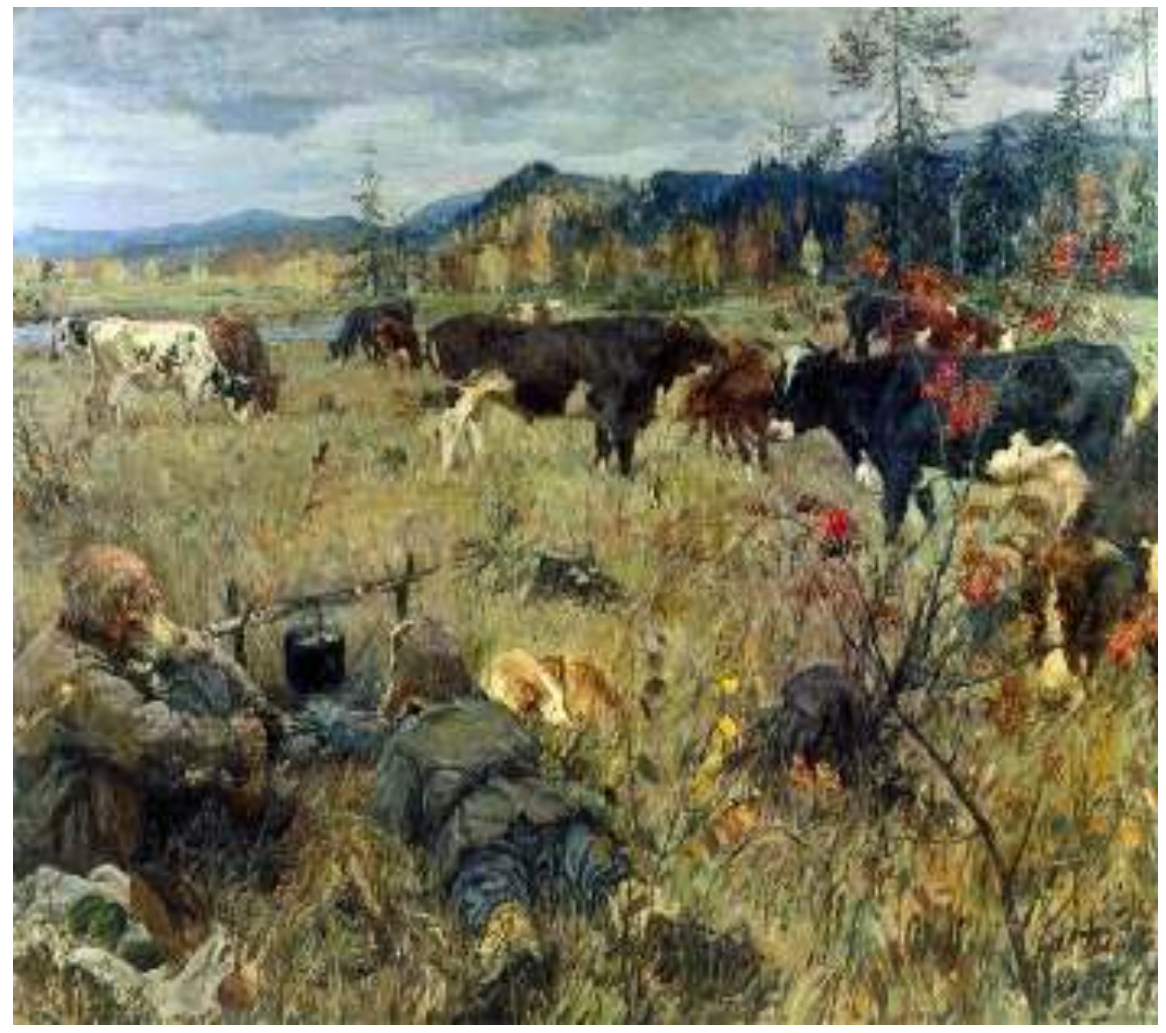

A. Plastov "A herd of tagilka cows" (1945) / А. Пластов "Стадо тагилок". 


\section{Chapter 5}

\section{The effect of politics on the migration geography of greater white-fronted geese in European Russia}

Mikhail Grishchenko, Herbert H.T. Prins, Ronald C. Ydenberg, Michael E. Schaepman, Willem F. de Boer, Sip E. van Wieren, Henrik de Knegt

\section{Abstract}

Geese are avian migrants that spend most of their migration time at stopover sites where they can rest and re-fatten. In the part of European Russia that is visited by the Atlantic greater white-fronted geese, vast areas of agricultural land have been abandoned since 1991, triggering field succession towards a more wooded landscape. We hypothesize that increasing land abandonment could contribute to a southward shift of goose migration because stopover sites in northern Russia have become progressively unsuitable for staging in spring and fall. To test this hypothesis we located stopover sites from information contained in $\mathbf{2 7 9 6}$ metal ring recoveries and field observations, using a kernel density estimator grid of recovery locations. To delineate the area corresponding to each stopover site, we divided stopover sites into a number of regions where each site centroid acted as starting point. The analysis yielded a total of 300 alleged stopover sites in European Russia, distributed over three time periods in order to study the effect of land abandonment: 1960 - 1991, $1992-2000$ and 2001 - 2013. Our study focused on the north of European Russia, where Atlantic greater white-fronted geese stop on their way from wintering areas to breeding areas. To account for known factors we examined the effects of latitude, distance to nearest waterbody and settlement and period on the relative density of stopover sites which we used as a proxy for stopover site usage. Our results suggest that in three decades following the break-up of the USSR greater white-fronted geese shifted their migration pathways in European Russia southward, thereby confirming our hypothesis. These changes were most visible in the last decade. We attribute these changes as a probable response to 
reorganisation of agriculture and wide-spread land abandonment in the European part of Russia since the break-up of the USSR.

Key words: agriculture, geese migration, land use change, political ecology, Russia, stopover sites

\section{Introduction}

Every year geese migrate from their wintering grounds in Western Europe to their summer breeding grounds in northern Russia and back. Most goose species are typical avian migrants that spend much of their migration period at stopover sites. Hedenström and Alerstam (1997) estimate the ratio of time at stopover sites to time in flight for a typical small migratory bird at about $7: 1$. The ratio is even higher for large birds, like geese. Some geese migrate nearly or totally without any stop, like brent geese Branta bernicla (Ebbinge et al. 1999; Dokter and Ebbinge 2013) or lesser white-fronted geese Anser erythropus (Aarvak and Oien 2003; Romanov and Pospelov 2010), but other species, such as barnacle geese B. leucopsis (Eichhorn et al. 2006; de Boer et al. 2014), use many stopover sites. These particular sites along their migration routes are then used to rest and to restore their energy reserves needed during long distance flying (Drent et al. 1978; van der Graaf et al. 2006).

Greater white-fronted geese $A$. albifrons are perhaps the most numerous of all geese that use the East Atlantic flyway, and their current population is estimated to be around 1.3 Mio individuals (Koffijberg and van Winden 2014). They breed in the northern Russian tundra, ranging from Kolguev Island (Kondratyev and Kruckenberg. 2013) up to the Taymir Peninsula (Mooij 1997). Greater white-fronted geese that breed further to the East, mainly in the Lena Delta, do not overwinter in Atlantic Europe, but along the Yangtze River in China (Yali Si pers. comm.).

The "Atlantic" greater white-fronted geese concentrate their wintering time in the Netherlands (Mooij 1997; Hornman et al. 2012), but also overwinter in northern Germany, the United Kingdom, France and Denmark (Madsen and Cracknell 1999). Their spring migration takes them to a northeasterly direction, 
usually clustered in a narrow front at first. Then, different from the other goose species and more like Mallard Anas platyrhynchos (Scott and Rose 1996), their migration routes fan out in an ever-widening front across Belarus, Ukraine and European Russia, to become a narrower front again towards the Russian Arctic (Madsen and Cracknell 1999). Hence, stopover sites for this species can be found all across this vast area. The geese show a similar pattern in the fall, when they migrate back from the north, again over nearly the whole of European Russia north of $50^{\circ} \mathrm{N}$ (Madsen and Cracknell 1999; Emelchenko 2009).

A second group of greater white-fronted geese overwinters on the Hungarian plains (Farago 2010), and their migration is to the south of Belgorod, but to the north of the Danube Delta, the Sea of Azov, and the Volga Delta (Mooij 1997; Emelchenko 2009). Individual "Hungarian" geese are known to interchange between the flyways connecting wintering and breeding areas (Mooij et al. 1996; Bart Nolet pers. comm.). So all over these lands of roughly $4 \mathrm{M} \mathrm{km}^{2}$ one can find pieces of land that are used by migrating greater whitefronted geese in spring or fall as stopover sites where they can rest and re-fat.

These stopover sites in Russia have been studied only to a limited extent when compared with wintering grounds and breeding grounds. This lack of attention over the past 40 years, during which the study of goose migration increased both on the seaboards of the North Sea (Arzel 2006) and the Russian Arctic Ocean (Arzel 2006; Emelchenko 2009), can be explained by the fact that most if not all stopover sites have very limited accessibility during the migration period. This is mainly due to the poor conditions of the Russian country roads especially during thaw-up or rain, the vastness of the lands, political isolation precluding foreign ornithologists visiting the sites, and a dearth of Russian scientists studying bird migration.

Besides such practical reasons, the development of the theory explaining animal abundance presented a more conceptual reason why these stopover sites received less attention from the ecological community. In the 1950s Lack's work (Lack 1956) led to the idea that bird numbers were determined by the abundance of their food sources, leading to the concept of bottom-up control. This idea was later modified by influential goose biologist and ornithologist Rudi Drent (Drent and van der Waal 1998), who was greatly influenced by this work 
and posited that geese were mainly limited in their numbers by their food supply in winter (Drent and Prins 1987). Later the question arose whether they were limited by the food supply in summer instead. Fred Cooke and Bob Jefferies (Cooke et al. 1983; Jefferies and Rockwell 2002) set out to test these ideas when studying Snow geese Anser caerulescens on the tundra of the Hudson Bay in Canada. Improving relations between the West and Russia also allowed a series of expeditions to Taymir Pensinsula (Russia) to test these ideas (Kostin and Mooij, 1995; Mooij et al. 1996; Ebbinge et al. 2013). However, fluctuations in geese numbers, and especially breeding success, still could not be explained well, and it became increasingly clear that the conditions during spring migration modulated were important in modulating brood output, thus population abundance (Ebbinge 1985; Drent et al. 2006). Therefore, accumulated knowledge of geese behaviour at the breeding and wintering grounds alone could not fully explain the migration geography of geese.

The third reason for limited knowledge of the stopover site geography is the lack of appropriate tracking technology, in particular the lack of satellitetracking possibilities before the 1990s (Nowak and Berthold 1991). With new tracking technologies of animal migration (colour ring or neck collars; satellite tracking) combined with increased interest in hunting and birdwatching in Russia, Ukraine and Poland, sufficient data became available to study geographical patterns of migration and changes over time to better understand which factors influence migration of the greater white-fronted geese in Europe (Ebbinge 1991; Kokko et al. 1998).

Studies that nonetheless focussed on stopover sites found that they are mostly located on agricultural land created or modified by people. An ideal spring stopover site for greater white-fronted geese is characterised by (1) the proximity of a fresh water body of minimally 20 ha and maximally up to several thousand $\mathrm{km}^{2}$, such as found at the shorewaters of Lakes Ladoga, Onega and Ilmen $\left(58^{\circ} \mathrm{N}-60^{\circ} \mathrm{N}\right)$ which provide good sites for staging geese, (2) fields consisting of grass (shorter than seven cm: Heuermann et al. 2011; Si et al. 2011; Zhang et al. 2016), cereals (wheat, barley, oats, rye), stubbles (Nilsson and Persson 1998, Rosin et al. 2012) or leftovers from potato or sugar beet from the previous fall (Ely and Raveling 2011). 
After the break-up of the USSR in 1991, there has been a sweeping reorganisation of agriculture in the part of European Russia that is frequently visited by Atlantic greater white-fronted geese (Chapter 2). Vast areas of agricultural land were abandoned because it was not economically profitable to maintain agriculture when subsidized collective farming came to an end (Wegren 1995). Since land abandonment in this eco-climatic zone mostly leads to field succession and eventually forest (Kümmerle et al. 2015), we argue that everincreasing land abandonment will negatively impact the abundance and quality of stopover sites to migrating geese, thereby reducing their use of degrading sites whilst increasing the distance between remaining stopover sites. As the changes in Russian agriculture started in the economically peripheral areas (i.e., the north; Grishchenko and Prins 2016) and spread towards the south (Ioffe and Nefedova 2004), we hypothesize that a coincident progression of stopover site deterioration occurred as a result. We thus expect that in the decades following the break-up of the USSR, greater white-fronted geese forsake stopover sites in a manner predicted by changes in the political ecology of Russia, and therefore shifted utilisation of stopover sites in European Russia to the south.

\section{Materials and Methods}

Sample and materials used

This study focuses on the northern part of European Russia, over which Atlantic greater white-fronted geese migrate on their way from their northwestern European wintering areas to breeding areas in the Russian Arctic. We focussed on their stopover sites, and thus omitted the wintering and breeding sites from the analyses. Due to data availability we restricted the study area to provinces in European Russia (Table 5.1 and Figure 5.1), excluding Nenets Autonomous Okrug province, as this province is located in the tundra zone and contains (putatively) breeding sites of the Atlantic greater white-fronted goose.

Table 5.1. List of Provinces in European Russia from which goose data were retrieved. Total number of recoveries for each province is reported. 


\begin{tabular}{|c|c|c|c|c|}
\hline Province & $\begin{array}{l}\text { Federal } \\
\text { District }\end{array}$ & $\begin{array}{l}\text { Number of } \\
\text { recoveries }\end{array}$ & Capital & Area, $\mathbf{k m}^{2}$ \\
\hline Belgorod Oblast & Central & 35 & Belgorod & 27,000 \\
\hline Bryansk Oblast & Central & 12 & Bryansk & 35,000 \\
\hline Vladimir Oblast & Central & 26 & Vladimir & 29,000 \\
\hline Voronezh Oblast & Central & 13 & Voronezh & 52,000 \\
\hline Ivanovo Oblast & Central & 39 & Ivanovo & 21,000 \\
\hline Kaluga Oblast & Central & 9 & Kaluga & 30,000 \\
\hline Kostroma Oblast & Central & 1159 & Kostroma & 60,000 \\
\hline Kursk Oblast & Central & 13 & Kursk & 30,000 \\
\hline Lipetsk Oblast & Central & 22 & Lipetsk & 24,000 \\
\hline Moscow Oblast & Central & 95 & Moscow & 44,000 \\
\hline Oryol Oblast & Central & 5 & Oryol & 25,000 \\
\hline Ryazan Oblast & Central & 166 & Ryazan & 40,000 \\
\hline Smolensk Oblast & Central & 13 & Smolensk & 50,000 \\
\hline Tambov Oblast & Central & 22 & Tambov & 34,000 \\
\hline Tver Oblast & Central & 93 & Tver & 84,000 \\
\hline Tula Oblast & Central & 26 & Tula & 26,000 \\
\hline Yaroslavl Oblast & Central & 100 & Yaroslavl & 36,000 \\
\hline Republic of Karelia & Northwestern & 572 & Petrozavodsk & 181,000 \\
\hline Republic of Komi & Northwestern & 45 & Syktyvkar & 417,000 \\
\hline Arkhangelsk Oblast & Northwestern & 383 & Arkhangelsk & 590,000 \\
\hline Vologda Oblast & Northwestern & 117 & Vologda & 145,000 \\
\hline Kaliningrad Oblast & Northwestern & 21 & Kaliningrad & 15,000 \\
\hline Leningrad Oblast & Northwestern & 70 & Saint Petersburg & 84,000 \\
\hline Murmansk Oblast & Northwestern & 12 & Murmansk & 145,000 \\
\hline Novgorod Oblast & Northwestern & 93 & Veliky Novgorod & 55,000 \\
\hline Pskov Oblast & Northwestern & 24 & Pskov & 55,000 \\
\hline Perm Krai & Volga & 2 & Perm & 160,000 \\
\hline Republic of Bashkortostan & Volga & 2 & Ufa & 143,000 \\
\hline Republic of Mary El & Volga & 9 & Joshkar-Ola & 23,000 \\
\hline Republic of Mordovia & Volga & 15 & Saransk & 26,000 \\
\hline Republic of Tatarstan & Volga & 22 & Kazan & 68,000 \\
\hline Republic of Udmurtiya & Volga & 7 & Izhevsk & 42,000 \\
\hline Chuvash Republic & Volga & 6 & Cheboksary & 18,000 \\
\hline Kirov Oblast & Volga & 47 & Kirov & 120,000 \\
\hline Nizhny Novgorod Oblast & Volga & 37 & Nizhny Novgorod & 77,000 \\
\hline Orenburg Oblast & Volga & 6 & Orenburg & 124,000 \\
\hline Penza Oblast & Volga & 9 & Penza & 43,000 \\
\hline Samara Oblast & Volga & 8 & Samara & 54,000 \\
\hline Saratov Oblast & Volga & 9 & Saratov & 101,0000 \\
\hline Ulyanovsk Oblast & Volga & 7 & Ulyanovsk & 37,000 \\
\hline Krasnodar & Southern & 4 & Krasnodar & 75,000 \\
\hline Astrakhan & Southern & 1 & Astrakhan & 49,000 \\
\hline Volgograd & Southern & 9 & Volgograd & 113,000 \\
\hline \multirow[t]{2}{*}{ Stavropol Krai } & North & 1 & Stavropol & 66,000 \\
\hline & Caucasus & & & \\
\hline Total: 45 & 5 & 3386 & 45 & $3,673,000$ \\
\hline
\end{tabular}




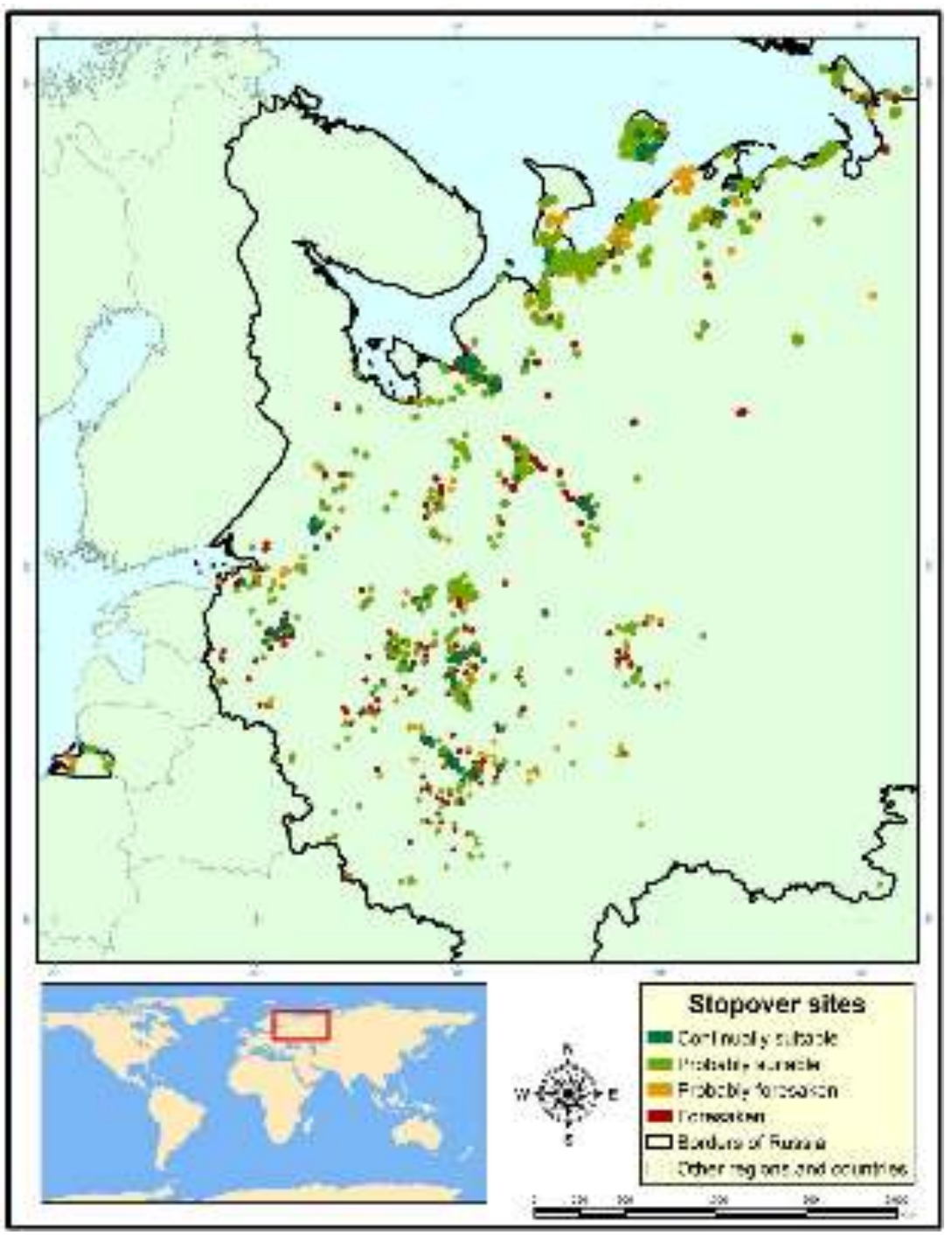

Figure 5.1. Stopover sites for migrant Atlantic greater white-fronted geese 1990 - 2013, identified using recoveries of metal rings from shot birds, and sightings of birds with neck collars (Data courtesy B.S. Ebbinge).

We set out to identify the locations of stopover sites from information contained in two datasets: (1) the geographical location at which geese, ringed in the Netherlands during 1960 - 2013, were shot in the study area. In Russia 
geese are hunted using shotguns loaded with pellets, which are lethal only at short distances (Noer et al. 2007). Kills are thus made close to or at stopover sites. The metal ring numbers of shot birds were reported to Vogeltrekstation Nederland. (2) Visual observations of geese with coloured, numbered neck collars fitted in the Netherlands ( $95 \%$ ) or northwest Germany (5\%) between 1990 - 2013. The locations of these geese in Russia sighted by volunteer observers were reported via geese.org (accessed on 25-10-2016).

Both metal ring and neck collar data were sourced through www.geese.org, a joint initiative of Alterra, SOVON and NIOO (data courtesy B.S. Ebbinge). Each record had goose ID, geographical coordinates of ringing site and recovery sites, date and time of ringing, date and time of recovery. The recovery of an individual metal ring is unique to a single goose. However, individual neck collars could potentially contribute many records. For these data we only analysed the location of the first observation of an individual in each year; subsequent observations were included only if located at least $7.5 \mathrm{~km}$ distant from the previous record in that year. This threshold was determined by analysing the spatial distribution of nearest-neighbour distances between all stopover sites known prior to this analysis. The distribution of distances between nearest stopover sites greater white-fronted geese is depicted on Figure 5.2.

Sample sizes are summarized in Table 5.2. Totals of 901 metal rings and 2,075 neck collar sightings were retained after removing 410 duplicate records. These records ( $n=2,976$ ) were divided into three time periods, chosen to reflect major changes in the economy and land use of European Russia (Chapter 2). These are "period 1" (1960 - 1991), "period 2" (1992 - 2000), and "period 3" (2001 - 2013).

Table 5.2. Number of metal ring and neck collars reported from European Russia for Atlantic greater white-fronted geese in three periods: period 1, 1960 - 1991, period 2, 1992 - 2000, and period 3, $2001-2013$.

\begin{tabular}{lllll}
\hline & $\begin{array}{l}\text { Metal } \\
\text { rings }\end{array}$ & $\begin{array}{l}\text { Neck } \\
\text { collars }\end{array}$ & Total & $\begin{array}{l}\text { Number of } \\
\text { polygons }\end{array}$ \\
\hline Period 1 & 319 & 47 & 366 & 200 \\
Period 2 & 212 & 169 & 381 & 158 \\
Period 3 & 370 & 1859 & 2229 & 295 \\
\hline
\end{tabular}




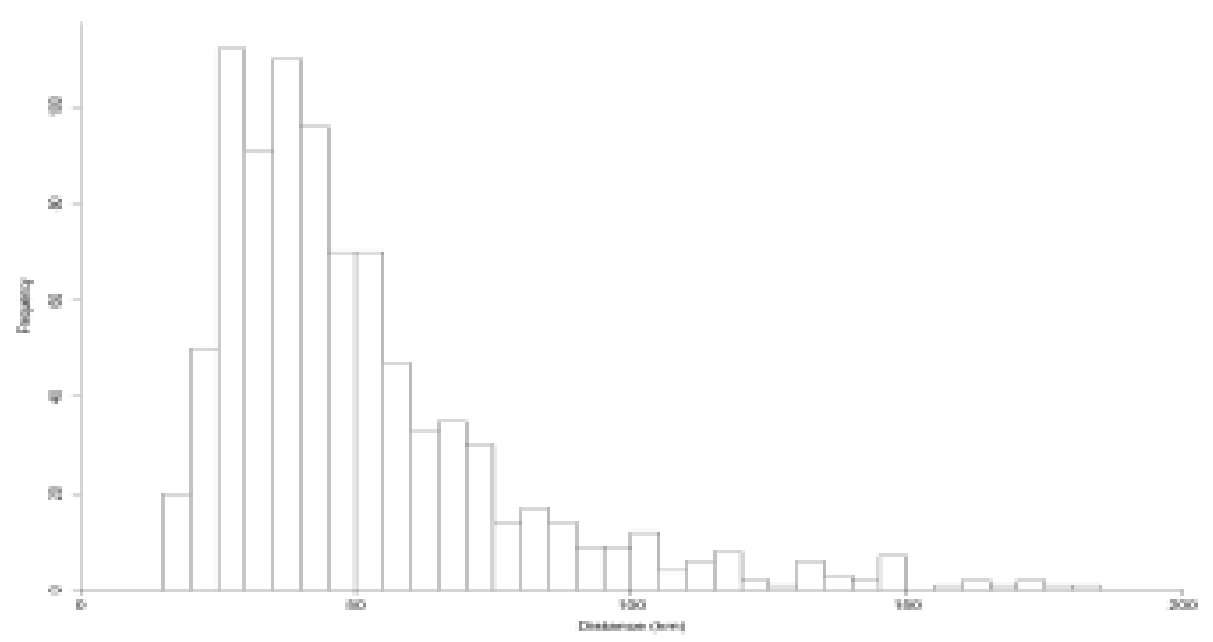

Figure 5.2. Distance between nearest-neighbour stopover sites of Atlantic greater whitefronted Geese in European Russia 1990 - 2013, based on recoveries of metal rings from shot birds, and sightings of birds with neck collars.

\section{Spatial analysis}

The spatial location of stopover sites was identified by first calculating a kernel density estimator (KDE) grid for recovery locations. Equal weight was assigned to each recovery, although a few individuals had several entries in the data. Based on the output KDE surface, the centre of a grid cell was scored as a stopover site centroid if the grid cell's KDE value was equal to the maximum value in its $5 * 5$ grid-cell neighbourhood centred on the focal site (equalling a neighbourhood that extends $5 \mathrm{~km}$ in each direction).

To delineate the area corresponding to each stopover site, we partitioned the space using a Voronoi tessellation based on the stopover site centroids (Du et al. 1999). Large polygons represent stopover sites with low stopover site density, whereas small polygons are found in areas with a high density of stopover sites. The KDE value for each stopover site represents the number of recoveries associated to it. We calculated the area of each polygon, relative to the mean polygon size for that period in order to account for differences in stopover site density caused by various number of collected recoveries between three study periods (ESRI ArcGIS 10.5). We used the inverse of relative area as 
a proxy for the relative spatial density of stopover sites, which we related to the land abandonment spatial gradient using regression analysis.

The regression analysis examined the relative density of stopover sites (a measure of the amount of stopover use) in relation to latitude, for each period (i.e., phases in time before and after the dissolution of the Soviet Union), while accounting for the effects of distance to the nearest settlement or the nearest waterbody. We performed this analysis to study the change in effect of latitude over the three time periods, in order to test our hypothesis regarding the effect of the north-southward gradient in land abandonment. We thus included the interaction between period (treated as a factor variable; p1, p2, p3) and latitude into the regression. We also included distance to water and distance to main human settlement in the model, because it is known that stopover sites are generally located close to appropriate water sources, and in areas modified by agriculture, thus close to main human settlements. By including distance to water and human settlements, we accounted for the confounding in latitudinal pattern generated by the spatial patterns of water bodies and agriculture. Both distances to water and to settlements were log-transformed to better fit the assumptions of regression analysis. We included latitude into the model using a linear term as well as a squared term, in order to allow for non-linearity in the response of stopover site density to the latitudinal gradient. We performed all regression analyses in $\mathrm{R}$ Studio ( $\mathrm{R}$ version 3.3.2, R Core Team 2016).

\section{Results}

The KDE analysis yielded a total of 300 stopover sites in European Russia (Figure 5.3). These stopover sites were assigned to Voronoi tessellation polygons for each period, which resulted in 200 polygons in period 1, 158 polygons in period 2 and 295 polygons in period 3 (Figure 5.4). Statistics for the regression analysis are summarized in Table 5.3. The overall regression was significant (Table 5.3; $\mathrm{F}_{6,646}=24.99, \mathrm{p}<0.001$, adjusted $\left.\mathrm{r}^{2}=0.18\right)$. The squared latitude term was highly significant, with the negative coefficient indicating that relative density of stopover sites declined toward both north and south with highest densities at mid-latitudes. Mid-latitude densities were not very high due to external factors 
(scale of agriculture, abundance of water and cities), whereas to the southeast densities increased again, both in space and over time. The effect of distance to the nearest settlement was not significant, but the effect of distance to the nearest waterbody was negative, indicating that the nearby presence of a waterbody increased the relative density of stopover sites. Regression coefficients for both interaction terms (latitude by period) were negative, with the period three (2001 - 2013) interaction larger and significant. These interaction terms suggest a southward shift in the density of stopover sites from period 1 through period 3 (from 1960 through 2013), depicted in Figure 5.5. The predicted relative density for all three periods intersect at a latitude of about $58^{\circ} \mathrm{N}$, , where the majority of metal rings and neck collars were recovered, and, hence, the relative density of stopover sites is highest. The shift was most pronounced in period three (Figure 5.5). This shift supports our prediction, that the increasing abandonment of agricultural lands in the northern parts of European Russia causes the loss of suitable stopover sites as forests reestablish, and a consequent southward shift of goose migration routes.

Table 5.3. Multiple regression analysis $\left(F_{6,646}=24.99, p<0.001\right.$, adjusted $\left.r^{2}=0.18\right)$ with the relative density of stopover sites as response variable and as predictors: latitude, distance to settlement, distance to water, and the interaction of latitude and period. Latitude included in the analysis is mean latitude around $58^{\circ} \mathrm{N}$. To remove correlation between the linear and squared term for the predictor latitude, we centred the predictor to zero mean.

\begin{tabular}{lrrr}
\hline Factor & b & \multicolumn{1}{l}{ SE } & p-value \\
\hline Latitude & -0.0115 & 0.0178 & N.S. \\
Latitude $^{2}$ & $\mathbf{- 0 . 0 1 8 5}$ & $\mathbf{0 . 0 0 2 0}$ & $<\mathbf{0 . 0 0 1}$ \\
In distance to settlement & -0.0644 & 0.0699 & N.S. \\
In distance to water & $\mathbf{- 0 . 1 3 5 9}$ & $\mathbf{0 . 0 4 2 5}$ & $<\mathbf{0 . 0 1}$ \\
Latitude: $1991-2000$ & -0.0158 & 0.0275 & N.S. \\
Latitude: $\mathbf{2 0 0 1}-\mathbf{2 0 1 3}$ & $\mathbf{- 0 . 0 7 4 2}$ & $\mathbf{0 . 0 2 3 7}$ & $<\mathbf{0 . 0 1}$ \\
\hline
\end{tabular}




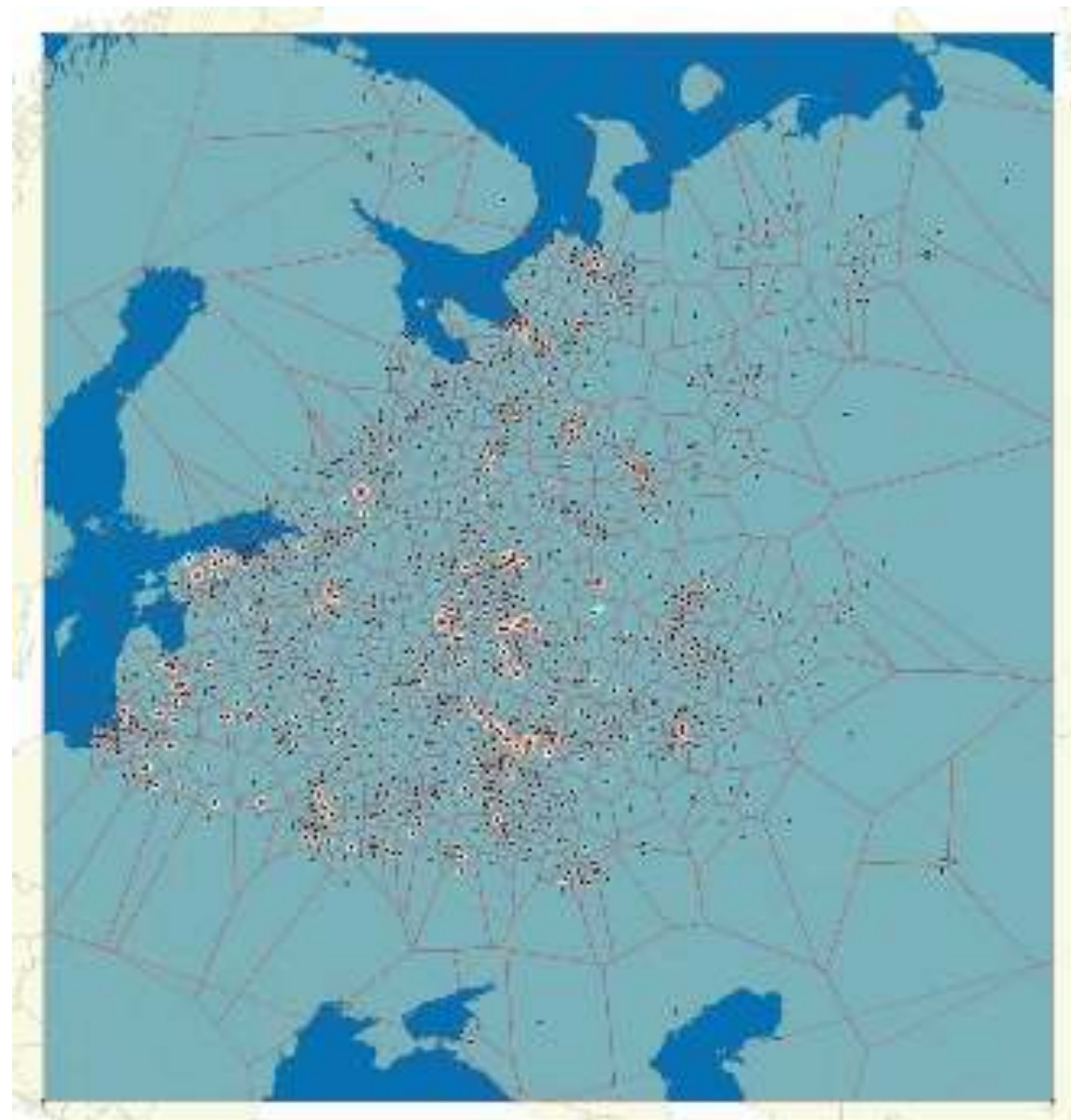

Figure 5.3. Stopover site partitioning for Period 1 (1960 - 1990) overlaid with a kernel density estimator of stopover sites. Large polygons were clipped within the study area extent to account for boundary effects. 


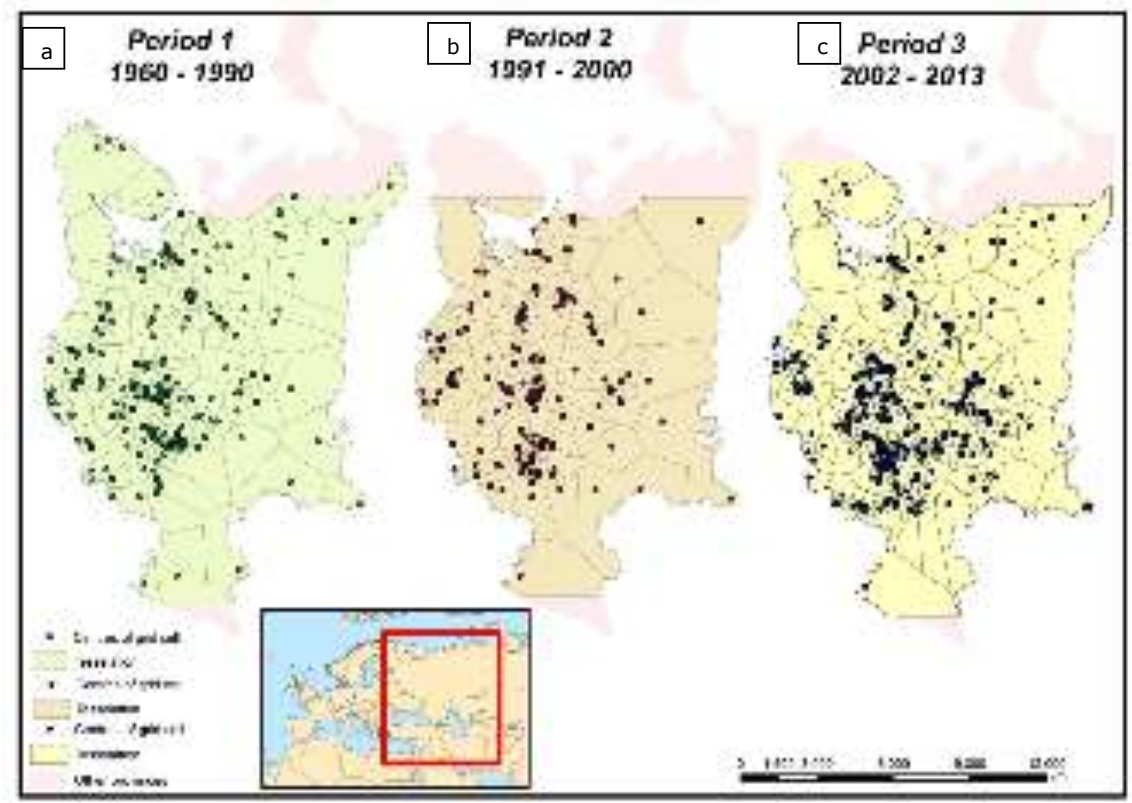

Figure 5.4. Space tessellation of the study area during three observational periods (a. Period one (1960 - 1990); b. Period two (1991 - 2000); c. Period three (2001 - 2013)).

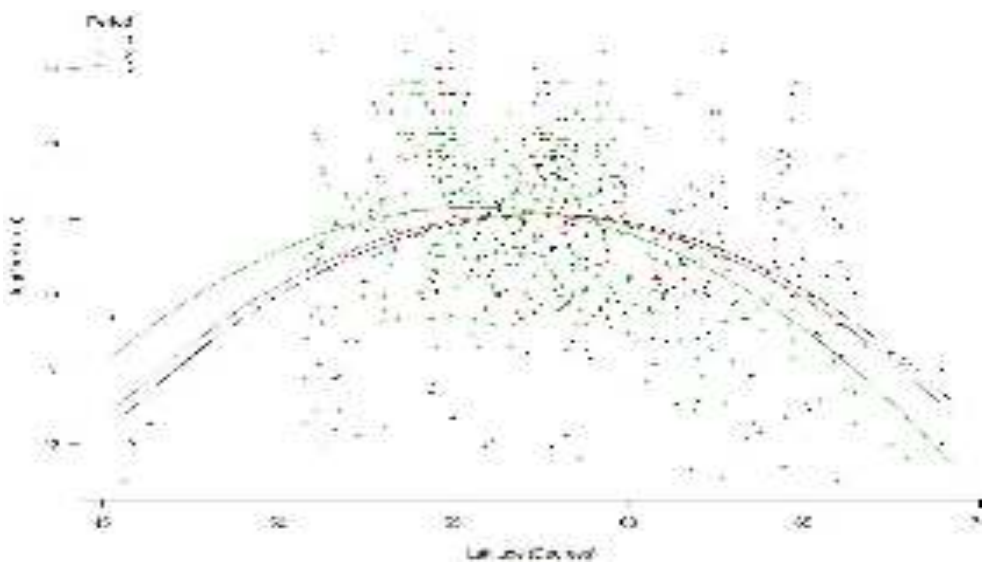

Figure 5.5. Relative density change in the observed and predicted (inverse lines) log relative density of stopover sites as a function of latitude during three observational periods (Period 1 : black, 1960 - 1990); Period 2: red, 1991 - 2000); Period 3: green, 2001 - 2013)). 


\section{Discussion}

The results suggest that after the break-up of the USSR in 1991 migrating greater white-fronted geese shifted their use of stopover sites utilisation in European Russia towards the south. The analysis shows that migrating geese started to abandon stopover sites in the north, and instead start to make use of new stopover sites in the south. This trend began already in the 1990s but strengthened after 2000 as changes in agricultural land use spread through the landscape. Despite the increased numbers of metal- and neck-ring recoveries in successive periods (Table 5.2), the number of stopover sites located by our analysis remained between 200 and 300 . The highest densities of stopover sites were found within a short flying distance from waterbodies and in the proximity of settlements.

Already in the first decade following the break-up of the USSR the area of stopover sites has decreased thus indicating higher density of stopover sites (Figure 5.5). The analysis shows that the relative density of stopover sites has been shifting towards the south since the early 1990s. Our results show a decrease in relative area of stopover sites in the south and an increased in relative area size in the north, the inverse of which thus holds for the latitudinal gradient in spatial density of stopover sites. Our analysis suggests that this shift became significant in the early 2000s when a large number of stopover sites in the north became unsuitable. The most likely explanation of the southward shift in migration is changes in agricultural practices in European Russia (Chapter 2), thereby creating a time lag in geese response to land abandonment. After the break-up of the USSR agriculture was under stress for almost 30 years, resulting in cessation of many agricultural activities and wide-spread field abandonment (Prishchepov et al. 2013). This abandonment started in the economic periphery of Russia, mainly in the north, and spread gradually towards the Central Russia (Ioffe and Nefedova 2004). However, abandoned fields need some time to evolve into old fields that are not suitable for migrating geese for staging (Grishchenko and Prins 2016). This old-field succession is a gradual process at some fields around 15 years and longer. However the succession already reduces attractiveness of stopover site after three years since abandonment 
(pers. obs.). This old-field succession will limit food supply and diminish its quality along the migration route (Drent et al. 2006). As geese ascertain that more and more stopover sites become unsuitable, they are forced to use other stopover sites, including sites that they used only marginally before. These new stopover sites can only be found in the south of Russia where agriculture is more profitable than in the North and where farmers cultivate crops that geese can make use of (e.g., winter wheat, potatoes, sugar beets). This would make a formerly marginal stopover site into a viable substitute to abandoned sites in central and northwestern Russia.

Alternatively, geese can use a migration route similar to barnacle geese and stage in the Baltic states or Finland where agriculture enjoys more favourable conditions due to EU subsidies (Strijker 2005; Whitfield 2006). However, the foraging base along this route is more limited compared to the south of Russia, where agriculture is profitable and widespread. This shift could stimulate the geese to use the south for migration instead of the Baltics (Eichhorn et al. 2009).

An alternative explanation for the observed shift could perhaps lie in a hunting pressure in the North of Russia. Greater white-fronted goose is a game species in Russia, where $10 \%$ to $30 \%$ of the entire population is being shot annually (Kokko et al. 1998; B.S. Ebbinge pers. comm.). If geese are hunted, their response can be to minimise disturbance and find safer stopover sites (Fox and Madsen 1997). These safer stopover sites can be found in the vicinity of protected areas, e.g., important bird areas (IBA), or in areas or countries where hunting is not permitted, at least during the migration season (as shown by Pink-footed Geese Anser brachyrhynchus which move back to Belgium in spring when the hunting is opened further north, Eckhart Kuijken pers. comm.) However, most hunters in Russia live in areas with high human population density, i.e. in the south and in the centre around Moscow (Ioffe and Nefedova 2004; Braden 2014). Therefore, geese should have shifted their migration to the north, and not to the south, if they had responded to increased hunting pressure. 
Another possible explanation of the shift towards the south, we can only speculate about, is the response of geese to increased number of big birds of prey, e.g. White-tailed eagle (Haliaeetus albicilla). Research of migration and spring staging of barnacle geese that winter in the Netherlands suggest a link between their migration timing and presence of eagles (Jonker et al. 2010; Marinde Out pers. comm.). In recent decades, the numbers of eagles have dramatically increased throughout Europe, especially along the Baltic Sea, which poses a potential danger of predation at stopover sites (Jonker et al. 2010). However, with scarce data on both geese and eagle migration over European Russia it is hard to test this hypothesis. Moreover, because of the decreasing industrial activities along the major rivers in Russia we observed large numbers of White-tailed eagles along the southern range of the greater white-fronted geese migration network (pers. obs.).

Climate change could explain the shift in goose migration and bird migration in general. Enough evidence suggests that average mean temperatures have been increasing in the past 100 years, especially in the subpolar areas where the majority of geese breeds (Bauer et al. 2008; Fox et al. 2010). This temperature increase is believed to lead to changes in the carbon balance and stimulates tree growth. This growth could results in a northernly shift of the tree line while former tree-covered areas would be replaced by more open landscapes, e.g. steppes. Hence, climate change is expected to contribute to a shift in goose migration in a northern direction where more and more land will become available for them. Yet we conclude that the effect of land abandonment and increasing tree cover overrides any climatic change signal in the data on greater white-fronted geese in Russia. From our analysis we conclude that migrating greater white-fronted geese are abandoning their stopover sites in the north and are establishing new stopover sites in the south as a response to shifting agricultural activities since the break-up of the USSR. 


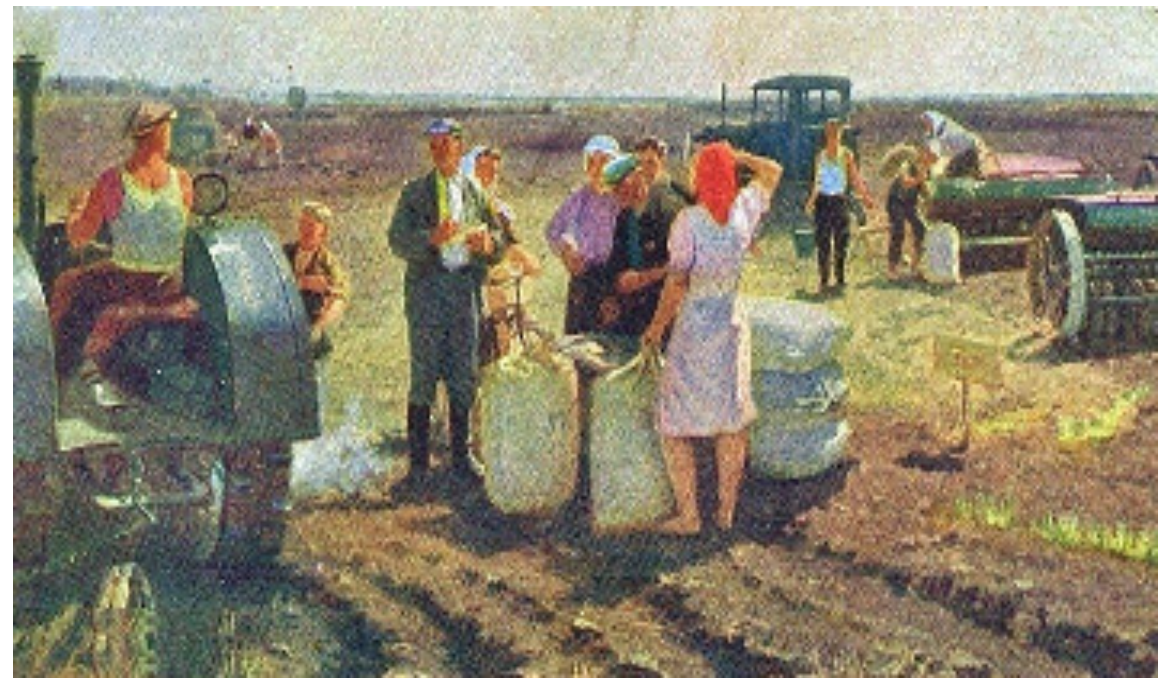

I. Penteshin "Sowing" (1953) / И. Пентешин "Сев". 


\section{Chapter 6}

\section{Synthesis: greater white-fronted geese in the Anthropocene}

Where did geese migrate from before the Modern Era?

The waterfowl (Anseriformes) is an ancient group of birds. Within that group, true geese are among the oldest, dating back to the Miocene (Gonzalez et al. 2009). Within the group of geese, there are two major genera, namely Branta and Anser, which split during the Miocene around 3.5 million years ago (Ottenburghs et al. 2016). My thesis focuses on the genus Anser, and especially on the greater white-fronted goose Anser albifrons, which split from other Anser species around 2.4 million years ago (Ottenburghs et al. 2016) and, thus, has been in existence as chronospecies for the whole of this period, encompassing the Pliocene, the Pleistocene, and the Holocene. This implies that this species, like so many other, has dealt with many environmental changes over the long duration of its existence: the current climate change most likely falls completely within the amplitude of change it has been adapted to.

The last million years or so (the Quaternary period) have been characterised by alternations between glacial and interglacial periods. The exact number of these are ill defined, but currently some twenty advances of glaciers form the north into Eurasia have been recognised (Svendsen et al. 2004; Ehlers \& Gibbard 2007). During major glaciations, such as the penultimate (called 'Dnepr' in Russian, 'Würm' in European, and 'Illinois' in North American literature), most of the current breeding range of the greater white-fronted goose, except for the Siberian Far East, was under hundreds if not thousands of meters of ice in both Eurasia and North America. Also during the last hyper-arid and cold period (about 30,000 years ago) the breeding range of this species, as those of many other waterfowl that currently breed in the Arctic, must have been much further south due to glaciation. Most likely the breeding range then encompassed a vegetation type that is called "tundra steppe" (Prins 1998) or "mammoth steppe" (Guthrie 1982). Paleontologically much is known about the large mammal species occurring in the tundra steppe (Prins 1998; Zimov et al. 2012), but little is known about its birds (Walker et al. 2001; Guthrie 2013). The vegetation type disappeared with changing climate during the Holocene; 
perhaps the last place where it occurred was on Wrangel Island in northeastern Siberia, which was also the place where the last mammoths lived until about 4000 BCE (Zimov 2005). Not much is known about the distribution of birds during the end of the Pleistocene, although the work by Paul Wenink (Wenink \& Baker 1996) on the genetics of waders may throw light on the occurrence of Pleistocene refugia for waterfowl and waders.

At the beginning of the Holocene, forest regeneration took place over most of North America (Gajewski et al. 1993), Europe (Mitchell 2005) and Siberia (Kleinen et al. 2011). The tundra steppe disappeared, and was largely replaced, via a number of intermediate stages, by either broad-leaved forest in the West or with taiga in the North East. Apparently little opportunity for breeding greater white-fronted geese remained, because at the onset of the scientific period there are no breeding records for this species from the European temperate zone (Johan Mooij pers. comm.), but there are records from the Russian and Canadian Far North (Georgi 1775, Pallas 1831, Middendorff 1869). This begs the question why these geese started breeding in these modern Arctic tundra: was it because it was the best place in terms of breeding success, as was suggested by e.g. Drent (Drent \& Daan 1980, Dent et al. 2007), or was it because of too high hunting pressure further south (Ebbinge 1991; Madsen 1999). A problem with this type of ecological questions is that they cannot be answered with certainty, simply because the events took place in the past. We do know, however, that very recently both barnacle geese Branta leucopsis and greater white-fronted geese started breeding in the Netherlands and adjacent Germany. Recent estimate in 2012 showed that these numbers stand at 25,500 (Sovon 2012a) and 2350 pairs (Sovon 2018b), respectively (Sovon 2018b). It appears that from a fitness perspective there is little difference between individuals breeding in the Arctic tundra or those in Western Europe (Jonker 2012, van der Jeugd 2017). This makes it likely that these species could have maintained breeding colonies in the zone that formerly was covered by steppe tundra (Figure 6.1) if sufficient high quality grasslands and safe sleeping places would have remained available, instead of having been taken over by forests and people. In other words, I maintain as central tenet for my thinking that White-fronted geese must be highly adaptable to changing land cover: if good 
sites, which offer the right type of food (i.e., highly digestible grass) and safe places where foxes and other predators cannot catch them, are available, greater white-fronted geese can thrive. From this I deduced that this species is a very good indicator species for land use changes induced by man, and thus a species that is sensitive to the Anthropocene (Crutzen 2002).
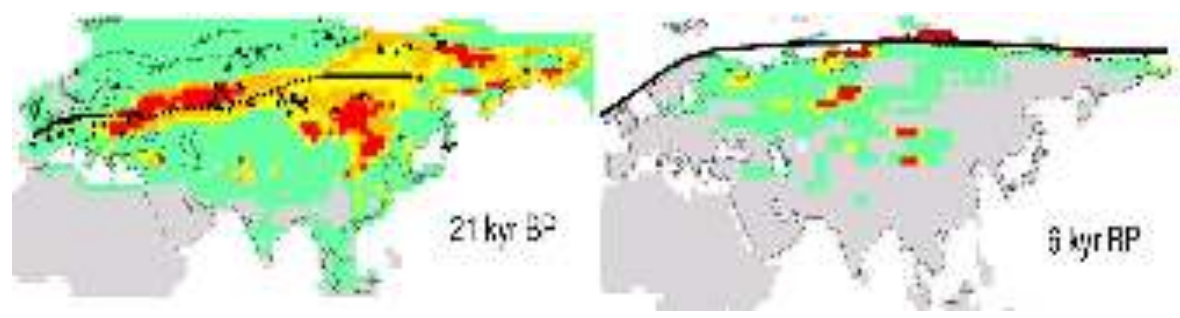

Figure 6.1. Extent of steppe tundra (green) in Eurasia 6000 to 21,000 years before present (adopted from Nogués-Bravo et al. 2008). Colour-scale classes indicate projected climate suitability for woolly mammoth (Mammuthus primigenius).

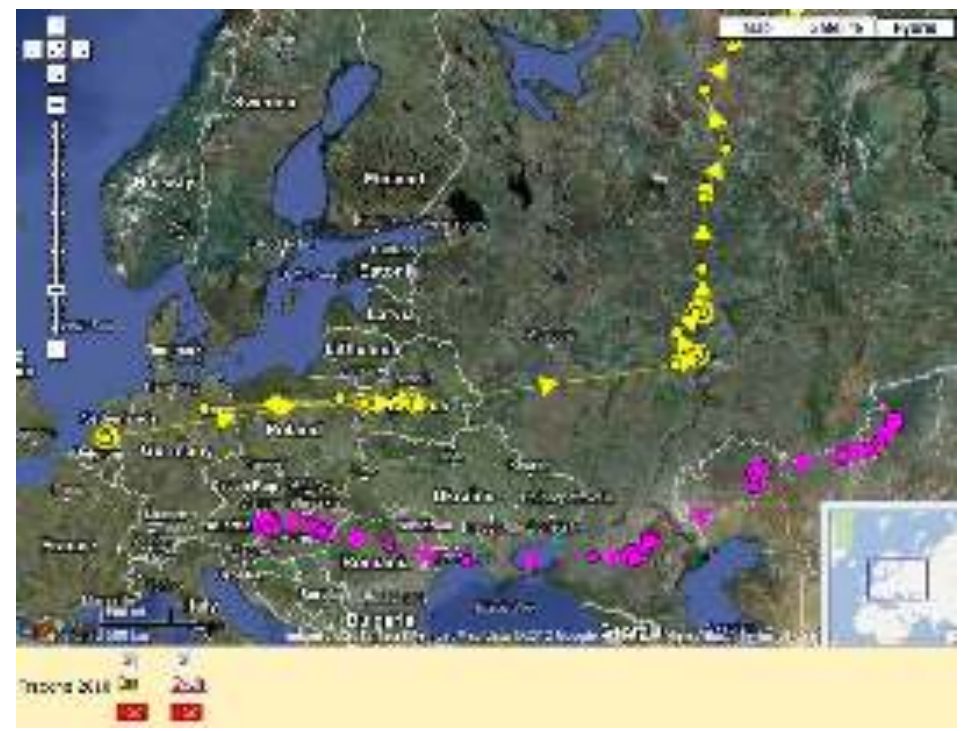

Figure 6.2. Satellite tracking of greater white-fronted geese individuals: Cas (yellow) and Gyula (pink), Blessgans, 2010. Note that Dutch (the origin of the trajectory of 'Cas') and Hungarian geese (where 'Gyula' left from) and the Netherlands show quite extensive exchange in winter. 
Presently, the 'normal' pattern is, still, that nearly all 1.3 million-odd Eurasian greater white-fronted geese migrate between the tundra of northern Russia and Western Europe (Fox et al. 2010); in addition a small group migrates between northern Russia and China (Si et al. 2015, Zhang et al. 2016). My work only concentrated on the East Atlantic Flyway, thus on the migration between Russia and Western Europe. Other migration patterns exist, or have existed. Currently, greater white-fronted geese also migrate from the north to Kazakhstan and from there to Hungary, and further to the Netherlands again (Figure 6.2). Greater white-fronted geese have been reported from along the Tigris and Euphrates in Iraq (Cramp \& Brooks 1992), and even from central Iran (pers. comm. Herbert Prins). Paintings of greater white-fronted geese and redbreasted goose Branta ruficolis in Pharaoh-era tombs in Egypt (from around 2500 BCE) (Alison 1978) may be perhaps taken as evidence of a migration route that does not exist anymore. This hints at the possibility that migration routes and flyways are not cast in stone but are dynamic. Of other geese species likewise evidence is available: many barnacle geese shortened their migration considerably by starting breeding (Figure 6.2) on Gotland and later Oland (Sweden) instead of going all the way to Novaya Zemlya (Larsson \& van der Jeugd 1997, van der Jeugd 2013), or gave up migration altogether and stayed in the Netherland (Jonker et al. 2011). Red-breasted geese recently transferred their wintering grounds from Azerbaijan to Bulgaria (Hunter \& Black 1996, Sultanov 2008). There is even tantalizing information that Snow geese Anser caerulescens that now breed on Wrangel Island and the coastal tundra of East Siberia and mirgrate via the Bering Strait and Alaska towards California, may have been wintering in Germany in the $16^{\text {th }}$ or $17^{\text {th }}$ Century CE (pers. comm. Johan Mooij). I do not know when greater white-fronted geese started breeding in the Russian Arctic tundra, but the present locations cannot have been used before about $5000 \mathrm{BCE}$, because the kilometres-thick ice sheet only disappeared around that time (Velichko et al. 1997, Zimov 2005). In Europe this was the Atlantic Period ( 8000 to $4000 \mathrm{BP}$ ) and the forest cover was at its maximum extent (Peterken 1993, Velichko et al. 1997, Prins 1998).

So, it is quite impossible to talk of the 'original breeding habitat' of greater white-fronted geese in Eurasia (and by the same token in North America). From 
the geological history it can be deduced that during the last glacial periods they cannot have been breeding in an Arctic tundra in West Asia, simply because Arctic tundra did not exist there at that time. So they may have been breeding further East in the present-day northern Russian Far East, which was ice-free (Zimov 2005). Or they may have been breeding in present-day Alaska, which was equally ice-free during the peak of the glaciation (Hopkins et al. 2013). Alternatively they may have been breeding further south in the steppe-tundra of Eurasia and North America. When the ice retreated, they may have extended their breeding range into the present-day Arctic tundra that developed on Taymyr peninsula, Kolguyev and Vaygach islands. This tundra cannot be much older than about 9000 years or so (Clayden et al. 1997, Zimov 2005). During the Atlantic Period, also some 7000 years ago the steppe-tundra of Europe disappeared to be replaced by broad-leaved forest (Prins 1998). Even the puszta of present-day Hungary was covered by forest at that time (Peterken 1993). Saltmarshes along the North Sea only developed first around 500 BCE (Zagwijn 1989), to be washed away in the first centuries of our era, and to re-establish about a thousand years ago (Zagwijn 1989). In other words, if greater whitefronted geese were breeding in the western part of the Russian North, it is likely that their wintering grounds were to be found in what is now Kazakhstan (Figure 6.2). The most likely flyway at that time must have been the River $\mathrm{Ob}$ and the Irtysh River, nearly directly connecting the areas in the North with those in the South (pers.obs.). To the East and to the West of this fly way vast forests developed, and favourable stop-over sites were absent from the West.

\section{Stopover sites for migrating geese}

What is a favourable stopover site for greater white-fronted geese? From grazing experiments we know that a goose of the size of a greater white-fronted goose has the highest intake rate when the sward is about seven $\mathrm{cm}$ tall (Heuermann et al. 2011). We also know that the quality of the grass must be high, with low cellulose levels and a crude protein content of some 8 per cent or more (Ydenberg and Prins 1981). Today sites with such grass can be found in heavily managed grasslands where farmers graze their livestock or mow the grass frequently for their livestock (Haynes and Williams 1993: Burke 1998). We also 
know that geese need safe sleeping places where foxes (and nowadays hunters) cannot reach them (or shoot them): these sleeping sites are on open water preferably minimally 20 ha in size (Koffijberg et al. 1997). For Western Europe there is no evidence for naturally occurring open grasslands except above the tree line in the mountains, along the sea coast, and on some salt-domes in the interior (Prins 1998). All other grasslands are man-made. From satellite data I know that the average distance that greater white-fronted geese fly between stopover sites during migration is $480 \mathrm{~km}$ (Kölzsch et al. 2016). From this I conclude that a migration network between the breeding grounds in Russia's North and salt-marshes in the West could only develop when Man started opening the forests in between, since the short grasslands along the Baltic are man-made (Andersen 1995; Prins 1998). So, a critical question for my Synthesis is to answer how Man opened these forests of Western Europe and Russia to create the network of stopover sites that currently occur (Figure 5.3).

The Neolithic, by definition, describes the period of cultural development during which agriculture started. There was a "wave of advance" of arable agriculture and associated livestock originating in the Zagros Mountains (on the border between present-day Iran and Iraq; around 8000 BCE), via Turkey and the Balkan towards northwestern Europe. The earliest agriculture, with cereals as emmer and einkorn, was conducted in the loess zone stretching from the Balkan towards to most southeastern part of the Netherlands (Sherratt 1990). This early form of arable agriculture was conducted in burnt forest, and because ploughs or iron axes did not exist, the type of forest that was converted was birch-oak forest (Prins 1998; Thorpe 1999; Jones et al. 2012). It did not yield any sort of new staging grounds for greater white-fronted geese. A similar wave of advance of the Neolithic took place in what is now Russia, and it also emanated from Turkey (Pinhasi et al. 2005). An important point arising from the archaeological record is that the steppe zone was not taken into cultivation during the Neolithic (Murphy et al. 2013) or even Bronze and Iron Ages (Frachetti et al. 2010, Murphy et al. 2013), beginning 10,200 BCE, 3300 BCE and 1200 BCE respectively. 
The emergence of the Anthropocene

From "the goose point of view" major changes take place only with the invention of hay making, the strongly increased need for draught-horses and -oxen, and the invention of the modern mouldboard plough that enabled soil inverting to bring nutrients to the surface, while iron axes became widely available for agricultural use. In Western Europe that was around 1300 CE (Prins 1998; Lal et al. 2007; Andersen et al. 2016). From that time onwards, more and more forest on heavy soils could be taken into cultivation, and, because of crop rotation, good quality grasslands became available in areas that were previously forest (Prins 1998). In northwestern Europe this was also a period that saltmarshes started forming again after the Carolingian period, but now embankment along the North Sea coast from Flanders until Denmark (Louwe Kooijmans 1980; Zagwijn 1989) led to more-and-more high quality grasslands emerging along the coast too. I posit here that there and then the wintering grounds for greater white-fronted geese (and other goose species) were formed: for geese the Anthropocene started a few centuries before that for other species, and it must have been beneficial!

The history of the landnam in Russia is not fundamentally different from that of Western Europe. Farming had been spreading on light soils in the forest too (see above), but also here technological innovation led to spreading cultivation into the steppe zone around 1400 CE (Sunderland 2006). Most of this was spearheaded by Cossacks (Moon 1997) but the Volga Germans (WolgaDeutscher) were of great importance too (Scheuerman 1980). In the North a city culture sprang up; the first there was the important trading town of Novgorod, but other cities followed suit, such as Pskov and Tver (Figure 6.3). Between $1400 \mathrm{CE}$ and $1600 \mathrm{CE}$ a wave of advance of trading towns spread further and further across the taiga, to reach the White Sea and the Kara Sea in the extreme north. Each town needed its supporting agriculture, not only to feed its people but equally important to feed the horses and cattle that people needed to live. Deforestation to support firewood played a role too. Around 1600 CE I think that the network of stopover sites for migratory geese had been formed. Then the agricultural wave of advance started touching upon the breeding range of the geese in the Arctic tundra (Figure 6.3). It is likely that 
since blunderbusses and other early fire weapons were of little use at close range, human hunting pressure was not much of an issue yet. Man had thus created over the whole of Europe a network of stopover sites where geese could use.

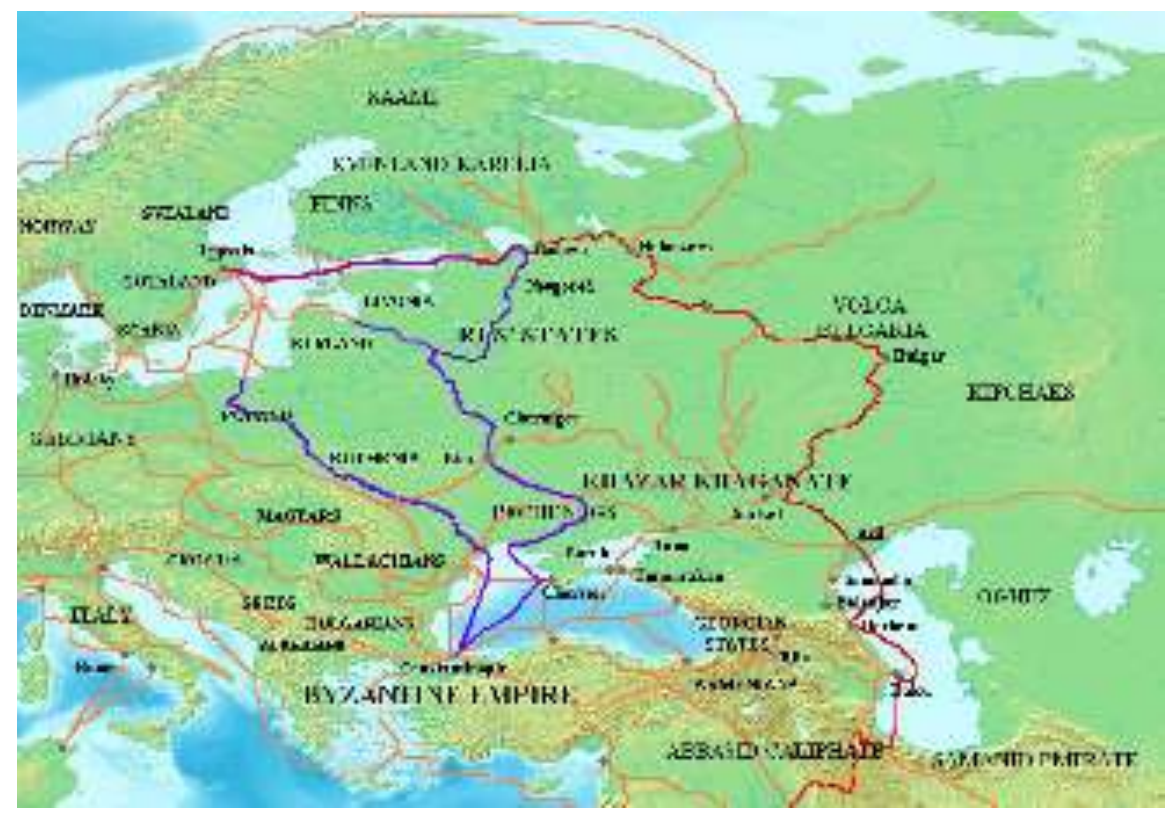

Figure 6.3. Map showing major trade routes in Central, Eastern and Northern Europe in the $8^{\text {th }}-$ $11^{\text {th }}$ centuries. The route from the Varangian's to Byzantium is shown in purple, the Volga trade route is shown in red and all other trade routes are shown in orange. Adopted from the Wikimedia Atlas of the world (Electionworld, 2018) under the Creative Commons Attribution-Share Alike 3.0 Unported License.

The 19th century was perhaps the period of the greatest extent of agriculture in Russia: horsepower was needed everywhere, so the demand for hay, barley and oats must have been enormous. Likewise, the armies of the time needed their cavalry, again augmenting the need for cultivated land that geese could use. In North Russia we have the luck of extremely detailed land use maps of the 1840s till 1860s, which could form the basis of a whole new PhD study. A close comparison of Landsat imagery with these maps (Figure 6.4) illustrates the near-total land conversion of much of Russia's North. 

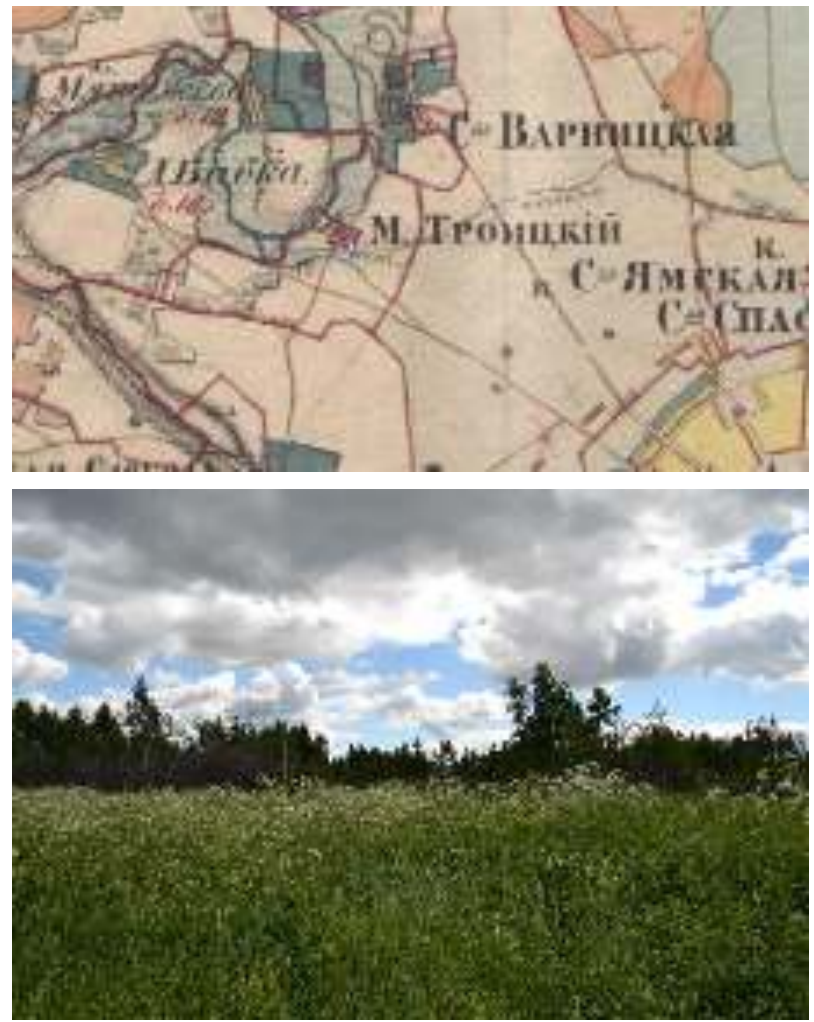

Figure 6.4. Illustration of land abandonment around Rostov (Yaroslavl province): upper image a Mende topographic map of the area in 1857 (EtoMesto, 2018), lower image - an abandoned field in the area visited in June 2014 (M. Grishchenko).

\section{Land abandonment and old-field succession}

Major land use changes took place in European Russia in the $20^{\text {th }}$ century following a number of historical pivot points. Three revolutions, two world wars, one civil war, unprecedented industrialization of economy, collectivization of agriculture and break-up of the USSR were among major historical events that left their traces in land use and rural economy in Russia. Most profound transformations of landscape in European Russia were caused by the modernization of the economy in the Soviet Period (Ioffe and Nefedova 2004, Ioffe 2005) but others by the devastating effects of the Second World War (the Great Patriotic War). The modernization of the economy in 1930s led to more 
rational agriculture: larger fields, extensive use of machinery and fertilizer. The newly emerging collective agriculture did not need horses for ploughing but relied on tractors (Bobyliov et al. 1984).

The War led to devastating reductions in human population sizes (Ioffe 1991): people and industries were evacuated to Siberia from the oncoming German occupation (Lieberman 1983). Other people were translocated towards the area of the Third Reich where they were used for labour by the conqueror (Spoerer and Fleischhacker 2002), and finally, many surviving people were mauled by the war machineries marching over the lands between Smolensk, Moscow and Kiev. Hundreds of thousands of people abandoned agriculture, and old-field succession led to the reduction of grazing lands over vast territories of European Russia. These negative effects were most pronounced in affected provinces in central and northeastrern parts of European Russia (e.g. Tver, Bryansk, Pskov, Smolensk, Novgorod) where post-war populations never reached their per-war levels (Ioffe 1991).

Extensive travels during my PhD study in 2014 time and again led me to places were blocks of land were now occupied with rather mature forests that showed all evidence of having sprung up between the 1930s and 1950s. Comparing the landcover from before (EtoMesto 2018) that time with the present, however, did not give the impression that this old-field succession of the mid-20th century had led to a major infringement of the migratory network of greater white-fronted geese though, but, again, this could be the whole basis of another PhD study. Indeed, the very fast increase of greater white-fronted geese numbers (Fox et al. 2010) over the last 50 years does not provide reasonable evidence for a collapsing migratory network at that time!

The post-war recovery in European Russia in 1950s - 1960s resulted in major reconstruction of nearly all destroyed factories and fuelled the on-going urbanization (White 2007). Around the same time massive hydrotechnical works, that had begun in 1930s, were completed across European Russia to stabilise water levels in the Volga basin for commercial shipment and irrigation which greatly increased available open water surface for migrating geese. This development along should have greatly improved field accessibility and migration network connectivity for greater white-fronted geese. Already by mid- 
1950 s more than $50 \%$ of population lived in urban areas. Rural areas already depleted by the War were rapidly losing their remaining economically active population (Rowland 1998). We arrived to similar conclusions (Chapter 2) analysing post-war demographic development across European Russia. The state census of 1959 indicated that over $75 \%$ of municipal districts smaller than 100,000 inhabitants had shrinking populations amid increasing total population size of respective provinces. Municipal districts with smallest population numbers and located in peripheral parts of provinces showed the largest declines among all municipalities. This suggests that the decline was unfolding in mostly rural municipalities while cities were growing rapidly absorbing the relocating rural dwellers (Rowland 1998). High population growth was restricted to a few high industrial potential urban areas where the government instigated construction of new enterprises, often serving novel industries (nuclear, petrochemicals, electronics).

By the early 1960s the government realized the severity of the situation in rural areas of the USSR, especially in European Russia, where a large decline in agricultural output should have followed the observed rapid depopulation in rural areas (Ioffe 1991). These developments were eroding the food security of the USSR which was unacceptable during the time of increased tension with the West (the Cuban missile crisis in 1962). Thus, the government designed two large assistance programmes to modernise agriculture (Lewis and Rowland 1979; Johnson and Brooks 1983) and to support new manufacturing facilities in small and mid-sized urban areas. This assistance to agriculture resulted in colossal direct investment (Wegren 1998) in modern infrastructure of collective farms (buildings, equipment, machinery and fertilizer). Staggering land improvement works were conducted to improve water drainage. Large investments were made to build new and upgrade existing rural schools, kindergartens, hospitals and to organize a system of agricultural professional and higher education (colleges, universities) where new agronomists and technologists were taught. After driving across European Russia for 15,000 km I have a vivid memory of this infrastructure, many buildings featured construction year on facades (ranging between 1967 and 1991). 
After the break-up of the USSR in 1991 Russian economy entered a transition period where the former state-planned economy was dismantled and a new market economy was established (Andrienko and Guriev 2004). The government had a hard time to balance the state budget which forced it to cut the subsidies to agriculture by over $90 \%$ (White 2007, Prishchepov et al. 2013). Such drastic change in state policy towards agriculture had an almost immediate effect on agricultural production across European Russia (Wegren 1995; Lerman 1998), but especially in peripheral municipalities (Chapter 2) which were already disadvantaged by dwindling population numbers, lower efficiencies and isolation. This resulted in the total area under cultivation in the North of European Russia dropped by more than $50 \%$, the area under grains decreased by more than $90 \%$. This led to disappearance of grain production (wheat, barley and oat) from nearly all northern municipalities. I discovered that cattle numbers declined by over $80 \%$ in the North of European Russia. My field observations confirm that the cow became a rare animal in European Russia while it is much easier to spot an elk (Alces alces) or even a wolf (Canis lupus). Nearly all farmhouses and silos are slowly falling apart. Counts for goats and sheep showed a five-fold decline (Chapter 2) which was, perhaps, unseen in European history. I had a limited access to other agricultural statistics but descriptive analyses of available datasets on national and provincial levels reveal similar developments (Grishchenko and Prins 2016, Chapter 2). Even though there is no documented evidence of similar downturns in agriculture in Russia and Europe, I posit that such massive land alterations are unprecedented on absolute scale and on a relative scale could be comparable to the Mongol invasion and the Black Death in Europe.

No wonder, these drastic changes in agricultural practices worsened living conditions in rural areas of European Russia which resulted in almost uninterrupted decline of human population numbers in majority of surveyed municipalities (Chapter 2). While municipal districts with 100,000 people and more showed moderate decline, or even sometimes signs of growth, most small ones declined by over $25 \%$ of their 1989 levels (last USSR census). The group of smallest municipalities lost over $50 \%$ of their 1989 -level population (Chapter 2) which is not surprising considering $80-90 \%$ plunge in major agricultural 
activities (Chapter 2). The loss of economy of scale led to increased costs of doing business in agriculture (Heleniak 1997; Wegren 1998) which overlapped with negative impact of temperature (Chapter 2 ) because most of European Russia is classified as a zone of 'risky agricultural activities' (Ioffe et al. 2004). Reforms in agriculture, which aimed to boost its productivity (Wegren 1995), did not meet their targets. On the contrary, this vicious circle of failed restructuring resulted in even lower than in 1970s productivity (Ioffe and Nefedova 2004) and lower food quality (pers. obs.). Up until 2014 a lion's share of food market in Russia was taken with foodstuff imported from the EU and CIS. However recent investments in agriculture and counter-sanctions are stimulating local food production and processing in Russia, and are improving overall productivity of agriculture and food technology (Russian Statistical yearbook 2017).

From supervised landcover classification of selected areas of European Russia around stopover sites (Chapter 4) I could detect a $56 \%$ reduction in arable lands between 1990 and 2014 which is in line with overall reduction in cropland and grain fields (Chapter 2). Along with staggering decline of arable land, grass and forest landcover classes grew by $13 \%$ and $11 \%$, respectively. I interpret these landcover changes as confirmation of old-field development on previously abandoned agricultural fields where grains and grasslands were eventually replaced with shrubs and forest. My observations of vegetation structure and composition during the field season in 2014 led me to the same conclusion (Chapter 3, Chapter 4). I recorded five stages of old-field development within 25 years from active grain field to young forest. Initially abandoned fields were likely to be invaded by herbs, shrubs and tree species from adjacent habitat (Core 1949). Seed dispersal Tiebel et al. 2018 but also soil type, humidity and microstructures seemed to affect development of succession (Odum 1960). Therefore, not all fields left 20-25 years ago were fully covered by forest and forest species on the new growth differed too. It looks like the old field development accelerated after 2002 (Chapter 4) with more abandoned fields to be encroached by thick vegetation in a near future. On basis of this, I conclude that unprecedented land abandonment in European Russia and progressing old-field succession near stopover sites formerly used by 
migrating greater white-fronted geese should diminish habitat suitability at staging sites and increase pressure on the existing migration network.

\section{The now and the future}

My work was focussed on the more recent land use changes in Russia. The underlying thought was that with the economic transition a sweeping reorganisation of the economy followed. This reorganisation also encompassed agriculture, and in nearly the whole of northern European Russia agriculture was halted (Chapter 2). From work of NIOO (van Wijk et al. 2012) and previous PhD students in our group (Heuermann et al. 2011; Si et al. 2011), I could deduce what geese need for accepting particular locations in the landscape as stopover site. I developed this in Chapter 3 where I reported on the development of an automatic classification to map goose stopover sites. The algorithm yielded 1931 stopover sites (as of 2014) where migrating greater white-fronted geese can stop to rest and fatten-up. These geese occupy man-made grasslands and cropland associated with major riverine systems of European Russia. Few stopover sites are located in a vicinity of large lakes, man-made reservoirs (1930s - 1950s) and ponds. When I visited a sample set of stopover sites to validate them, nearly all sites were in active agricultural use ranging from winter wheat to pastures (Chapter 3 ). Not all of them featured migrating greater whitefronted geese but this would not be feasible with poor road condition and exceptionally dry winter, resulting in low levels of water in waterbodies. However, modelled stopover sites match by almost $90 \%$ with recoveries of greater white-fronted geese reported from multiple sources (metal rings, neckbands and GPS tracking). Contrary to the argument that migrating geese would search for protected areas to minimise the hunting pressure (Ebbinge 1991 ), over $30 \%$ of stopover sites were located outside areas designated for bird conservation (Chapter 3 ).

Ring recovery data from geese that were shot, or were observed in the field, show how land use changes described above lead to different patterns of occupancy of migrating geese in Russia (Chapter 5). In three decades of oldfield development greater white-fronted geese choose a more southern migration route giving up their conventional migration routes through Central 
and Northern Russia. Even though land abandonment began in early 1990s (Chapter 2), I saw that migrating geese started to abandon stopover sites only in early 2000s with ever increasing density of recoveries originating from the South of European Russia up until now (Chapter 5). These results are in line with early described sweeping reorganisation of the Russian agriculture (Chapter 2 ), which led to land abandonment where on formerly used cropland an old-field succession took place (Chapter 4). Because these processes develop around stopover sites, my interpretation is that greater white-fronted geese are facing a collapsing migratory network. With more than $80 \%$ of abandoned cropland, of which about $45 \%$ is undergoing a vegetation succession, stopover sites suitable in late 1980s, 1990 s and early 2000 s are being skipped as not suitable anymore. I expect that this number will only increase in the near future when fields abandoned in 2000s and 2010s (Chapter 2, Chapter 4) will become unsuitable too. The collapse of the network appears to be stronger in the north than in the central part of European Russia (Chapter 5).

What will this mean for migrating greater white-fronted geese? My findings suggest that stopover sites used by migrating greater white-fronted geese are witnessing large-scale landcover changes that are politically initiated. Despite a rather optimistic outlook of the Russian agriculture after 20104 (Russian Statistical yearbook 2017), I see little evidence to believe that these trends will prevail in the area to the north of the line Yaroslavl - Moscow Smolensk thus affecting a large area where currently migrating geese have found their staging sites during the last century or so. If I attempt to extrapolate these results, described land use changes might negatively affect foraging quality of stopover sites, which would make them less suitable for migrating geese. This in turn might reduce the total number of available stopover sites and might drive geese to look for alternative habitats in the South of Russia or adjust their migration behaviour. Non-migratory behaviour of some geese species (Jonker 2012; van der Jeugd and Kwak 2017), also the greater whitefronted goose, might imply that they will breed in even greater numbers at their wintering sites (the Netherlands, Germany) than ever recorded. Altering migration might create even more human-wildlife conflicts in some of the most densely populated areas of Europe. 


\section{Management recommendations}

The critical issues is to identify how many sites will be needed to maintain a functioning migratory network in the Anthropocene, and to identify how a minimal configuration of stopover sites network has to look like (Kanai et al. 2002). Future work should shed light on this pressing issue. Hence, I recommend to analyse the modelled stopover sites and to identify those key stopover sites among them which harbour most geese during migration. After that, conservation agencies, local authorities and governments along the flyways should develop a programme to maintain active agriculture at the key stopover sites. Yet I do not discard the incredible adaptability of greater whitefronted geese during the Anthropocene which might create a new migration route: from the Russian Arctic along the Ob and Irtysh (pers. obs. 2015) to Kazakhstan and Kalmykia (pers. comm. Sip van Wieren and Herbert Prins), and thence Hungary (pers. comm. Bart Ebbinge and Marta Ferenczi) towards the Netherlands. Another area for future research is to study the unexpected positive legacies of observed land abandonment. One topic is to study a contribution of wide-spread old-field development in Russia and Eastern Europe to carbon fixation and reduction of carbon dioxide concentration in the atmosphere. I expect that massive growth of trees of shrubs on abandoned cropland will lead to biomass accumulation will greatly contribute to the Russian carbon budget in 2-3 decades to come. Another topic worth researching is ongoing effortless (natural) reforestation and rewilding in European Russia, their stages, constrains and benefits. I believe that understanding of these two phenomena should greatly contribute to heated debates about rewilding Europe (Pereira and Navarro 2015) which seem to completely miss the Russian perspective.

If I am right in my deductions that the migration network of greater whitefronted geese may face a serious onslaught on its functioning because of the overgrowing of stopover sites that geese need when migrating between the Netherlands and the Arctic Russia and back, then one may ask oneself whether mitigation actions are possible. The work of Ducks Unlimited springs to mind: this organisation was set up to protect the migratory geese and ducks that were suffering from overhunting and the collapse of their network due to the Dust 
Bowl Years (the 1930s in the prairie of Canada and the USA) (Bolen 2000). Ducks Unlimited compensates farmers for protecting prairie holes (water points), buys up staging grounds between Mexico and Canada, and carries out land management for the production of goslings and ducklings in the wild. Much of the costs are financed through hunting licenses. An organization like Ducks Unlimited does not exist in Europe but it would be a great way to protect the East Atlantic Flyway. 'Geese Unlimited' would unify people from the Russian Arctic all the way to the North Sea coasts and from these areas even to those in Eastern Europe, and the steppes of Russia, Ukraine and Kazakhstan, in their endeavour to enjoy these geese that formed the subject of my study and to sustainably harvest them. My work led me to appreciate the efforts of ornithologists but also of that of the many unknown hunters in Russia that took the effort to send back ringing data to a, to them unknown, organisation like the Netherlands Vogeltrekstation. My first recommendation is thus to form 'Geese Unlimited', a Eurasian equivalent of Ducks Unlimited!

My second recommendation also follows from my work on land abandonment and old-field succession. Indeed, what geese need are sites in Russia that are well protected against hunting and predators but where the grass is short and nutritious at the time of their passage. In the past this was an unintended side-effect of agriculture and livestock keeping. With the sweeping reorganisation of agriculture in Russia it may become time that bird protection organisations in Western Europe team up with Russian counterparts to adopt some strategically located sites along the migration route for long-term intense management with haymaking, mowing and lightly fertilising. Other species, especially meadows birds (Herzon et al. 2008), such as bar-tailed godwit Limosa limosa and Lapwing Vanellus vanellus may benefit from such measures too. Such measurements may prove to be much more effective than bird protection in Western Europe.

My third recommendation is to dedicate more research studying land use changes and their impact on biodiversity, particularly migration ecology of waterfowl. Up until now most of the research was diverted to climate change and understanding its effects on migration, habitat and population numbers. With all due respect to importance of climate change discourse, I believe that 
its impacts on waterfowl will appear in a long-term, in course of hundreds or even thousands year from now. Moreover, we saw that up until the Anthropocene geese and other waterfowl species were able to cope with drastic changes in climate in the distant and recent past. If our understanding of evolution theory, paleoecology and quaternary studies is correct, waterfowl should be able to cope with climate changes to come. While we are spending time studying the long-lasting effects of climate change, land use changes alter previously suitable habitats and induce drastic changes in population numbers in a matter of years. Countless examples of land use changes with severe impacts for biodiversity include deforestation in Brazil and Indonesia, old-field development in former USSR, critical decline in meadow birds' population in Western Europe. Therefore, I call upon the scientific community to devote their time studying land use changes and their underlying causes, especially looking at socio-economic and political factors which became tremendously important in the Anthropocene.

My fourth recommendation is to keep politics out of the scientific equation. I address a rather new generation of scientists who do not have vivid Cold war. My research project was developed and two fieldworks were conducted amid an unfolding confrontation between Russia and the West. Nevertheless, it was a success because of open attitude and collaborative environment within the scientific community. Migratory birds respect no borders, which is why studies of their migration thrived in the globalized world where openness, cooperation and exchange prevail. Therefore, we should maintain solidarity within the scientific community, promote academic exchange and knowledge transfer despite political circumstances, if we would like to excel in research of birds' migration ecology. 


\section{References}

\section{A}

Aarvak T. and Oien I.J. 2003. Moult and autumn migration of non-breeding Fennoscandian Lesser White-fronted Geese Anser erythropus mapped by satellite telemetry. Bird Conservation International 13 (3): 213 - 226.

Abraham, K. F., Jefferies, R. L., \& Rockwell, R. F. 2005. Goose-induced changes in vegetation and land cover between 1976 and 1997 in an Arctic coastal marsh. Arctic, Antarctic, and Alpine Research 37 (3): 269 - 275.

Ahrend, R. 2005. Can Russia Break the 'Resource Curse'? Eurasian Geography and Economics 46 (8): $584-609$.

Alisauskas, R.T., Rockwell, R.F., Dufour, K.W., Cooch, E.G., Zimmerman, G., Drake, K.L., Leafloor, J.O., Moser, T.J. and Reed, E.T., 2011. Harvest, survival, and abundance of midcontinent lesser snow geese relative to population reduction efforts. Wildlife Monographs 179 (1): 1 - 42.

Alix-Garcia, J., Munteanu, C., Zhao, N., Potapov, P.V., Prishchepov, A.V., Radeloff, V.C., Krylov, A. and Bragina, E. 2016. Drivers of forest cover change in Eastern Europe and European Russia, 1985 - 2012. Land Use Policy 59: 284 - 297.

Andersen, U.V., 1995. Succession and soil development in man-made coastal ecosystems at the Baltic Sea. Nordic Journal of Botany 15 (1): 91 - 104.

Andersen, T.B., Jensen, P.S. and Skovsgaard, C.V., 2016. The heavy plow and the agricultural revolution in Medieval Europe. Journal of Development Economics 118: 133 - 149.

Andrienko, Y., and S. Guriev 2004. Determinants of interregional mobility in Russia. Economics of transition 12 (1): 1 - 27.

Ankney, C. D. 1996. An embarrassment of riches: too many geese. The Journal of wildlife management: 217 - 223.

Arzel C., Elmberg J. \& Guillemain M. 2006. Ecology of spring-migrating Anatidae: a review, Journal of Ornithology 147 (2): 167 - 184.

Avakyan, A. B., and V. A. Sharapov 1970. Reservoirs of hydroelectric stations of the USSR. Hydrotechnical Construction 4 (4): 375-380. Bach, M., Breuer, L., Frede, H. G., Huisman, J. A., Otte, A., \& Waldhardt, R. 2006. Accuracy and congruency of three different digital land-use maps. Landscape and urban planning 78 (4): 289 - 299.

\section{B}

Baveco, J.M., Kleijn, D., de Lange, H.J., Lammertsma, D.R., Voslamber, B. and Melman, T.C., 2013. Populatiemodel voor de Grauwe gans: enkele scenarioberekeningen voor aantalsregulatie (No. 2445). Alterra.

Berka, R., 1990. Inland capture fisheries of the USSR (No. 311). Food \& Agriculture Org.

Best, R.G., Hause, D., Wehde, M. and Fowler, R., 1982. Aerial thermal infrared census of Canada geese in South Dakota. 
Bettencourt, L. M., Lobo, J., Helbing, D., Kühnert, C., and G. B. West 2007. Growth, innovation, scaling, and the pace of life in cities. Proceedings of the National Academy of Sciences 104 (17): 7301 - 7306.

Bezlepkina, I. V., Lansink, A. G., and A. J. Oskam 2005. Effects of subsidies in Russian dairy farming. Agricultural Economics 33 (3): 277 - 288.

Bobyliov I.V., Gopka B.M. and K.B. Svechkin 1984. Konevodstvo, Cosmos Publishing, Moscow.

Bolen, E.G., 2000. Waterfowl management: Yesterday and tomorrow. The Journal of wildlife management: 323 - 335.

Bongaarts, J. 2009. Human population growth and the demographic transition. Philosophical Transactions of the Royal Society of London B: Biological Sciences 364 (1532): 2985 2990.

Braden, K. 2014. Illegal recreational hunting in Russia: the role of social norms and elite violators. Eurasian Geography and Economics 55 (5): 457 - 490.

Bradshaw R.H.W. 2004. Past anthropogenic influence on European forests and some possible genetic consequences. Forest Ecology and Management 197 (1-3): 203 - 212.

Brovkin, V., Claussen, M., Driesschaert, E., Fichefet, T., Kicklighter, D., Loutre, M.F., Matthews, H.D., Ramankutty, N., Schaeffer, M. and Sokolov, A., 2006. Biogeophysical effects of historical land cover changes simulated by six Earth system models of intermediate complexity. Climate Dynamics 26 (6): 587 - 600.

Burke, I.C., Lauenroth, W.K., Vinton, M.A., Hook, P.B., Kelly, R.H., Epstein, H.E., Aguiar, M.R., Robles, M.D., Aguilera, M.O., Murphy, K.L. and Gill, R.A., 1998. Plant-soil interactions in temperate grasslands. In Plant-induced soil changes: Processes and feedbacks (pp. 121143). Springer, Dordrecht.

\section{C}

Calvert, A.M., Gauthier, G. and Reed, A., 2005. Spatiotemporal heterogeneity of greater snow goose harvest and implications for hunting regulations. Journal of Wildlife Management 69 (2): 561 - 573.

Chudzińska, M.E., van Beest, F.M., Madsen, J. and Nabe-Nielsen, J., 2015. Using habitat selection theories to predict the spatiotemporal distribution of migratory birds during stopover-a case study of pink-footed geese Anser brachyrhynchus. Oikos 124 (7): 851 -860 .

Clayden, S.L., Cwynar, L.C., MacDonald, G.M. and Velichko, A.A., 1997. Holocene pollen and stomates from a forest-tundra site on the Taimyr Peninsula, Siberia. Arctic and Alpine Research: 327 - 333.

Core, E.L., 1949. Original treeless areas in West Virginia. Journal of the Elisha Mitchell Scientific Society, 65(2), pp.306-310.

Cooke, F., Findlay, C.S., Rockwell, R.F. and Abraham, K.F., 1983. Life history studies of the lesser snow goose (Anser caerulescens caerulescens). Behavioral Ecology and Sociobiology 12 (2): $153-159$. 
Cramp, S. and Brooks, D.J., 1992. Handbook of the birds of Europe, the Middle East and North Africa. The birds of the western Palearctic, vol. VI. Warblers (pp. 396-405). Oxford University Press, oxford.

Crutzen, P.J., 2002. Geology of mankind. Nature 415 (6867): 23.

\section{D}

de Boer, R., Bauer, S., van der Jeugd, H.P., Ens, B.J., Griffin, L., Cabot, D., Exo, K.M., Nolet, B.A. and Kölzsch, A., 2014. Een vergelijking van de voorjaarstrek van drie populaties Brandganzen met behulp van GPS-satellietzenders. Limosa 87 (2): 99 - 106.

Dokter A.M. and Ebbinge B.S. 2013. Year-round itinerary of a GPS-tracked Brent goose Branta b. bernicla that visited the Bassin d'Arcachon, France. Wildfowl 63 (3): 135 - 141.

Dong, Z.Y., Wang, Z.M., Liu, D.W., Song, K.S., Li, L., Ren, C.Y. and Jia, M.M., 2014. Spatial decision analysis on wetlands restoration in the lower reaches of Songhua River (LRSR), Northeast China, based on remote sensing and GIS. International Journal of environmental research 8 (3): 849 - 860.

Douphrate, D. I., Hagevoort, G. R., Nonnenmann, M. W., Lunner Kolstrup, C., Reynolds, S. J., Jakob, M., and M. Kinsel 2013. The dairy industry: A brief description of production practices, trends, and farm characteristics around the world. Journal of agromedicine 18 (3): $187-197$.

Drent, R., Ebbinge, B., \& Weijand, B. 1978. Balancing the energy budgets of arctic-breeding geese throughout the annual cycle: a progress report. Verhandlungen der Ornithologischen Gesellschaft in Bayern 23: 239 - 264.

Drent, R.H. and Daan, S., 1980. The prudent parent: energetic adjustments in avian breeding. Ardea 68: 225 - 252.

Drent, R. and Prins, H.H.T., 1987. The herbivore as prisoner of its food supply. In Disturbance in grasslands (pp. 131 - 147). Springer, Dordrecht.

Drent, R.H. and Mehlum, F.R.I.D.T.J.O.F., 1998. Arctic geese: Herbivore-vegetation interaction, predators and human pressures a symposium synthesis. Skrifter-Norsk Polarinstitutt: $313-320$.

Drent, R. H. and Van der Wal, R. 1998. Cyclic grazing and the manipulation of the food resources. - In: Olff, H., Brown, V. K. and Drent, R. H. (eds), Herbivores between plants and predators. Blackwell, pp. $271-299$.

Drent R.H., Fox A.D. and Stahl J. 2006. Travelling to breed. Journal of Ornithology 147 (2): 122 $-134$.

Drent, R. H., Eichhorn, G., Flagstad, A., Van der Graaf, A. J., Litvin, K. E., \& Stahl, J. 2007. Migratory connectivity in Arctic geese: spring stopovers are the weak links in meeting targets for breeding. Journal of ornithology 148 (2): 501 - 514.

Du, Q., Faber, V., and Gunzburger, M. 1999. Centroidal Voronoi tessellations: applications and algorithms. SIAM review 41 (4): 637 - 676. 
Ebbinge B.S. 1985. Factors determining the population size of arctic-breeding geese wintering in Western Europe. - Ardea 73: 121 - 128.

Ebbinge, B.S., 1989. A multifactorial explanation for variation in breeding performance of Brent Geese Branta bernicla. Ibis 131 (2): 196 - 204.

Ebbinge, B. S. 1991. The impact of hunting on mortality rates and spatial distribution of geese wintering in the Western Palearctic. Ardea 79 (2): 197 - 210.

Ebbinge B.S., Berrevoets C., Clausen et al. 1999. Dark-bellied Brent Goose Branta bernicla bernicla. In J. Madsen, G. Cracknell and A. D. Fox (eds.), Goose Populations of the Western Palearctic. A Review of Status and Distribution: 284 - 297.

Ebbinge, B.S., Blew, J., Clausen, P., Günther, K., Hall, C., Holt, C., Koffijberg, K., Le DréanQuénec'hdu, S., Mahéo, R. and Pihl, S., 2013. Population development and breeding success of Dark-bellied Brent Geese Branta b. bernicla from 1991-2011. Wildfowl: 74 89.

Ehlers, J. and Gibbard, P.L., 2007. The extent and chronology of Cenozoic global glaciation. Quaternary International 164: 6 - 20.

Eichhorn G., Afanasyev V., Drent R.H. and van der Jeugd H.P. 2006. Spring stopover routines in Russian Barnacle Geese Branta leucopsis tracked by resightings and geolocation. Ardea 94 (3): 667 - 678.

Eichhorn, G., Drent, R. H., Stahl, J., Leito, A., and Alerstam, T. 2009. Skipping the Baltic: the emergence of a dichotomy of alternative spring migration strategies in Russian barnacle geese. Journal of Animal Ecology 78 (1): 63 - 72.

Ely C.R. and Raveling D.G. 2011. Seasonal variation in nutritional characteristics of the diet of greater white-fronted geese. Journal of Wildlife Management 75 (1): 78 - 91.

Emelchenko N.N. 2009. A review of white-fronted goose (Anser albifrons) migrations in western Palearctic. Zoologicheskil zhurnal 88 (9): 1090 - 1108.

Etomesto.ru. 2018. Карта Менде Ярославской губернии. [online] Available at: http://www.etomesto.ru/map-yaroslavl_mende/ [Accessed 2 Mar. 2018].

\section{F}

Farago S. 2010. Numbers and distributions of geese in Hungary 1984 - 2009. Ornis Svecica 20 (3-4): $144-154$.

Frachetti, M.D., Spengler, R.N., Fritz, G.J. and Mar'yashev, A.N., 2010. Earliest direct evidence for broomcorn millet and wheat in the central Eurasian steppe region. Antiquity 84 (326): 993 - 1010.

Fox, A. D., and Madsen, J. 1997. Behavioural and distributional effects of hunting disturbance on waterbirds in Europe: implications for refuge design. Journal of Applied Ecology: 1 13.

Fox, A.D., Ebbinge, B.S., Mitchell, C., Heinicke, T., Aarvak, T., Colhoun, K., Clausen, P., Dereliev, S., Faragó, S., Koffijberg, K. and Kruckenberg, H., 2010. Current estimates of goose 
population sizes in western Europe, a gap analysis and an assessment of trends. Ornis Svecica 20 (3-4): $115-127$.

\section{G}

Gadallah, F.L., 2002. Historical vegetation reconstruction of a degraded sub-arctic coastal marsh using Landsat imagery and ancillary data. Ecoscience 9 (2): 271 - 279.

Gadallah, F. and Csillag, F., 2002. Vegetation quantification in a sub-arctic salt marsh using reflectance data. In Geoscience and Remote Sensing Symposium 6: 3293 - 3295.

Gajewski, K., Payette, S. and Ritchie, J.C., 1993. Holocene vegetation history at the borealforest--shrub-tundra transition in North-Western Quebec. Journal of Ecology: $433-443$.

Gauthier, G., Bêty, J., Giroux, J. F., \& Rochefort, L. 2004. Trophic interactions in a high arctic snow goose colony. Integrative and comparative biology 44 (2): 119 - 129.

Georgi, I.G., 1775. Bemerkungen einer Reise im Russischen Reich 1772-1774. St. Petersburg, p. 439.

Goldewijk, K. K. 2001. Estimating global land use change over the past 300 years: The HYDE Database. Global Biogeochem. Cycles 15 (2): 417 - 433.

Gonzalez, J., Düttmann, H. and Wink, M., 2009. Phylogenetic relationships based on two mitochondrial genes and hybridization patterns in Anatidae. Journal of Zoology 279 (3): $310-318$.

Grishchenko, M. and H.H.T. Prins 2016. Abandoned field succession in Russia and its potential effect on Corncrake Crex crex habitats. Vogelwelt 136: 175 - 184.

Guo, M., Li, J., Sheng, C., Xu, J. and Wu, L., 2017. A Review of Wetland Remote Sensing. Sensors 17 (4): 777.

Guthrie, R.D., 1982. Mammals of the mammoth steppe as paleoenvironmental indicators. In Paleoecology of Beringia (pp. 307-326).

Guthrie, R.D., 2013. Frozen fauna of the mammoth steppe: the story of Blue Babe. University of Chicago Press.

Guriev, S., and E. Vakulenko 2015. Breaking out of poverty traps: Internal migration and interregional convergence in Russia. Journal of Comparative Economics 43 (3): 633 649.

\section{H}

Hatvany, M., Cayer, D. and Parent, A., 2015. Interpreting salt marsh dynamics: Challenging scientific paradigms. Annals of the association of american geographers 105 (5): 1041 1060.

Haynes, R.J. and Williams, P.H., 1993. Nutrient cycling and soil fertility in the grazed pasture ecosystem. In Advances in agronomy (Vol. 49, pp. 119-199). Academic Press.

Heleniak, T. 1997. Internal migration in Russia during the economic transition. Post-Soviet Geography and Economics 38 (2): 81-104. 
Henderson, J. V., and H. G. Wang 2007. Urbanization and city growth: The role of institutions. Regional Science and Urban Economics 37 (3): 283 - 313.

Herzon, I., Auninš, A., Elts, J. and Preikša, Z., 2008. Intensity of agricultural land-use and farmland birds in the Baltic States. Agriculture, ecosystems \& environment 125 (1-4): $93-100$.

Heuermann, N., van Langevelde, F., van Wieren, S.E. and Prins, H.H., 2011. Increased searching and handling effort in tall swards lead to a Type IV functional response in small grazing herbivores. Oecologia 166 (3): 659 - 669.

Heyland, J.D., 1976. Monitoring nesting success of Greater Snow geese by means of satellite imagery. In Canadian Symposium on Remote Sensing, 3rd, Edmonton, Alberta, Canada (pp. 243-256).

Hedenström A. and Alerstam T. 1997. Optimum Fuel Loads in Migratory Birds: Distinguishing Between Time and Energy Minimization. Journal of Theoretical Biology 189 (3): 227 234.

Hornman, M., Van Roomen, M., Hustings, F., Koffijberg, K., Van Winden, E. and Soldaat, L., 2012. Populatietrends van overwinterende en doortrekkende watervogels in Nederland in 1975-201. Limosa 85 (3): 97.

Hopkins, D.M., Matthews, J.V. and Schweger, C.E. eds., 2013. Paleoecology of Beringia. Elsevier.

Hubbard C.E. 1978. Grasses. Published by Penguin Books.

Hunter, J.M. and Black, J.M., 1996. International action plan for the Red-breasted Goose (Branta ruficollis). Globally threatened birds in Europe: 79 - 98.

Hübner, C.E. 2006. The importance of pre-breeding areas for the arctic Barnacle Goose Branta leucopsis. Ardea 94 (3): 701 - 713.

\section{I}

Ickes, B. W., and G. Ofer 2006. The political economy of structural change in Russia. European Journal of Political Economy 22 (2): 409 - 434.

Ioffe, G. V. 1991. Shifts in rural human population patterns and changes in the agriculture of the central regions of the European U.S.S.R. Geoforum 22 (1): 91 - 97.

Ioffe, G. 2005. The downsizing of Russian agriculture. Europe - Asia Studies 57 (2): 179 - 208.

Ioffe, G. \& T. Nefedova 1997. Persistent features of the Russian countryside: Communal attachment and reform. GeoJournal 41 (3): 193 - 204.

Ioffe, G., and T. Nefedova 2004. Marginal Farmland in European Russia, Eurasian Geography and Economics 45 (1): 45 - 59.

Ioffe, G., Nefedova, T., and I. Zaslavsky 2004. From spatial continuity to fragmentation: the case of Russian farming. Annals of the Association of American Geographers 94 (4): 913 $-943$. 
Jankowiak, Ł., Skórka, P., Ławicki, Ł., Wylegała, P., Polakowski, M., Wuczyński, A. and Tryjanowski, P., 2015. Patterns of occurrence and abundance of roosting geese: the role of spatial scale for site selection and consequences for conservation. Ecological research 30 (5): $833-842$.

Jano, A.P., Jefferies, R.L. and Rockwell, R.F., 1998. The detection of vegetational change by multitemporal analysis of LANDSAT data: the effects of goose foraging. Journal of Ecology 86 (1): 93 - 99.

Jefferies R. L. and Rockwell R.F. 2002. Foraging geese, vegetation loss and soil degradation in an Arctic salt marsh. Applied vegetation science 1: 7 - 16.

Jefferies, R. L., Rockwell, R. F., \& Abraham, K. F. 2004a. The embarrassment of riches: agricultural food subsidies, high goose numbers, and loss of Arctic wetlands a continuing saga. Environmental Reviews 11 (4): 193 - 232.

Jefferies, R.L., Rockwell, R.F. and Abraham, K.F., 2004b. Agricultural food subsidies, migratory connectivity and large-scale disturbance in arctic coastal systems: a case study. Integrative and Comparative Biology 44 (2): 130 - 139.

Jefferies, R. L. \& R. H. Drent 2006. Arctic geese, migratory connectivity and agricultural change: Calling the sorcerer's apprentice to order. Ardea 94 (3): 537 - 554.

Johnson, D. G., and K. M. Brooks 1983. Prospects for Soviet Agriculture in the 1980s (Vol. 300). Indiana University Press.

Jones, G., Jones, H., Charles, M.P., Jones, M.K., Colledge, S., Leigh, F.J., Lister, D.A., Smith, L.M., Powell, W. and Brown, T.A., 2012. Phylogeographic analysis of barley DNA as evidence for the spread of Neolithic agriculture through Europe. Journal of Archaeological Science 39 (10): 3230 - 3238.

Jonker, R. M., Eichhorn, G., Van Langevelde, F., \& Bauer, S. 2010. Predation danger can explain changes in timing of migration: the case of the barnacle goose. PLoS One 5 (6): e11369.

Jonker, R.M., Kurvers, R.H.J.M., van de Bilt, A., Faber, M., Van Wieren, S.E., Prins, H.H.T. and Ydenberg, R.C., 2012. Rapid adaptive adjustment of parental care coincident with altered migratory behaviour. Evolutionary ecology 26 (3): 657 - 667.

\section{K}

Kaiser, A. 1999. Stopover strategies in birds: A review of methods for estimating stopover length. Bird Study 46: 299 - 308.

Kalashnikov V.V. 2001. Kontseptsiya razvitiya konevodstva Rossii do 2010 goda, Russian Academy of Agricultural Sciences, Institute of horses. http://www.ruhorses.ru/economics/economics.html, Accessed on 19/11/2015

Kalchreuter, H. 1991. On the impact of hunting on goose populations - a literature search. Ardea 79 (2): $211-216$.

Kanai, Y., Ueta, M., Germogenov, N., Nagendran, M., Mita, N. and Higuchi, H., 2002. Migration routes and important resting areas of Siberian cranes (Grus leucogeranus) between 
northeastern Siberia and China as revealed by satellite tracking. Biological Conservation 106 (3): 339 - 346.

Keller B.A. 1927. Distribution of vegetation on the plains of European Russia, Journal of Ecology 15 (2): $189-233$.

Kerbes, R. H., Kotanen, P. M., \& Jefferies, R. L. 1990. Destruction of wetland habitats by lesser snow geese: a keystone species on the west coast of Hudson Bay. Journal of Applied Ecology: 242 - 258.

Kleijn, D., van der Hout, J., Voslamber, B., van Randen, Y. and Melman, T.C.P., 2012. Broedende Grauwe ganzen in Nederland: ontwikkelingen in landbouwkundige schade en factoren die hun ruimtegebruik beïnvloeden (No. 2343). Alterra Wageningen UR.

Kleinen, T., Tarasov, P., Brovkin, V., Andreev, A. and Stebich, M., 2011. Comparison of modeled and reconstructed changes in forest cover through the past 8000 years: Eurasian perspective. The Holocene 21 (5): 723 - 734.

Koffijberg, K., B. Voslamber \& E. van Winden 1997. Ganzen en zwanen in Nederland. Overzicht van pleisterplaatsen in de periode 1985-94. SOVON Vogelonderzoek Nederland. BeekUbbergen.

Koffijberg \& van Winden (2014): Naar een populatiemodel voor de Kolgans. Radboud Universiteit Nijmegen, NIOO \& Sovon. Nijmegen/Wageningen.

Kokko, H., Pöysä, H., Lindström, J. and Ranta, E., 1998. Assessing the impact of spring hunting on waterfowl populations. Annales Zoologici Fennici: 195 - 204.

Kondratyev A. and Kruckenberg H. 2013. Barnacle Goose Branta leucopsis abundance on Kolguev Island - Current status and history of population growth. Wildfowl 63: $56-71$.

Korovkin, A.G., Dolgova, I.N. and Korolev, I.B., 2006. Labor shortage in the Russian economy: A macroeconomic estimate. Studies on Russian Economic Development 17 (4): 365 376.

Koser, K., and H. Lutz (Eds.). 1998. The new migration in Europe: Social constructions and social realities. Springer.

Kostin, I.O. and Mooij, J.H., 1995. Influence of weather conditions and other factors on the reproductive cycle of red-breasted geese Branta ruficollis on the Taymyr Peninsula. Wildfowl 46 (46): 45 - 54.

Kölzsch, A., Bauer, S., Boer, R., Griffin, L., Cabot, D., Exo, K.M., Jeugd, H.P. and Nolet, B.A., 2015. Forecasting spring from afar? Timing of migration and predictability of phenology along different migration routes of an avian herbivore. Journal of Animal Ecology 84 (1): 272 - 283.

Kölzsch, A., Müskens, G.J., Kruckenberg, H., Glazov, P., Weinzierl, R., Nolet, B.A. and Wikelski, M., 2016. Towards a new understanding of migration timing: slower spring than autumn migration in geese reflects different decision rules for stopover use and departure. Oikos 125 (10): 1496 - 1507. 
Kümmerle, T., Hostert, P., St-Louis, V. and Radeloff, V.C., 2009. Using image texture to map farmland field size: a case study in Eastern Europe. Journal of Land Use Science 4 (1-2): 85 - 107.

Kümmerle T., Kaplan J.O., Prishchepov A.V., Rylsky I., Chaskovskyy O., Tikunov V.S. \& Muller D. 2015. Forest transitions in Eastern Europe and their effects on carbon budgets, Global change biology 21 (8): 3049 - 3061.

\section{$\mathbf{L}$}

Lack, D. 1956. Swifts in a tower. - Methuen, London.

Lal, R., Reicosky, D.C. and Hanson, J.D., 2007. Evolution of the plow over 10,000 years and the rationale for no-till farming.

Larsson, K. and Van der Jeugd, H.P., 1997. Continuing growth of the Baltic barnacle goose population: number of individuals and reproductive success in different colonies. In The Svalbard Goose Symposium, Oslo, Norway, 23-26 September 1997 (Vol. 200, pp. 213219). Norsk polarinstitutt.

Laruelle, M., 2007, August. Central Asian Labor Migrants in Russia: The" Diasporization" of the Central Asian States?. In China \& Eurasia Forum Quarterly (Vol. 5, No. 3).

Lerman, Z. 1998. Does land reform matter? Some experiences from the former Soviet Union. European Review of Agricultural Economics 25 (3): 307 - 330.

Lewis, R. A., and R. H. Rowland 1979. Population redistribution in the USSR: Its impact on society. New York: Praeger.

Li, X., Si, Y., Ji, L. and Gong, P., 2017. Dynamic response of East Asian Greater White-fronted Geese to changes of environment during migration: Use of multi-temporal species distribution model. Ecological Modelling 360: 70 - 79.

Lieberman, S.R., 1983. The evacuation of industry in the Soviet Union during World War II. Soviet Studies 35 (1): 90 - 102.

Lioubimtseva, E., and G. M. Henebry 2012. Grain production trends in Russia, Ukraine and Kazakhstan: New opportunities in an increasingly unstable world? Frontiers of Earth Science 6 (2): 157-166.

Lioubimtseva, E., de Beurs, K. M., and G. M. Henebry 2013. Grain production trends in Russia, Ukraine, and Kazakhstan in the context of the global climate variability and change. In Climate change and water resources (pp. 121 - 141). Springer Berlin Heidelberg.

Louwe Kooijmans, L.P., 1980. Archaeology and coastal change in the Netherlands.

\section{M}

Madsen, J. 1985a. Relations between change in spring habitat selection and daily energetics of pink-footed geese Anser brachyrhynchus. Ornis Scandinavica: 222 - 228.

Madsen, J. 1985b. Impact of disturbance on field utilization of pink-footed geese in West Jutland, Denmark. Biological Conservation 33 (1): 53 - 63. 
Madsen, J. 1998. Experimental refuges for migratory waterfowl in Danish wetlands. II. Tests of hunting disturbance effects. Journal of Applied Ecology 35 (3): 398 - 417.

Madsen, J., \& Cracknell, G. 1999. Goose populations of the Western Palearctic.

Malakoff D. 2016. By 2050, 66\% of us will live in cities. Here's what that's going to mean for the environment, Science Retrieved 1 March 2017, from http://www.sciencemag.org/video/2050-66-us-will-live-cities-here-s-what-s-goingmean-environment.

McAlister, M.A., Moorman, C.E., Meentemeyer, R.K., Fuller, J.C., Howell, D.L. and DePerno, C.S., 2017. Using Landscape Characteristics to Predict Distribution of Temperate-Breeding Canada Geese. Southeastern Naturalist 16 (2): 127 - 139.

Middendorff, A., 1869. A Travel to the North and East of Siberia. Vol. 2, Natural History of North and East of Siberia. Russian.] St. Petersburg.

Milanovic, B., 1998. Income, inequality, and poverty during the transition from planned to market economy (pp. p-237). Washington, DC: World Bank.

Mitchell, F.J., 2005. How open were European primeval forests? Hypothesis testing using palaeoecological data. Journal of Ecology 93 (1): 168 - 177.

Mooij, J. H. 1993. Development and management of wintering geese in the Lower Rhine area of North Rhine-Westphalia/Germany. Voge/warte 37: 55 - 77.

Mooij J.H. 1997. The status of White-fronted Goose (Anser a. albifrons) in the Western Palearctic. Vogelwarte 39 (1): $61-81$.

Mooij J.H., Ebbinge B.S., Kostin I.O. et al. 1996. Panmixia in White-fronted Geese (Anser albifrons) of the Western Palearctic, Ecology of geese wintering at the Lower Rhine area (Germany), $192 \mathrm{p}$.

Moon, D., 1997. Peasant Migration and the Settlement of Russia's Frontiers, 1550-1897. The Historical Journal 40 (4): 859 - 893.

Morrison, R.I.G., 1997. The use of remote sensing to evaluate shorebird habitats and populations on Prince Charles Island, Foxe Basin, Canada. Arctic: 55 - 75.

Moss, M.L. and Erlandson, J.M., 2013. Waterfowl and lunate crescents in Western North America: The archaeology of the Pacific Flyway. Journal of world prehistory 26 (3): 173 $-211$.

Murphy, E.M., Schulting, R., Beer, N., Chistov, Y., Kasparov, A. and Pshenitsyna, M., 2013. Iron Age pastoral nomadism and agriculture in the eastern Eurasian steppe: implications from dental palaeopathology and stable carbon and nitrogen isotopes. Journal of Archaeological Science 40 (5): 2547 - 2560.

\section{$\mathbf{N}$}

Naugle, D.E., Gleason, J.S., Jenks, J.A., Higgins, K.F., Mammenga, P.W. and Nusser, S.M., 1997. Factors influencing wetland use by Canada geese. Wetlands 17 (4): 552 - 558.

Nilsson, L. \& H. Persson 1998. Field choice of staging Greylag Geese Anser anser in relation to changes in agriculture in South Sweden. Ornis Svecica 8 (1-2): 27 - 39. 
Nogués-Bravo, D., Rodríguez, J., Hortal, J., Batra, P. and Araújo, M.B., 2008. Climate change, humans, and the extinction of the woolly mammoth. PLoS biology 6 (4): 79.

Noer, H., Madsen, J. and Hartmann, P., 2007. Reducing wounding of game by shotgun hunting: effects of a Danish action plan on pink-footed geese. Journal of Applied Ecology 44 (3): 653 - 662.

Nowak, E., and Berthold, P. 1991. Satellite tracking: a new method in orientation research. In Orientation in birds (pp. 307-321). - Birkhäuser Basel.

\section{o}

Odum, E.P., 1960. Organic production and turnover in old field succession. Ecology 41 (1): 34 $-49$.

Ortega, C. P. 2012. Effects of noise pollution on birds: a brief review of our knowledge. Ornithological Monographs 74 (1): 6 - 22.

Ottenburghs, J., Megens, H.J., Kraus, R.H., Madsen, O., van Hooft, P., van Wieren, S.E., Crooijmans, R.P., Ydenberg, R.C., Groenen, M.A. and Prins, H.H., 2016. A tree of geese: A phylogenomic perspective on the evolutionary history of True Geese. Molecular phylogenetics and evolution 101: $303-313$.

Owen, M., and J. M. Black 1991. Geese and their future fortune, Ibis 133 (s1): $28-35$.

\section{P}

Pal, M., 2005. Random forest classifier for remote sensing classification. International Journal of Remote Sensing 26 (1): 217 - 222.

Pallas, P.S., 1831. Zoographia Rosso-Asiatica, sistens omnium animalium in extenso Imperio Rossico et adjacentibus maribus observatorum recensionem, domicilia, mores et descriptiones, anatomen atque icones plurimorum (Vol. 1). Office caes. Academiae scientiarum.

Papi, F., Gudmundsson, G.A., Benvenuti, S., Alerstam, T., Åkesson, S. and Papi, C.F., 1993. Migratory flights of Arctic geese tracked by satellite. Rendiconti Lincei 4 (2): 153 - 156.

Pereira, H. M. and L. M. Navarro 2015. Rewilding European landscapes. New York: Springer.

Peterken, G.F., 1993. Woodland conservation and management. Springer Science \& Business Media.

Pinhasi, R., Fort, J. and Ammerman, A.J., 2005. Tracing the origin and spread of agriculture in Europe. PLoS biology: 3 (12): 410.

Prins, H.H., 1998. Origins and development of grassland communities in northwestern Europe. In Grazing and conservation management (pp. 55-105). Springer, Dordrecht.

Prishchepov, A. V., Müller, D., Dubinin, M., Baumann, M., and V. C. Radeloff 2013. Determinnts of agricultural land abandonment in post-Soviet European Russia. Land use policy 30 (1): $873-884$.

Prishchepov, A.V., Müller, D., Baumann, M., Kuemmerle, T., Alcantara, C. and Radeloff, V.C., 2017. Underlying drivers and spatial determinants of post-soviet agricultural land 
abandonment in temperate Eastern Europe. In Land-Cover and Land-Use Changes in Eastern Europe after the Collapse of the Soviet Union in 1991 (pp. 91-117). Springer, Cham.

Poschlod, P., Bakker, J.P. and Kahmen, S., 2005. Changing land use and its impact on biodiversity. Basic and Applied Ecology 6 (2): 93 - 98.

\section{Q}

Queiroz, C., Beilin, R., Folke, C. and Lindborg, R., 2014. Farmland abandonment: threat or opportunity for biodiversity conservation? A global review. Frontiers in Ecology and the Environment 12 (5): 288 - 296.

\section{$\mathbf{R}$}

R Core Team 2016. R: A language and environment for statistical computing. R Foundation for Statistical Computing, Vienna.

Ramankutty, N. and J. A. Foley 1999. Estimating historical changes in global land cover: Croplands from 1700 to 1992, Global Biogeochem. Cycles 13 (4): 997 - 1027.

Rodriguez-Galiano, V.F., Ghimire, B., Rogan, J., Chica-Olmo, M. and Rigol-Sanchez, J.P., 2012. An assessment of the effectiveness of a random forest classifier for land-cover classification. ISPRS Journal of Photogrammetry and Remote Sensing 67: 93 - 104.

Romanenkov, V., Rukhovich, D., Koroleva, P. and McCarty, J.L., 2014. Estimating black carbon emissions from agricultural burning. In Novel Measurement and Assessment Tools for Monitoring and Management of Land and Water Resources in Agricultural Landscapes of Central Asia (pp. 347-364). Springer, Cham.

Romanov A.A. and Pospelov I.N. 2010. Intracontinental spatial connections of lesser whitefronted geese (Anser erythropus) from mountain subarctic regions of the Central Palearctic. Russian Journal of Ecology 41 (1): 63 - 66.

Rosin, Z.M., Skórka, P., Wylegała, P., Krakowski, B., Tobolka, M., Myczko, Ł., Sparks, T.H. and Tryjanowski, P., 2012. Landscape structure, human disturbance and crop management affect foraging ground selection by migrating geese. Journal of Ornithology 153 (3): 747 $-759$.

Rowland, R. H. 1998. Metropolitan population change in Russia and the former Soviet Union, 1897 - 1997. Post-Soviet Geography and Economics 39 (5): 271 - 296.

Rozenfeld, S. B., and I. S. Sheremetyev, 2016. Arctic Geese (Anser) and brants (Branta) of Eurasia: An analysis of factors that control population dynamics and geographical ranges. Biology Bulletin Reviews 6 (5): 436 - 455.

Russian Statistical Yearbook 2017. Available online in Russian and English | FSSS [online] Available at: http://www.gks.ru/bgd/regl/b17_13/Main.htm [Accessed 1 Mar. 2018]. 
Sandow, E. 2008. Commuting behaviour in sparsely populated areas: evidence from northern Sweden. Journal of Transport Geography 16 (1): 14 - 27.

Scheuerman, R.D. and Trafzer, C.E., 1980. The Volga Germans: Pioneers of the Northwest. University Press of Idaho.

Scott D.A. and Rose P.M. 1996. Atlas of Anatidae populations in Africa and Western Eurasia. Wageningen, The Netherlands: Wetlands International Publication No. 41, Wetlands International.

Shariati, M., Skidmore, A.K., Darvishzadeh, R., Exo, K.M., Kölzsch, A., Griffin, L., Stahl, J., Cabot, D. and Toxopeus, A.G., 2017. Expert system for modelling stopover site selection by barnacle geese. Ecological modelling 359: 398 - 405.

Sherratt, A., 1990. The genesis of megaliths: Monumentality, ethnicity and social complexity in Neolithic north-west Europe. World Archaeology 22 (2): 147 - 167.

Shvidenko A., Nilssson S. and V. Roshkov 1997. Possibilities for increased carbon sequestration through the implementation of rational forest management in Russia, Water, Air and Soil Pollution 94 (1): 137-162.

Si, Y., Skidmore, A.K., Wang, T., de Boer, W.F., Toxopeus, A.G., Schlerf, M., Oudshoorn, M., Zwerver, S., Jeugd, H.V.D., Exo, K.M. and Prins, H.H., 2011. Distribution of Barnacle Geese Branta leucopsis in relation to food resources, distance to roosts, and the location of refuges. Ardea 99 (2): $217-226$.

Si, Y., Xin, Q., Prins, H. H., de Boer, W. F., \& Gong, P. 2015a. Improving the quantification of waterfowl migration with remote sensing and bird tracking. Science Bulletin, 60 (23): 1984 - 1993.

Si, Y., Xin, Q., de Boer, W. F., Gong, P., Ydenberg, R. C., \& Prins, H. H. 2015b. Do Arctic breeding geese track or overtake a green wave during spring migration? Scientific reports (5): 8749.

Soininen, J., Bartels, P., Heino, J., Luoto, M. and Hillebrand, H., 2015. Toward more integrated ecosystem research in aquatic and terrestrial environments. BioScience 65 (2): $174-$ 182.

Sovon.nl. 2018a. Brandgans | Sovon.nl. [online] Available at: https://www.sovon.nl/nl/soort/1670 [Accessed 1 Mar. 2018].

Sovon.nl. 2018b. Kolgans | Sovon.nl. [online] Available at: https://www.sovon.nl/nl/soort/1590 [Accessed 1 Mar. 2018].

Speed, J.D., Woodin, S.J., Tømmervik, H., Tamstorf, M.P. and Van Der Wal, R., 2009. Predicting habitat utilization and extent of ecosystem disturbance by an increasing herbivore population. Ecosystems 12 (3): 349 - 359.

Spoerer, M. and Fleischhacker, J., 2002. Forced laborers in Nazi Germany: categories, numbers, and survivors. Journal of Interdisciplinary History 33 (2): 169 - 204.

Stefanski, J., Chaskovskyy, O. and Waske, B., 2014. Mapping and monitoring of land use changes in post-Soviet western Ukraine using remote sensing data. Applied Geography 55: 155 - 164. 
Strakhov V.V., Pisarenko A.I. and V.A. Borisov 2001. Lesa mira i Rosssiji, Ministry of Natural Resources of Russia 9: 49 - 63.

Strayer R. 1998. Why did Soviet Union collapse? Understanding Historical Change. M.E. Sharpe Inc.

Strijker, D. 2005. Marginal lands in Europe - causes of decline. Basic and Applied Ecology 6 (2): $99-106$.

Sukachev, V.N., 1928. Principles of classification of the spruce communities of European Russia. Journal of Ecology 16 (1): 1 - 18.

Sultanov, E.L.C.H.I.N., 2008. Recent waterbird counts in Gyzylagach, the Azerbaijan Republic's most important Ramsar site, with comments on conservation. Podoces: 3 (1/2): 31 - 38.

Sunderland, W., 2006. Taming the wild field: colonization and empire on the Russian steppe. Cornell University Press.

Svendsen, J.I., Alexanderson, H., Astakhov, V.I., Demidov, I., Dowdeswell, J.A., Funder, S., Gataullin, V., Henriksen, M., Hjort, C., Houmark-Nielsen, M. and Hubberten, H.W., 2004. Late Quaternary ice sheet history of northern Eurasia. Quaternary Science Reviews 23 $(11-13): 1229-1271$.

\section{$\mathbf{T}$}

Teitelbaum, M. S. 2013. The fear of population decline. Academic Press.

Thorpe, I.J., 1999. The origins of agriculture in Europe. Psychology Press.

Tiebel, K., Huth, F., \& Wagner, S. 2018. Soil seed banks of pioneer tree species in European temperate forests: a review. iForest-Biogeosciences and Forestry 11(1): 48.

Tikhomirov, V. 2000. The political economy of post-Soviet Russia. Springer.

Tombre, I. M., Tømmervik, H., \& Madsen, J. 2005. Land use changes and goose habitats, assessed by remote sensing techniques, and corresponding goose distribution, in Vesterålen, Northern Norway. Agriculture, Ecosystems and Environment 109 (3-4): 284 $-296$.

Tombre, I.M., Tømmervik, H., Gullestad, N. and Madsen, J., 2010. Spring staging in the Svalbard-breeding Pink-footed Goose Anser brachyrhynchus population: site-use changes caused by declining agricultural management? Wildfowl 60 (60): 3 - 19.

Traphagan, J. W., and J. Knight 2003. Demographic change and the family in Japan's aging society. SUNY Press.

Travaini, A., Bustamante, J., Rodríguez, A., Zapata, S., Procopio, D., Pedrana, J. and Martínez Peck, R., 2007. An integrated framework to map animal distributions in large and remote regions. Diversity and Distributions 13 (3): 289 - 298.

Trostle, R. 2008. Global agricultural supply and demand: factors contributing to the recent increase in food commodity prices. Washington, DC, USA: US Department of Agriculture, Economic Research Service.

Trostle, R. 2011. Why Have Food Commodity Prices Risen Again? DIANE Publishing. 
Tsvetkov M.A. 1957. Izmeneniye lesistosti Evropeiskoy Rossii s kontsa 18 stoletiya po 1914, Academy of Sciences, Moscow.

\section{V}

van der Graaf A.J., Stahl J., Klimkowska A., Bakker J.P. and Drent R.H. 2006. Surfing on a green wave - how plant growth drives spring migration in the Barnacle Goose Branta leucopsis. Ardea 94 (3): 567 - 577.

van der Jeugd, H., 2013. Survival and dispersal in a newly-founded temperate Barnacle Goose Branta leucopsis population. Wildfowl 63 (63): 72 - 89.

van der Jeugd, H.P. and Kwak, A., 2017. Management of a Dutch resident barnacle goose Branta leucopsis population: How can results from counts, ringing and hunting bag statistics be reconciled? Ambio 46 (2): 251 - 261.

Van Eerden, M.R., Drent, R.H., Stahl, J. and Bakker, J.P., 2005. Connecting seas: western Palaearctic continental flyway for water birds in the perspective of changing land use and climate. Global Change Biology 11 (6): 894 - 908.

van Wijk, R. E., Kölzsch, A., Kruckenberg, H., Ebbinge, B. S., Müskens, G. J., \& Nolet, B. A. 2012. Individually tracked geese follow peaks of temperature acceleration during spring migration. Oikos 121 (5): 655 - 664.

Velichko, A.A., Andreev, A.A. and Klimanov, V.A., 1997. Climate and vegetation dynamics in the tundra and forest zone during the Late Glacial and Holocene. Quaternary International 41: 71 - 96.

Vilén, T., Cienciala, E., Schelhaas, M. J., Verkerk, P. J., Lindner, M., \& Peltola, H. 2015. Increasing carbon sinks in European forests: effects of afforestation and changes in mean growing stock volume. Forestry: An International Journal of Forest Research 89 (1): 82 -90 .

\section{W}

Walker, D.A., Bockheim, J.G., Chapin Iii, F.S., Eugster, W., Nelson, F.E. and Ping, C.L., 2001. Calcium-rich tundra, wildlife, and the "Mammoth Steppe". Quaternary Science Reviews 20 (1-3): 149 - 163.

Wegren, S. K. 1995. Rural migration and agrarian reform in Russia: a research note. EuropeAsia Studies 47 (5): 877 - 888.

Wegren, S. 1998. Agriculture and the state in Soviet and post-Soviet Russia. University of Pittsburgh Pre.

Wegren, S. K. 2012. Institutional impact and agricultural change in Russia. Journal of Eurasian Studies 3 (2): 193 - 202.

White, A. 2007. Internal migration trends in Soviet and post-Soviet European Russia. EuropeAsia Studies 59 (6): 887 - 911. 
Whitfield, J. 2006. Agriculture and environment: How green was my subsidy? Nature 439 (7079): 908 - 909.

Wickware, G.M., Sims, R.A., Ross, R.K. and Cowell, D.W., 1980. The application of remote sensing techniques for an ecological land survey of the Snow Goose colony at Cape Henrietta Maria, Hudson Bay.

Williams M. 2000. Dark ages and dark areas: global deforestation in the deep past. Journal of Historical Geography 26 (1): 28 - 46.

Wink, M., Hofer, A., Bilfinger, M., Englert, E., Martin, M. and Schneider, D., 1993. Geese and dietary allelochemicals-food palatability and geophagy. Chemoecology 4 (2): 93 - 107.

Wenink, P.W. and Baker, A.J., 1996. Mitochondrial DNA lineages in composite flocks of migratory and wintering dunlins (Calidris alpina). The Auk: 744 - 756.

WorldClim - Global Climate Data, Free Climate Data for ecological modelling and GIS, Retrieved 22 December 2016, from http://www.worldclim.org/.

\section{$\mathbf{Y}$}

Yavlinsky, G., and S. Braguinsky 1994. The inefficiency of laissez-faire in Russia: Hysteresis effects and the need for policy-led transformation. Journal of Comparative Economics 19 (1): $88-116$.

Ydenberg, R. C., \& Prins, H. T. 1981. Spring grazing and the manipulation of food quality by barnacle geese. Journal of Applied Ecology: 443 - 453.

\section{$\mathbf{Z}$}

Zagwijn, W.H., 1989. The Netherlands during the Tertiary and the Quaternary: a case history of coastal lowland evolution. In Coastal Lowlands (pp. 107-120). Springer, Dordrecht.

Zhang, Y., Prins, H.H., Cao, L., Zhao, M. and Boer, W.F.D., 2016. Variation in elevation and sward height facilitate coexistence of goose species through allometric responses in wetlands. Waterbirds 39 (1): $34-44$.

Zimov, S.A., 2005. Pleistocene park: return of the mammoth's ecosystem. Science, 308 (5723): $796-798$.

Zimov, S.A., Zimov, N.S., Tikhonov, A.N. and Chapin III, F.S., 2012. Mammoth steppe: a highproductivity phenomenon. Quaternary Science Reviews 57: 26 - 45.

СанПин 2.2.1/2.1.1.1200-03. Санитарно-защитные зоны и санитарная классификация предприятий, сооружений и иных объектов. - М., 2003/SanPiN 2.2.1/2.1.1.1200-03. Sanitarno-zashchitnye zony i sanitarnaya klassifikatsiya predpriyatiy, sooruzheniy i inykh objektov. Moscow, 2003. 


\section{Summary}

Since the break-up of the USSR in 1991 agriculture in European Russia has been going through sweeping reorganization that resulted in fundamental changes of land use practices. This transformation led a widespread land abandonment which resulted in old-field development on fields formerly used for grain production. These processes take place near stopover sites that are used by migrating greater white-fronted geese. This species uses a vast network of stopover sites across European Russia to rest and to forage on their way from Western Europe to the Russian Arctic and back. With old-field development near stopover sites in European Russia an ever increasing number of them should become unsuitable for migrating geese. This change might potentially reshape the migratory network of greater white-fronted goose across European Russia pushing the species to explore alternative migration routes.

In this Thesis I describe changes in agriculture and rural population in European Russia after the break-up of the USSR. To mode the network of potential stopover sites in European Russia I use an automated classification algorithm. With these analyses I explore how changes in agricultural practices contributed to development of old-fields near modelled stopover sites. I tests a hypothesis that geese might shift their migration to the South of European Russia as more formerly suitable stopover sites in the North become unsuitable due to reported transformation of the Russian agriculture.

In Chapter $2 \mathrm{I}$ begin with a description of changes in human population in provinces and selected municipal districts of European Russia. With data from 56 provinces and 350 municipal districts, I found that the growth rates in municipal districts has been falling throughout the past 60 years. Municipalities and provinces with larger population sizes experienced higher growth while smaller ones declined. However only the largest districts could maintain positive growth census after census at the expense of declining smaller ones. I also show two distinctive periods (Soviet and post-Soviet) in population changes in European Russia. While during the Soviet era human population in the study area was increasing, it stalled in the post-Soviet era. Largest declines in population in the post-Soviet era were observed in municipalities with smallest population size. I show similar developments for acquired agricultural statistics 
in the selected municipal districts. Total area under cultivation, area under grains, number of cattle and number of shoats show staggering declines following the break-up the USSR in 1991. This effect was influenced by low average annual temperature, geographic location, the distance to an urban centre.

To model a network of migration stopover sites for greater white-fronted geese in European Russia I developed an automated classification algorithm in Chapter 3. Over 1900 stopover sites within European Russia are available for migrating greater white-fronted geese. These locations are unequally distributed across the study area with highest concentration in central and northwestern parts of European Russia. I validated the classification approach with field visits of 64 randomly selected locations in April - May 2014. I also compared the results of automatic classification with already known Important Bird areas and available metal ring and neckband recoveries. While there is an almost $90 \%$ match of stopover sites with analysed recoveries, only $70 \%$ of Important Bird areas correspond to modelled stopover sites. Almost $30 \%$ of migrating stopover sites are located outside the protected areas. I believe that these findings contribute to better understanding of migration network of the species and potential utilisation of available stopover sites in the past and the near future.

In Chapter $4 \mathrm{I}$ investigate how described changes in land use practices after the break-up of the USSR transform landscapes near modelled stopover sites. I discovered that in 1990 - 2014 for overall area and around stopover sites number of arable pixels declined by $56 \%$ while grassland increased by $14 \%$ and forest increased by $12 \%$. I associated these changes with observed staggering declines in agricultural statistics and shrinking local population. After visiting in June 2014 of 84 randomly selected ground truth locations in European Russia, I could verify the classification. I also documented widespread old-field development on former agricultural fields. This old-field development started in late 1980 s and progressed in the past three decades with increase of land abandonment following the major restructuring in agriculture. I expect that these major habitat changes around stopover sites used by migrating greater white-fronted geese might contribute to changes of their migration behavior and reshape their migration network in European Russia. 
In Chapter 5 I test a hypothesis that increasing old-field development on previously suitable stopover sites in European Russia might contribute to a shift in migration towards the South. About 300 alleged stopover sites in European Russia were deduced from the spatial analyses. I found that greater whitefronted geese indeed shifted their migration routes towards the South of European Russia after the break-up of the USSR in 1991. Even though the shift was mild in the first decade, it became more profound in the last decade with greater number of geese favouring more stopover sites in the South of European Russia. I attribute this shift in migration routes to old-field development on former agricultural lands. With advanced stages of succession around the stopover sites, greater white-fronted geese are likely to find more suitable and still underutilised staging sites in the South.

In Chapter 6 I summarize and review the results from four main chapters of the Thesis. I explore the history of goose migration after the last glacial period with focus on increasing human activities. With growth of human population and proliferation of agriculture, landscapes of Western Palearctic change dramatically which facilitates migration of geese species. Perhaps, geese were also among the biggest beneficiaries of Anthropocene. With booming production of food and intensive agriculture they were able to flourish and to increase their populations to the highest ever recorded levels. However an unseen bust due to unprecedented land abandonment might follow this sudden population boom. This land abandonment had a human-induced nature and spurs from a political decision taken in 1991 with long-lasting implications for human population, land use and biodiversity. This phenomenon illustrates the Anthropocene with impact of human activities comparable or greater than geological forces. To counteract potential negative effect of land use changes on geese migration, I recommend working on "Geese unlimited" conservation initiative in the Western Palearctic. This and similar initiatives should endorse effective collaboration between different countries, organisations, scientists and hunters to ensure a sustainable future for migrating waterfowl and all people who enjoy these wonderful birds. 


\section{Samenvatting}

Sinds het uiteenvallen van de Sovjet-Unie in 1991 heeft de landbouw in Europees Rusland een ingrijpende verandering ondergaan die leidde tot een fundamentele herstructurering van het landgebruik. Deze transformatie leidde tot een wijdverbreide landverlating die resulteerde in de ontwikkeling van oude velden op velden die vroeger werden gebruikt voor de graanproductie. Deze processen vinden plaats in de buurt van pleisterplekken die worden gebruikt door kolganzen. Deze soort maakt gebruik van een uitgebreid netwerk van pleisterplekken in heel Europa op weg van West-Europa naar het Russische Noordpoolgebied en terug om uit te rusten en te foerageren. Met de ontwikkeling van oude velden nabij pleisterplekken in Europees Rusland zou een steeds groter aantal van hen ongeschikt moeten worden voor migrerende ganzen. Deze verandering zou het migratienetwerk van kolganzen in Europees Rusland een nieuwe vorm kunnen geven door de soort te dwingen om alternatieve migratieroutes te verkennen.

In dit proefschrift beschrijf ik veranderingen in de landbouw en de plattelandsbevolking in Europees Rusland na het uiteenvallen van de SovjetUnie. Om het netwerk van potentiële pleisterplekken in Europees Rusland te modelleren, gebruik ik een geautomatiseerd classificatie-algoritme. Met deze analyses onderzoek ik hoe veranderingen in landbouwpraktijken hebben bijgedragen tot de ontwikkeling van oude velden in de buurt van gemodelleerde pleisterplekken. Ik test de hypothese dat ganzen hun migratie naar het zuiden van Europees Rusland zouden kunnen verplaatsen omdat voormalige geschikte stopplaatsen in het noorden ongeschikt zouden worden vanwege de vermelde transformatie van de Russische landbouw.

In hoofdstuk 2 begin ik met een beschrijving van demografische ontwikkelingen in provincies en geselecteerde gemeenten van Europees Rusland. Met statistieke gegevens uit 56 provincies en 350 gemeenten kwam ik erachter dat de groeicijfers in de gemeenten de afgelopen 60 jaar zijn gedaald. Gemeenten en provincies met grotere een bevolkingsomvang hadden een hogere groei, terwijl kleinere daalden. Alleen de grootste gemeenten zouden echter na de volkstelling een positieve groeicurve kunnen handhaven ten koste van de afnemende kleinere. Ik toon ook twee verschillende periodes (Sovjet- en 
post-Sovjetperiode) in bevolkingsveranderingen in Europees Rusland. Gedurende de Sovjetperiode nam de bevolking in het studiegebied toe, terwijl deze tot stilstand kwam in de post-Sovjetperiode. De grootste dalingen van het bevolkingsaantal in de post-Sovjetperiode werden waargenomen in gemeenten met de kleinste bevolkingsomvang. Ik toon vergelijkbare ontwikkelingen voor verworven landbouwstatistieken in de geselecteerde gemeenten. Het totale oppervlak, het oppervlak aan granen, het aantal runderen en het aantal schapen en geiten tonen een enorme afname na het uiteenvallen van de Sovjet-Unie in 1991. Dit effect werd beïnvloedt door de lage gemiddelde jaartemperatuur, de geografische locatie en de afstand tot een stadscentrum.

Voor het modelleren van een netwerk van migratieplekken voor kolganzen in Europees Rusland, heb ik in hoofdstuk 3 een geautomatiseerd classificatiealgoritme ontwikkeld. Binnen Europees Rusland zijn er meer dan 1900 pleisterplekken beschikbaar voor kolganzen. Deze locaties zijn ongelijk verdeeld over het studiegebied met de hoogste concentratie in de centrale en noordwestelijke delen van Europees Rusland. Ik valideerde de classificatiebenadering met veldbezoeken aan 64 willekeurig geselecteerde locaties in april - mei 2014. Ik vergeleek ook de resultaten van de automatische classificatie met reeds bekende belangrijke vogelgebieden en beschikbare terugwinning van metalen ringen en nekbanden. Hoewel bijna $90 \%$ van de pleisterplekken overeenkomt met geanalyseerde terugmeldingen, komt slechts $70 \%$ van de belangrijke vogelgebieden (IBA's) overeen met de gemodelleerde pleisterplekken. Bijna $30 \%$ van de pleisterplekken bevinden zich buiten de beschermde gebieden. Ik geloof dat deze informatie ons inzicht verbeterd in het migratienetwerk van de soort en het potentiële gebruik van beschikbare pleisterplekken in het verleden en de nabije toekomst.

In hoofdstuk 4 onderzoek ik hoe landschappen in de buurt van gemodelleerde pleisterplekken transformeren aan de hand van de beschreven veranderingen in het landgebruik na het uiteenvallen van de Sovjet-Unie. Voor de periode 1990 - 2014 ontdekte ik dat het aantal akkerpixels in het hele gebied en rond pleisterplekken daalde met $56 \%$, van grasland met $14 \%$ en van bos met $12 \%$. Ik associeerde deze veranderingen met de waargenomen onthutsende dalingen in landbouwstatistieken en een krimpende lokale 
bevolking. Ik kon de classificatie verifiëren na een bezoek aan 84 willekeurig geselecteerde ground truth-locaties in Europees Rusland in juni 2014. Ik documenteerde ook de grootschalige ontwikkeling van oude velden op voormalige landbouwgebieden. De ontwikkeling van verlaten velden begon eind jaren 80 en vorderde in de afgelopen drie decennia met een toename in landverlating na de grote veranderingen in de landbouwgebieden. Ik verwacht dat deze belangrijke habitatsveranderingen rond door kolganzen gebruikte pleisterplekken, kunnen bijdragen aan veranderingen in hun migratiegedrag en migratienetwerk in Europees Rusland.

In hoofdstuk 6 vat ik de resultaten samen van de vier kernhoofdstukken van het proefschrift. Ik verken de geschiedenis van de ganzenmigratie na de laatste ijstijd met een nadruk op de toename van menselijke activiteiten. Door de bevolkingsgroei en de verspreiding van de landbouw veranderden de landschappen in het West-Palearctisch gebied dramatisch, wat de migratie van ganzen makkelijker maakte. Waarschijnlijk behoorden ganzen ook tot de grootste begunstigden van het Antropoceen. Met een stijgende productie van voedsel en intensieve landbouw konden ze goed gedijen en hun populatie doen stijgen tot het hoogst geregistreerde niveau ooit. Desondanks kan een plotselinge daling in hun aantallen intreden als gevolg van ongekende landverlating. Deze landverlating was antropogeen van karakter en kwam voort uit een politieke beslissing in 1991 die leidde tot langdurige gevolgen voor de bevolking, het landgebruik en de biodiversiteit. Dit fenomeen illustreert het Antropoceen, waarin menselijke activiteiten vergelijkbaar of groter van kracht zijn dan geologische krachten. Om mogelijke negatieve effecten van veranderingen in landgebruik op ganzenmigratie te voorkomen, raad ik aan te werken aan het beschermingsinitiatief "Geese unlimited" in het WestPalearctisch gebied. Deze en soortgelijke initiatieven moeten de effectieve samenwerking tussen verschillende landen, organisaties, wetenschappers en jagers ondersteunen om een duurzame toekomst te garanderen voor migrerende watervogels en alle mensen die van deze prachtige vogels willen genieten. 


\section{Affiliation of co-authors}

Willem F. de Boer, Henrik J. de Knegt, Herbert H.T. Prins, Sipke E. van Wieren, Ronald C. Ydenberg: Resource Ecology Group, Wageningen University, Wageningen, the Netherlands.

Ronald C. Ydenberg: Department of Biological Sciences, Simon Fraser University, Vancouver, Canada.

Michael E. Schaepman: Department of Geography, Director of Remote Sensing Laboratories, University of Zurich, Zurich, Switzerland. 


\section{Acknowledgements}

A PhD is definitely a life-changing experience and this journey would not be possible without many wonderful people who I met on my way. During my PhD I had a pleasure to work, to talk and to exchange ideas with a great number of people from many countries all over the world. Most of them were my colleagues, fellow promovendi and MSc students whom I met in Wageningen University and the University of Zurich. In addition, some people I met during multiple conferences, fieldworks, courses and annual gatherings. I would like to thank all those people for making this thesis possible.

Herbert, after the interview I already had a feeling that I'd stay in REG for a while. Thanks for selecting me and giving that priceless opportunity to be a PhD student. From day one you were more than just a promotor, you were my teacher, my inspiration and sometimes my savior. Your thorough and exhaustive knowledge of the world, your expertise in ecology and science, your ability to interact effortlessly and in a positive way made my stay in Wageningen a very pleasant experience. I am very grateful that you were able to join two fieldworks seasons (2014 and 2015). I still vividly remember your high levels of trust to my driving in 2014 and our debates about world social and economic developments in 2015. You were a very flexible and uncomplicated travel companion, and it was my pleasure to share my knowledge about Russia and show you places. You were always open to my ideas and supported my decision to pursue an MBA in 2016. I will never forget parties in your house where people from REG stayed long evening to have a great time together. Being back to your house, where every item has a story behind, always feels like returning home.

Ron, we first met in June 2012 when we discussed my PhD Project proposal to see how you would be able to assist me in the coming years as part of cooperation with the Stichting de Eik. With years your involvement in my project grew tremendously and you took up a duty of co-promotor which I am very happy about. Your sharp thinking, clear approach to research objectives, editorial talent and optimism really helped to turn around some things in my research and give it a good boost exactly at the right time. Your input helped in shaping papers and reducing countless errors I made in original manuscripts. 
Special thanks for active support in preparation for the "Changing world of the goose" conference which I really enjoyed.

Michael, I am very grateful for your help and support of my thesis. Your vision, critical comments and profound knowledge of remote sensing opened new horizons on how to execute analyses. Thanks to you I had an opportunity to join RSL in Zurich and work with world leading scientists in spectroscopy and remote sensing. It was a pleasant stay with new ideas and insights every day, help from RSL people, exciting conferences and meetings. Your suggestion to use GoogleEarth Engine worked perfectly and helped me to reduce workload. I was also fascinated with your management and business skills, which played a role in my decision to do an MBA.

Henjo, your outstanding quantitative skills always impressed me and your passion for spatial ecology allowed us to speak the same language. Thanks to you I started to use R for statistical analyses and got to learn more about different spatial models. As a co-promotor, you were promptly available to discuss my thesis and analyses, gave your suggestions and took time and effort in clearly explaining what should be done.

My life at REG would not be exciting without all those great moments of interaction with its people. I will miss our discussions during coffee breaks and lunch breaks where we could talk about everything from Bayesian algebra to gazpacho recipe. Thanks to Milena, Pim, Fred, Ignas, David, Sip, Frank, Patrick, Kevin, Herman, Yorick I've learned a lot about the world, cooking, statistics, art, travelling, languages and countries. I was honored to assist in teaching of Wildlife Resource Management and Ecological Methods I where I could work closer with Sip, Pim, Fred, Ignas and Frank. Thanks to you I know what makes a great teacher! I also learned a lot from all those amazing students who challenged me with their questions and ideas during classes. Special thanks to Sip who helped me a lot with my fieldwork and survived all the hardship we had experienced. You are an amazing observer and a curious intellectual!

My work, and especially fieldwork, would not be possible without great contribution of Gerda, Patricia, Herman and Yorick. Gerda, thanks a lot for organizing and facilitating my fieldworks, classes, courses and equipment purchases. You are excellent and you always made sure that everything was 
done right, timely and smoothly. Your commitment to nature conservation is exception and I really admire that. Thanks to people like you we have some wildlife left. Patricia, you were always available to help and I never heard "no" from you. All my problems and requests you solved quickly, so that I could only see the result and not all the hard work behind. Thank you. Herman, you showed your genuine interest in Russia and the USSR which really impressed me. Your exhaustive knowledge of plants really helped to identify those species we collected with Herbert in the field. Yorick, your excellent technical knowledge and eagerness to help allowed me to purchase the right equipment and better organize fieldworks. Apart from that, I really enjoyed discussing socio-economic and political development with you and Helen.

My life at REG would not be complete without you, my peers. Thanks to Tim, Iris, Helen, Jente, Joost, Marinde, Martijn, Yussuf, Sintayehu, Jasper, Yin, Yanjie, Dorrit, Daniel, Priya, Anil, Vincent, Lennart, Eduardo, Tibor, Kyle, Yingying, Shyam. Special thanks to Iris who shared the same office with me for more than 4 years. Your knowledge, enthusiasm, optimism and passion for nature conservation inspired me! Thanks to Jasper and Yanjie who agreed to be my paranymfs. Special thanks goes to my peers in Zurich with whom I spent one semester: Irene, Anna, Daniela, Vincent, Sanne, Rogier, Carla, Hendrik, Marta, Fabian. You made me feel welcome at RSL where we could exchange our knowledge and have fun moments together. My stay at RSL would not be fruitful without input of Gabriela, Mathias, Andreas, Alex, David, Adrian and Felix.

I would also like to express my gratitude to Bart, Andrea, Silke and Lysanne from NIOO who were open for discussions about geese migration, modelling and land use changes. Thanks a lot for answering my questions, sharing your ideas and data. This project would not be possible without input and data from Alterra. Special thanks goes to Bart, Ralph, Martijn, Yke and David who helped me with metal rings recoveries acquisition and their interpretation, as well as defining what a stopover site is. I would also like to thank Yali Si for all discussion about geese migration, land use change and remote sensing we had.

Any research that concern Russia would not be possible without help and support of my dead Russian colleagues who continue studying migrating birds 
and geography despite political upheavals and difficulties with funding. My Russian colleagues from the Severtsov Institute of Ecology and Evolution opened the world of a goose in Russia for me. I really enjoyed our fieldwork in Kologriv in 2013, thank you Peter Glazov, Olga Pokrovskaya, Konstantin Litvin, Dmitry Dorofeev. Gregory Pozhvanov from the Komarov Botanical Institute opened the world of plants and photography to me! Many thanks for that. In the very beginning of my PhD I got a lot of assistance from my former colleagues in Tver State University. Without Alexander Zherenkov I would have never gone abroad in the first place. You were always supportive of my development since I came as a 16 year old boy to Tver State University in 2004. Andrei Zinoviev helped with overview of bird migration research in Russia. Sergey Sorokin gave the most comprehensive advice on how to prepare for the fieldwork of 2014 and how to choose a proper project car. Vadim Shavrin, you are a great and indispensable friend! With your active help I could collect the necessary data on agricultural statistics from regional statistical offices! Большое спасибо! Yakov Shrayberg from the Russian National Public Library for Science and Technology helped me to get access to the Scientific Library of the Russian Federal State Statistical Services, where I could collect necessary demographic data.

I would like to express my endless appreciation for the support I received from my family and friends: my mom, Jur, Iryna, Josep, Marcel, Joanne, Ivan, Artyom and Stas. Thank you for believing in me, especially at the moments when I did not believe in myself. Special thanks to my mom who took a duty of my personal assistant during my fieldworks in Russia in 2014-2015.

This project would not be possible without financial support of Nederlands Jagersvereneging (NJV) facilitated by de Stichting de Eik. In addition to that I would like to thank Faunafonds for providing additional funding to my project. Two fieldwork seasons of 2014 and 2015 would be much more challenging without financial support from KNAW Fonds Ecologie. Successful completion of the Training and Education Plan (PE\&RC) and printing of this thesis was possible due to financial support of Wageningen University and Research. 


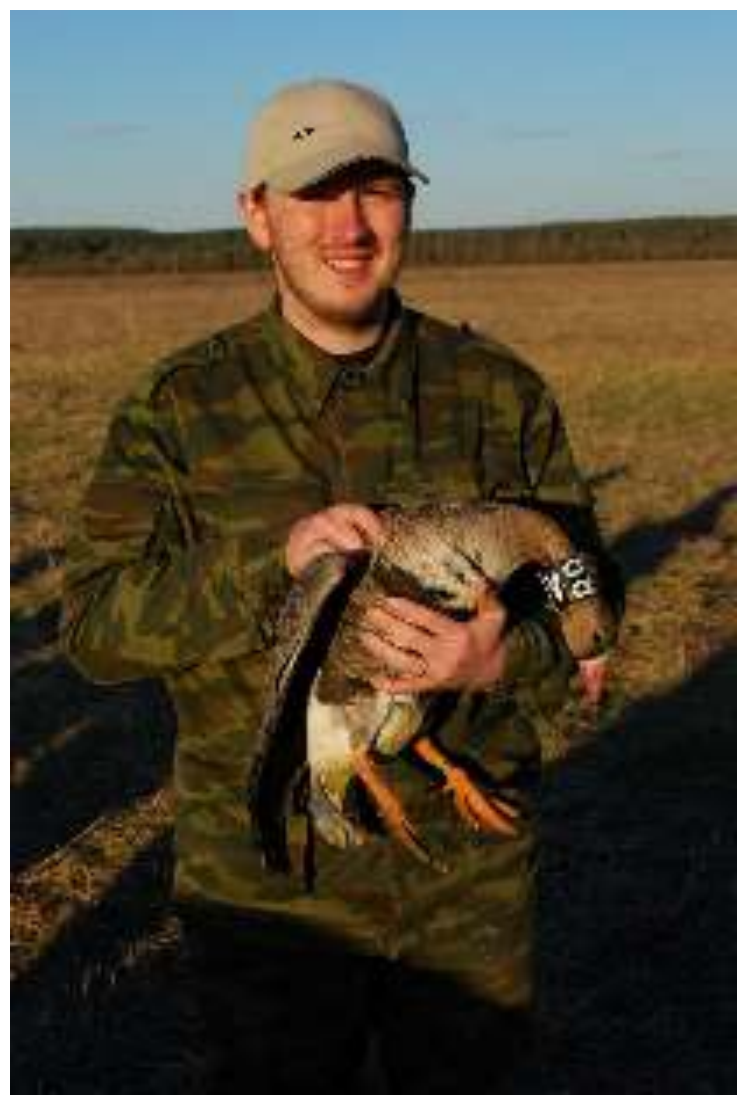




\section{Biography}

Mikhail Grishchenko was born on 16 July 1987 in Kalinin (now Tver), the USSR. He grew up in a city with declining textile industry in periods of perestroika and post-Soviet transition. He spent his summers in 1989 - 2002 in the rural environment of the North Caucasus (Krasnodar krai). In 1994 he started to attend a secondary school No. 32 in Tver, and in 1997 transferred to a secondary school No. 20 where he could focus more on physics and mathematics. He graduated from the school in 2004 with a distinction (silver medal). Since young age Mikhail showed a great interest in geography, biology, chemistry and history. He regularly participated in pupil's competition in geography, biology and history on local, regional and national levels in Russia.

Consequently, in 2004 Mikhail enrolled to the faculty of geography of Tver State University to study Geo-ecology with minor in Cartography (MSc). During his studies he showed a great interest in GIS, Remote Sensing and Land Surveying. Likewise, he attended national student competitions and multiple conferences for young scientists in fields of geo-ecology and GIS. In 2008 Mikhail was selected by the University board as one of two exchange students to spend one study semester in Finland (University of Eastern Finland) where he studied political and economic geography of the EU and Russia's borderland. He graduated from Tver State University in 2009 (cum laude) with MSc project on creation of digital decision support system for environmental monitoring in a municipal district.

In August 2009 Mikhail continued his education in the EU with a scholarship from the European Commission (Erasmus Mundus). During his multiple-degree MSc he attended four universities (University of Southampton, Lund University, University of Warsaw and University of Twente) where he studied GIS and Remote Sensing techniques for Environmental Modelling and Management. Mikhail conducted his MSc Thesis at the University of Twente working on a multi-scale assessment of intermodal freight networks in Europe.

In March 2012 Mikhail got a PhD position at Resource Ecology Group of Wageningen University where he got an opportunity to implement his multidisciplinary skills in studying land use changes in Russia and their impact on migrating geese. During his time at REG Mikhail had an opportunity to assist 
the Wildlife Resource Ecology and the Ecological Methods I courses. Likewise, he conducted two fieldworks, attended four conferences and spent one study semester at the University of Zurich (2014). Mikhail attended several courses of which "Entrepreneurship in and outside science" had the largest impact on him. This triggered him to pursue an MBA degree from TIAS (Tilburg University) in 2016 - 2017 with an MBA internship at the Royal DSM. At REG, TIAS and DSM Mikhail had a unique opportunity to develop into a professional who can translate sciences into business solutions.

In his free time Mikhail reads books on economy, politics and social development, travels to visit key biodiversity areas and learns foreign languages.

\section{List of publications}

Grishchenko M., H.H.T. Prins, M.E. R. C. Ydenberg, Schaepman, W.F. de Boer, S.E. van Wieren and H.J. de Knegt 2018 (submitted): Large-scale landscape change in European Russia after the break-up of the USSR, and its possible significance for goose migration. In: AMBIO.

Grishchenko, M. \& H.H.T. Prins 2016: Abandoned field succession in Russia and its potential effect on Corncrake Crex crex habitats. Vogelwelt 136: 175-184. 


\section{PE\&RC Training and Education Statement}

With the training and education activities listed below the $\mathrm{PhD}$ candidate has complied with the requirements set by the C.T. de Wit Graduate School for Production Ecology and Resource Conservation (PE\&RC) which comprises of a minimum total of 32 ECTS ( $=22$ weeks of activities)

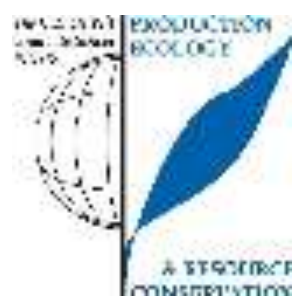

\section{Review of literature (6 ECTS)}

- Land use changes in Russia and their impact on migrating geese

\section{Writing of project proposal (2 ECTS)}

- PhD Research proposal facing changes: geese migration stopover sites in transition

\section{Post-graduate courses (2.6 ECTS)}

- Modelling critical transitions in nature and society; SENSE (2014)

- Introduction to R for statistical analysis; PE\&RC and SENSE (2015)

\section{Invited review of (unpublished) journal manuscript (1 ECTS)}

- Journal of Avian Biology: migration ecology of Arctic breeding birds (2014)

\section{Deficiency, refresh, brush-up courses (3 ECTS)}

- Ecological methods; REG (ESG), Wageningen (2012)

- Spectroscopy of earth system; RSL, University of Zurich (2014)

\section{Competence strengthening / skills courses (4.5 ECTS)}

- Voice matters/voice and presentation skills training; PE\&RC (2014)

- Scientific writing; Wageningen into Languages (2014)

- Brain training; PE\&RC (2015)

- Techniques for writing and presenting a scientific paper; PE\&RC (2015)

- Entrepreneurship in and outside science; PE\&RC (2015)

\section{PE\&RC Annual meetings, seminars and the PE\&RC weekend (1.2 ECTS)}

- PE\&RC Day (2012)

- PE\&RC Weekend, midterm (2014)

- PE\&RC Day (2015)

\section{Discussion groups / local seminars / other scientific meetings (6.3 ECTS)}

- Modelling and Statistics Network (MSN) (2012-2016)

- Symposium 'The Changing World of the Goose'; Wageningen, the Netherlands (2014)

- Movement Journal Club; Zurich University (2014)

- Swiss Geoscience Meeting; Fribourg, Switzerland (2014)

- Symposium 'Wild op Drift'; Wageningen, the Netherlands (2016)

International symposia, workshops and conferences (4.1 ECTS)

- Goose Specialist meeting; Arcachon, France (2013)

- International Corncrake conference; PIzen, Czechia (2015)

Lecturing / supervision of practicals / tutorials ( 3 ECTS)

Wildlife resource management (2012) 
Cover, layout, pictures and figures: Mikhail Grishchenko (unless other is specified).

Cover design: Vera van Beek.

The research described in this thesis was financially supported by the Nederlandse Jagersvereneging, Stichting de Eik, the Faunafonds and the KNAW Fonds Ecologie.

Financial support from Wageningen University for printing this thesis is gratefully acknowledged.

Printed by: ProefschriftMaken / Digiforce B.V. || Uitgeverij Boxpress 